Linköping Studies in Science and Technology

Licentiate Thesis No. 1834

\title{
The Supporting Role of Logistics during the Early Stage of Retail Internationalisation
}

Linnea Haag

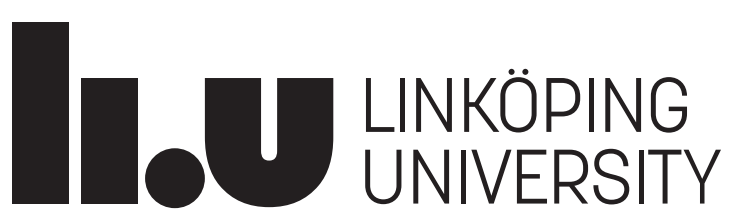


Linköping studies in Science and Technology

Licentiate Thesis No. 1834

\title{
The Supporting Role of Logistics during the Early Stage of Retail Internationalisation
}

\author{
Linnea Haag
}

2019 
(C) Linnea Haag

The Supporting Role of Logistics during the Early Stage of Retail Internationalisation

Linköping studies in Science and Technology, Licentiate Thesis No. 1834

ISBN: 978-91-7685-108-1

ISSN: 0280-7971

Printed by LiU-Tryck, Linköping 2018

Distributed by:

Linköping University

Department of Management and Engineering

SE-581 83 Linköping, Sweden

Tel: +4613281000 




\begin{abstract}
Retail internationalisation refers to the establishment of retailers into foreign sales markets and is an important success factor for many retail chains. Logistics has been acknowledged as an important prerequisite and key component of retail internationalisation, enabling physical distribution to new foreign markets as well as ensuring customer satisfaction in terms of on-time delivery and product availability. Despite the recognition of logistics, logistics managers struggle to adapt their logistics organisation and operations in order to efficiently and effectively support retail internationalisation due to the complexity of operating in multiple markets. Previous research seldom mentions how logistics supports retail internationalisation, especially when retail chains are at the beginning of their retailinternationalisation journey. By exploring the supporting role of logistics during the early stage of retail internationalisation, retailers can better understand how logistics organisation and operations can be organised in order to successfully expand into foreign sales markets. Therefore, the purpose of this licentiate thesis is to:
\end{abstract}

\title{
Explore the supporting role of logistics during the early stage of retail internationalisation.
}

This licentiate thesis is based on an abductive, multiple-case-study approach that combines empirical data with literature in an iterative process in order to explore the supporting role of logistics during the early stage of retail internationalisation. The selected case companies were three large-sized Swedish retail chains that have recently established themselves into nearby foreign sales markets.

The findings of this licentiate thesis suggest that logistics plays both a reactive and a proactive supporting role during the early stage of retail internationalisation. The reactive supporting role refers to logistics that adapts to predetermined conditions set by the retail company's top management team. As a reactive supporter, the logistics organisation is typically involved at an operational level and scales up its logistics operations in order to supply multiple markets. Beyond its reactive role, logistics can also play a proactive supporting role. This refers to its involvement at a strategic level within the retail company where it can influence the conditions of retail internationalisation. When logistics is involved more proactively, its operations can become better aligned with the other company operations involved in retail internationalisation. Furthermore, proactive logistics support enables more efficient and effective logistics that can better cope with increased complexity as well as more effectively keeping track of logistics costs. In addition to these findings, the importance of top management has been identified as a key aspect of proactive logistics support. More specifically, logistics competence within the top management team enables logistics to be prioritised at a strategic level and to be better integrated during retail internationalisation, including during individual establishments into new markets. The findings also suggest that the importance of logistics increases over time during retail internationalisation. The more markets the retailer enters, the more important efficient logistics becomes in order to deal with both complexity and logistics costs. By involving proactive logistics from the start of retail internationalisation, retail chains can more efficiently and effectively establish into and operate within foreign sales markets, which in turn supports a sustainable retail internationalisation. 
One of the main academic contributions of this licentiate thesis has been to study logistics in the specific context of retail internationalisation, which has previously not been researched in any great detail. In addition, logistics has often been studied as a static aspect, but in this thesis it is studied from a dynamic perspective in order to understand he supporting role changes over time during the early stage of retail internationalis Another important contribution is that the role of logistics has been studied from bou. . strategic and an operational level, as previous research has mostly focused on the strategic level of logistics related to retail internationalisation. In terms of practical contributions, this licentiate thesis clarifies the logistics characteristics and supply-chain capabilities that support the early stage of retail internationalisation. This licentiate thesis can also help practitioners to better prepare their logistics organisation and logistics operations for a future retail internationalisation, as well as helping them to avoid making logistical mistakes during the early stage of retail internationalisation. 




\section{Acknowledgements}

In your hand, you are holding a copy of my licentiate thesis, entitled: "The supporting role of logistics in the early stage of retail internationalisation". This licentiate thesis is based on a research project called "Geographical expansion of retail companies" that was conducted by me at Linköping University in Sweden. Since I started as a PhD student in the autumn 2016, I have come to know many interesting people, from both the academy and the retail industry. It has been a true privilege to work in depth with one of my favourite subjects and to work with this interesting project, which feels very up-to-date due to the increased internationalisation of the world.

To start, I would like to express a very special thanks to the Hakon Swenson Foundation, which funded this research project. With the support of the foundation, this licentiate thesis has become a reality. I have appreciated the foundation's interest in this project and I am looking forward to continuing our collaboration in the future.

Furthermore, I would like to give a very special thanks to all the informants who kindly participated in this research project. One of the highlights of this project has been to meet all of you. I am so grateful for the time and information you have given me, and your participation has been central to this project.

I would also like to express special gratitude to my supervisors, Erik Sandberg and Uni Sallnäs, for their guidance and support during the writing of this thesis. I have appreciated our discussions and you both have given me many good and important comments, which have resulted in a better thesis. I would also like to thank Mats Abrahamsson, who was my opponent at my Förslutsseminarium. The seminar was very fruitful for me and you gave me helpful comments that were important for me to consider before finishing my thesis. Also, I would like to acknowledge Kristina Dalberg for organising the licentiate presentation and helping me with the administrative activities related to my licentiate thesis. I would also like to give a special thanks to my colleagues, Björn, Henrik, Magdalena and Niklas, for your feedback on the thesis. I would also like to thank all my colleagues at the Logistics and Quality Management Division. Together, you have all created a wonderful workplace. In particular, I treasure our fika-stunder as well as our summer and Christmas parties. In addition, I want to thank my $\mathrm{PhD}$-student friends whom I have come to know during these last couple of years.

Last but not least, I would like to express very special gratitude to my lovely family. I am so happy for all your encouragement and all the fun moments we share together. Mum and Dad, Maria and Anna, my Adam, I love you all so much!

Linköping, March 2019

\section{Linnea}





\section{Table of content}

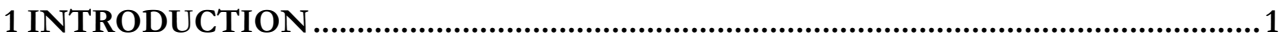

1.1 THE IMPORTANCE OF LOGISTICS IN RETAIL INTERNATIONALISATION ……..............................

1.2 PREVIOUS CONTRIBUTIONS ABOUT LOGISTICS IN A RETAIL-INTERNATIONALISATION ........... 2

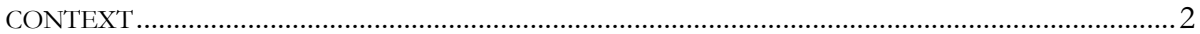

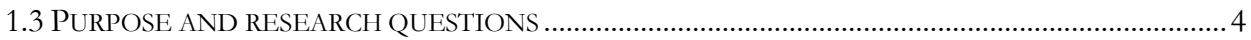

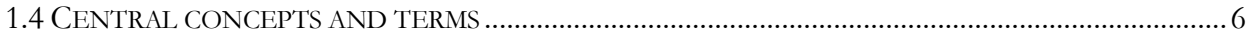

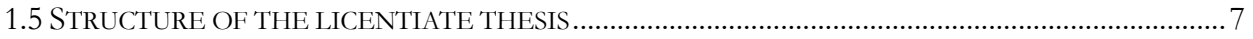

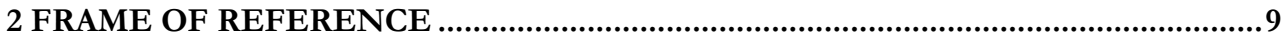

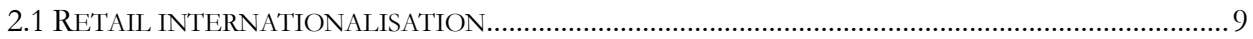

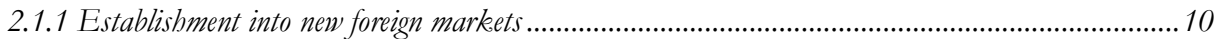

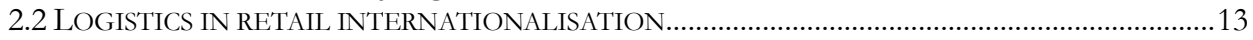

2.2.1 The match between logistics and marketing in retail internationalisation .......................................13

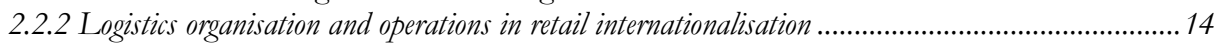

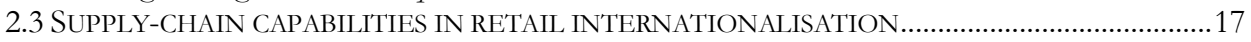

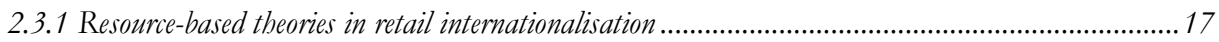

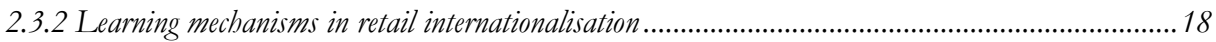

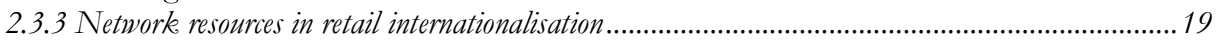

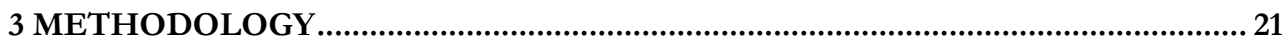

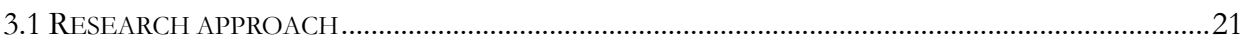

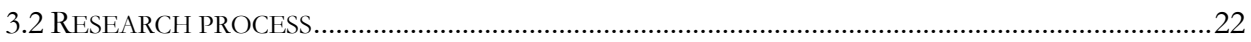

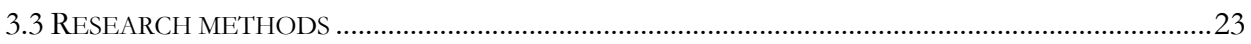

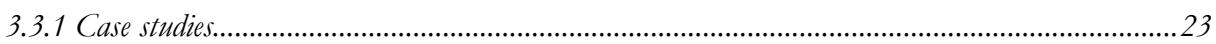

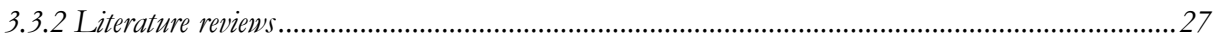

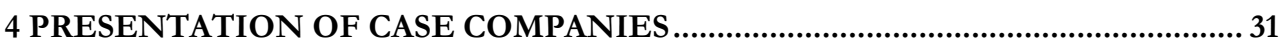

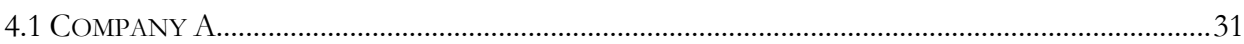

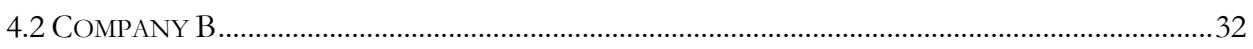

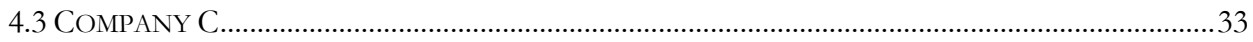

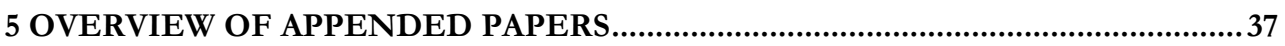

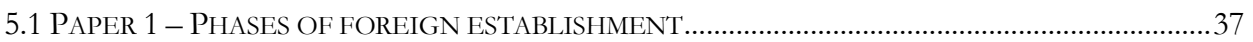

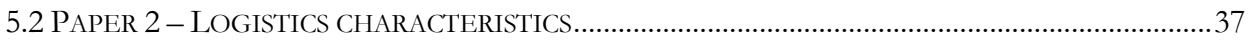

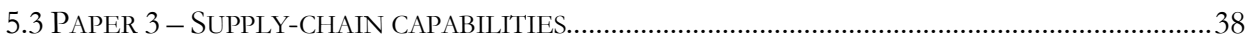

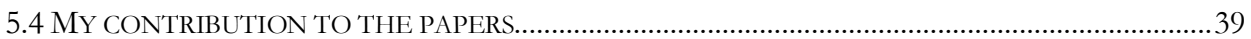

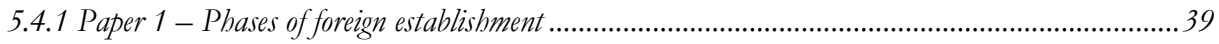

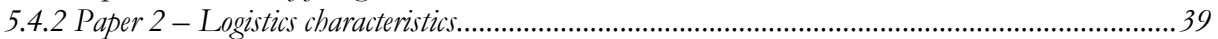

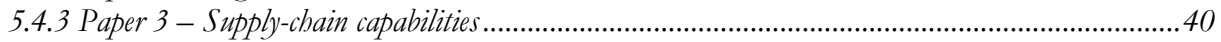

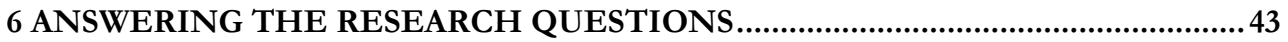

6.1 THE GENERAL PHASES OF THE FOREIGN ESTABLISHMENT PROCESS OF RETAILERS ..............43

6.1.1 The general phases of the foreign establishment process of retailers.....................................................

6.1.2 Concluding remarks regarding the establishment process.................................................................4

6.2 THE KEY LOGISTICS CHARACTERISTICS THAT SUPPORT RETAIL INTERNATIONALISATION .. 47

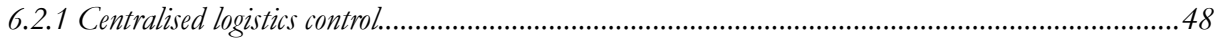

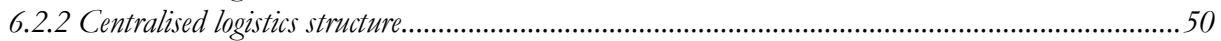

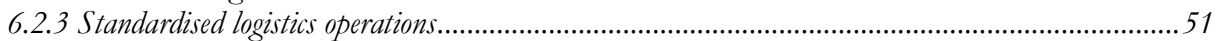

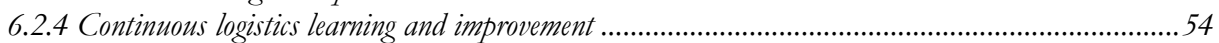

6.3 THE KEY SUPPLY-CHAIN CAPABILITIES THAT SUPPORT RETAIL INTERNATIONALISATION ... 54 


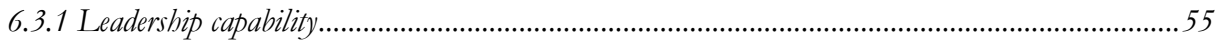

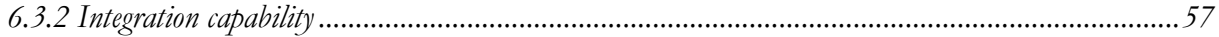

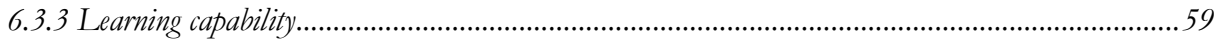

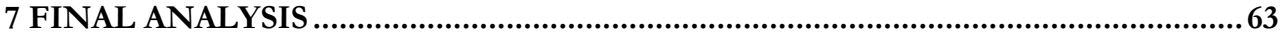

7.1 THE REACTIVE AND PROACTIVE SUPPORTING ROLE OF LOGISTICS IN RETAIL........................63

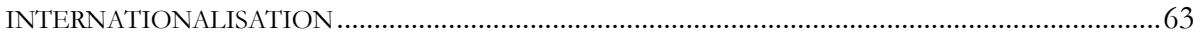

7.2 THE IMPORTANCE OF LOGISTICS OVER TIME IN RETAIL INTERNATIONALISATION................65

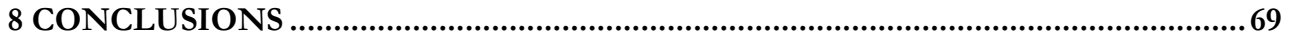

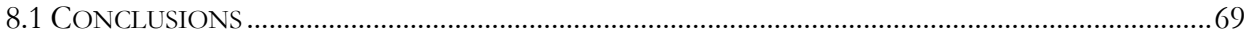

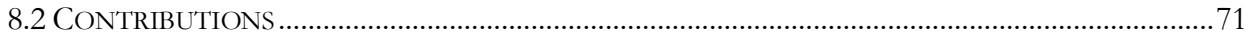

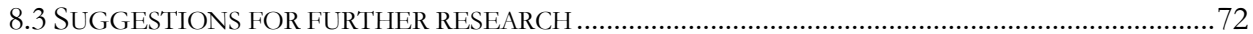

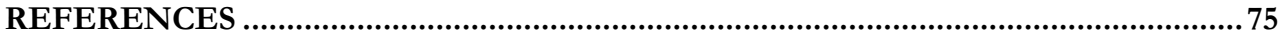

APPENDICES

APPENDIX 1 - Appended papers

APPENDIX 2 - Case reports

APPENDIX 3 - Interview guide 


\section{List of Figures}

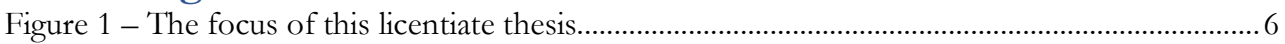

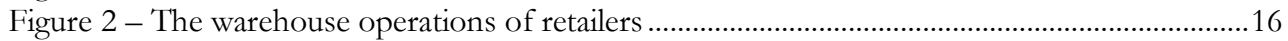

Figure 3 - Aspects of the warehouse design .....................................................................................16

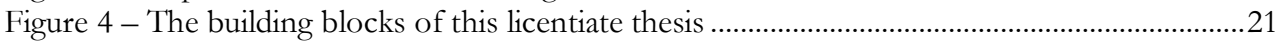

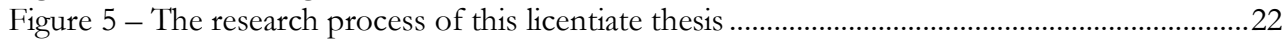

Figure 6 - The retail internationalisation via physical stores of Company A....................................32

Figure 7 - The retail internationalisation via physical stores of Company B .....................................33

Figure 8 - The retail internationalisation via physical stores of Company C...................................34

Figure 9 - The phases in the establishment process of retailers into a new foreign sales market.44

Figure 10 - The key logistics characteristics that support the early stage of retail

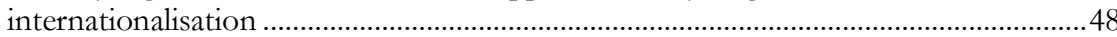

Figure 11 - The key supply-chain capabilities that support the early stage of retail

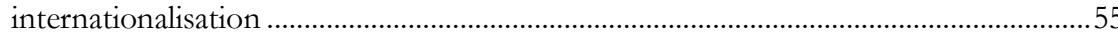

Figure 12 - The integration capabilities that support the early stage of retail internationalisation 57

Figure 13 - The reactive and proactive supporting role of logistics during the early stage of retail internationalisation

\section{List of Tables}

Table 1 - The informants and the type of empirical data collected in this licentiate thesis............25

Table 2 - Overall information about the case companies in the licentiate thesis............................... 31

Table 3 - The standardised warehouse operations important in retail internationalisation ............52 



\section{Introduction}

This chapter presents an introduction to this licentiate thesis. The chapter begins with a description of the importance of logistics in retail internationalisation, followed by a section reviewing the previous contributions related to logistics in a retail-internationalisation context. Thereafter, the purpose and research questions of this licentiate thesis are presented. The chapter ends with a list of central concepts and terms used in the thesis and a description of its structure.

\subsection{The importance of logistics in retail internationalisation}

Through the establishment of foreign sales operations, such as physical stores and online stores, retailers are becoming more international. Of the top 250 largest retailers in the world, $66.8 \%$ of them have foreign operations, which includes foreign sales operations (Deliotte 2017). The process by which retailers establish foreign sales operations is typically referred to as retail internationalisation (IGI Global n.d.), and is mostly driven by growth potential, saturated domestic markets, and the ease of legal trading barriers (Assaf et al. 2012). In addition, advances in transport and communication systems technology, as well as lower transportation costs, have driven the establishment of foreign sales operations (Straube et al. 2008). Currently, retail internationalisation is an important success factor for many large retail chains. There are numerous large retail chains, such as Walmart, IKEA and Zara, that are establishing themselves in foreign sales markets in order to achieve further economic growth and economies of scale for their operations.

Logistics has been acknowledged as an important prerequisite and key component in retail internationalisation (Creazza et al. 2010; Marchet et al. 2016; Swoboda et al. 2008). Logistics is defined here as "the process of planning, implementing, and controlling the efficient, effective flow and storage of goods, services, and related information from a point of origin to a point of consumption for the purpose of conforming to customer requirements" (CSCMP n.d.), which includes retailers' logistics organisation and the logistics operations involved in supplying foreign sales operations. Furthermore, logistics is recognised as a key ingredient in overall company strategies that support company objectives (Abrahamsson et al. 2003; Marchet et al. 2016; Straube et al. 2008), such as retail internationalisation. Logistics has been described as "the backbone of the internationalisation process" (Marchet et al. 2016, p. 74) and, in a similar vein, Abrahamsson et al. (2003) describe it as a resource base that adapts its resources in terms of organisation and operations in order to support company moves such as retail internationalisation. From a retail-internationalisation perspective, logistics enables physical distribution to new foreign markets and ensures customer satisfaction in terms of on-time delivery and product availability. However, establishing efficient and effective logistics in foreign markets is not an easy task and logistics managers worldwide struggle to adapt their logistics organisation and operations in such a way that it supports their companies' internationalisation objectives (Straube et al. 2008).

Previous research has emphasised the importance of a strategic fit between overall company strategy and logistics in order to successfully operate in foreign markets (e.g. Marchet et al. 
2016; Straube et al. 2008). According to Straube et al. (2008), logistics should interact with other relevant company functions, such as marketing, in order to successfully internationalise. Furthermore, Straube et al. (2008) argue that there is a close relationship between logistics and internationalisation activities. On the one hand, logistics enables and drives internationalisation, while on the other hand internationalisation directly affects logistics and increases the complexity of logistics systems (Straube et al. 2008).

As retailers establish themselves into new foreign markets, their logistics organisation and logistics operations need to expand accordingly. The expansion of a logistics system is recognised by both researchers and logistics managers as a great challenge because internationalisation increases the complexity of logistics systems (Marchet et al. 2016). Instead of supplying a single market, the logistics system has to handle multiple markets simultaneously, which might involve multiple sales channels, such as physical stores and online stores. Furthermore, retail internationalisation includes both individual establishments into new foreign markets and the daily operations of already-established foreign sales operations, which both need logistical support. For logistics to supply multiple markets, managers have to consider a number of internal logistical aspects in terms of staff and storage space, as well as external market aspects in terms of infrastructure, local customer demands and customs (Straube et al. 2008). These logistical aspects need to be carefully organised in order for logistics to support retailers' chosen foreign establishment approach in terms of business concept, including business offer, product range and sales channels. At the same time, logistics should supply multiple markets with the right products at the right time and of the right quality to ensure customer satisfaction, which is the foundational principle of logistics.

Despite the recognition of logistics as an important support, there is a lack of knowledge about how retailers' logistics organisation and logistics operations actually support retail internationalisation. Logistics in the context of retail internationalisation has seldom been discussed in detail in previous literature. However, as retail internationalisation is a critical success factor, it is of great importance to understand how logistics supports this internationalisation of retailers into foreign sales markets. In the following section, previous contributions about logistics in a retail-internationalisation context are further discussed.

\subsection{Previous contributions about logistics in a retail-internationalisation context}

Retail internationalisation has been studied since the 1990s and has covered a wide range of research topics. Most of this research has covered marketing-oriented aspects, such as foreign market selection (e.g. Swoboda et al. 2007), entry mode strategies (e.g. Doherty 1999; Picot-Coupey et al. 2014) and retail format transfer (e.g. Goldman 2001; Swoboda and Elsner 2013). Complementary to this marketing-oriented research, contributions discussing logistics in a retail-internationalisation context have been progressively registered. However, logistical aspects have not been studied to the same extent as marketing-oriented aspects. Furthermore, logistics has mostly been studied in the context of general internationalisation, which includes internationalisation of both manufacturers and retailers (e.g. Marchet et al. 2016; Straube et al. 2008;). For instance, Straube et al. (2008) studied logistics strategies for entering a new market and considered a number of general 
logistics strategies that apply to both manufactures and retailers. Another example is Marchet et al. (2016), who studied the development of logistics strategies in the internationalisation process that can also be applied to both manufactures and retailers. Literature on logistics strategies is of great importance as such strategies set the frame for how the overall logistics should be performed in terms of organisation, planning and operations. However, literature on the operational aspects of logistics is also important in order to achieve an in-depth understanding of how logistics at different levels supports retail internationalisation.

Furthermore, despite the fact that retail internationalisation is an ongoing process, logistics in an internationalisation context is often studied from a static perspective "without investigating its evolution over time" (Marchet et al. 2016 p. 74). Internationalisation is a learning-by-doing process in which commitments and activities change over time as companies gain more experiential knowledge (Johanson and Vahlne 1977). This suggests that logistics commitments in terms of resources (e.g. warehouses and staff) also change over time as retailers expand abroad, which requires efficient integration of logistics resources. In a recent contribution by Marchet et al. (2016), the shaping of logistics strategies in the internationalisation process is investigated in order to shed light on how companies align their international logistics strategies over time to fit their internationalisation choices. The results of this study suggest that companies may adopt three different international logistics strategies, depending on their internationalisation choices (Marchet et al. 2016). Despite Marchet et al.'s (2016) contribution, more research is needed for an in-depth understanding of the supporting role of logistics in retail internationalisation. For example, more research is needed that describes not just the strategic level, but also the operational level of logistics in the internationalisation process, which is neglected by Marchet et al. (2016) and other scholars. Furthermore, more research is needed that describes how retailers integrate logistics resources throughout retail internationalisation. A wider time frame and an additional operational level of logistics is needed in order to achieve an in-depth understanding of the supporting role of logistics in retail internationalisation. This would provide in-depth knowledge about how the actual logistics organisation and logistics operations should be organised and performed in order to efficiently supply multiple sales markets.

In addition, previous research has mostly focused on the logistics of global retail chains such as IKEA and Zara, which have rich experience of conducting international sales operations extending over several decades. These retail chains have well-established routines for how to enter and operate in foreign sales markets. However, retail chains that are have only become established in a few foreign markets lack routines for how to expand and operate abroad, which also includes logistics. The literature seldom describes in depth how logistics supports these chains at the beginning of their retail-internationalisation journey. Therefore, more research is needed in order to describe how logistics actually supports the first number of establishments during retail internationalisation. Hence, this licentiate thesis focuses on the early stage of retail internationalisation, which includes the first few establishments of foreign sales operations by large retail chains. This focus also allows a more dynamic perspective, in which the supporting role of logistics can be studied based on a number of establishments. 
To summarise, from an examination of previous contributions it was found that there is a lack of research about logistics in the retail-internationalisation context. Previous research has mostly studied logistics from a general internationalisation perspective in which the focus has been on strategic logistics aspects (e.g. logistics strategies), while neglecting operational aspects. Furthermore, logistics is often studied from a static perspective. However, retail internationalisation is a dynamic process, which suggests that logistics commitments in terms of logistics resources will change throughout the process of retail internationalisation. In addition, previous research has focused on long-standing global retail chains (e.g. IKEA) that are experienced in establishing into foreign sales markets, while more inexperienced retail chains that have only just started to move into foreign sales markets are seldom studied.

\subsection{Purpose and research questions}

The previous sections have exposed a lack of understanding about the supporting role of logistics in retail internationalisation. Therefore, this licentiate thesis aims to study this topic. To better understand how logistics supports retail internationalisation, both strategic and operational aspects of logistics are studied, instead of only strategic aspects. This provides an in-depth understanding of how logistics supports the establishment into new foreign sales markets at both a strategic and an operational level. Also, a broader scope that includes several establishments is used in order to study logistics from a more dynamic perspective that is more aligned with the dynamic process of retail internationalisation than previous research. Furthermore, in contrast to previous research that focused on global retail chains, this thesis focuses on large retail chains that are in the early stage of their retail internationalisation journey in the sense that they have only established themselves in a few, nearby foreign sales markets. By exploring the supporting role of logistics during the early stage of retail internationalisation, retailers can better understand how logistics organisation and operations can be organised in order to successfully expand into foreign sales markets. To summarise, this licentiate thesis aims to explore the supporting role of logistics during early stage of retail internationalisation. Hence, the purpose of this licentiate thesis is to:

\section{Explore the supporting role of logistics during the early stage of retail internationalisation.}

As a first step in exploring the supporting role of logistics in the early stage of retail internationalisation, the move into a new foreign sales market needs to be understood. The process of establishing into new foreign sales markets (here defined as a process that ranges from the first action to enter a new market, to full sales operations of one or several stores) includes different decisions, activities and resources, which can directly or indirectly influence the logistics support. This process of foreign establishment is seldom mentioned in the literature; however, literature on domestic store establishment (e.g. Sandberg 2014) that includes key decisions, key activities and key resources can be used as a starting point to map the foreign establishment process. Furthermore, by categorising the decisions, activities and resources into different phases, a more comprehensive description of the foreign establishment process, including the supporting role of logistics, can be achieved. Hence, the first research question (RQ1) is formulated as follows. 
RQ1. What are the general phases of the foreign establishment process of retailers?

Furthermore, as a second step, different logistics characteristics are studied in order to gain a comprehensive overview of logistics characteristics that actually support the early stage of retail internationalisation. Previous research has identified individual logistics characteristics that can help companies to cope with complexity related to retail internationalisation (e.g. Abrahamsson et al. 2003; Chow et al. 1995). For instance, the centralisation of warehouse facilities is a commonly given example. Furthermore, there are a few studies that cover several logistics characteristics related to internationalisation (e.g. Marchet et al. 2016). However, a set of key logistics characteristics that retailers should have when embarking upon their retail internationalisation have not been clearly presented in previous literature. Hence, to better understand how logistics supports retail internationalisation, a set of comprehensive logistics characteristics that support the early stage of retail internationalisation needs to be explored. To ensure an in-depth understanding, logistics characteristics span both the strategic and the operational level of logistics. The second research question (RQ2) is thus formulated as below.

\section{RQ2. What are the key logistics characteristics that support the early stage of retail internationalisation?}

In addition, beyond logistics characteristics, the supporting role of logistics can also be explored by applying a resource-based view that considers logistics to be a crucial resource for successful retail internationalisation. Retail internationalisation requires a large amount of resources, including both internal resources (e.g. logistics staff, logistics knowledge) and external resources (e.g. logistics providers), which need to be aligned throughout the process of retail internationalisation. To efficiently and effectively integrate supply-chain resources throughout the retail internationalisation, retailers need specific supply-chain capabilities. Capabilities shape resources into specific characteristics, which creates a competitive advantage. Furthermore, capabilities related to retail internationalisation have seldom been mentioned in the literature, apart from a few contributions (e.g. Cao 2011; Frasquet et al. 2018; Frasquet 2013; Lowe et al. 2012) that contribute to the understanding of dynamic capabilities in the context of internationalisation. However, all of these studies focus to a large extent on marketing-oriented aspects, while neglecting supply-chain aspects of the capabilities. Therefore, in this licentiate thesis, supply-chain capabilities are explored in order to better understand how logistics supports the early stage of retail internationalisation. Hence, the third research question (RQ3) is formulated as below.

\section{RQ3. What are the key supply-chain capabilities that support the early stage of retail internationalisation?}

Figure 1 illustrates the focus of this licentiate thesis and the three research questions. The figure describes the ongoing retail internationalisation of a retailer, including the establishment of a number of sales operations in new foreign countries. The move into a new country usually includes the establishment of both physical stores and an online store, which are both included in the establishment process. The last two research questions cover a broader scope of the early stage of retail internationalisation, including the first few foreign establishments. Beyond the aim and research questions of this licentiate thesis, this 
study contributes to a better understanding of the supporting role of logistics in retail internationalisation over time.

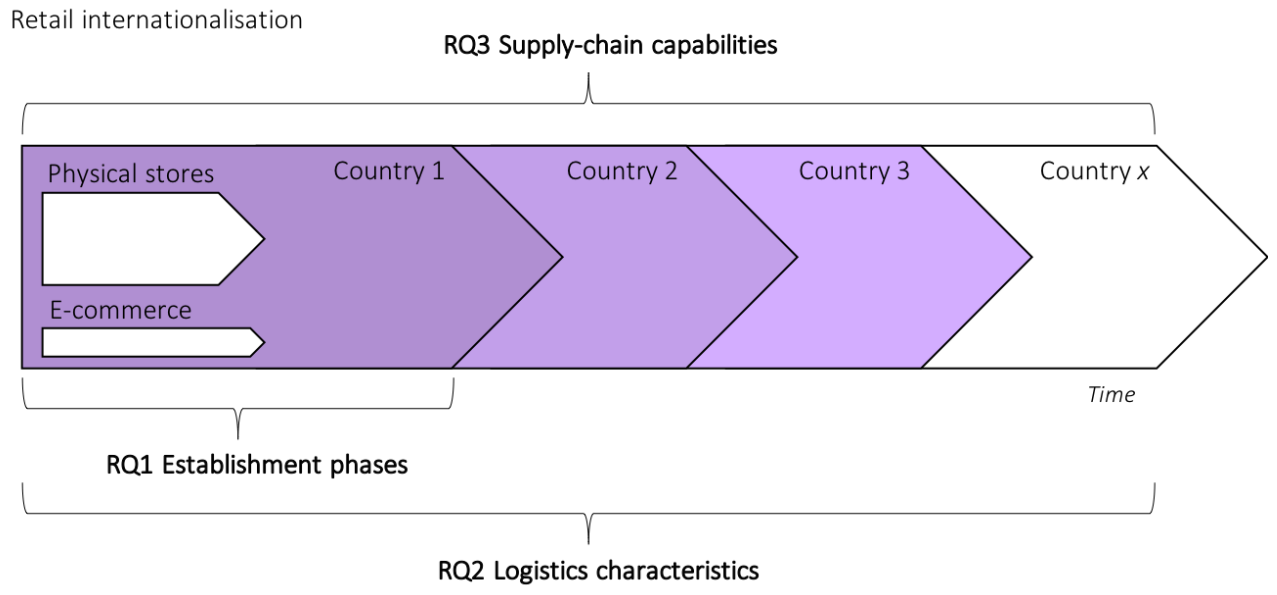

Figure 1- The focus of this licentiate thesis

\subsection{Central concepts and terms}

This section presents the central concepts and terms used in this licentiate thesis.

Logistics: There are several definitions of logistics. For this licentiate thesis, logistics is defined as "the process of planning, implementing, and controlling the efficient, effective flow and storage of goods, services, and related information from a point of origin to a point of consumption for the purpose of conforming to customer requirements" (CSCMP n.d.). It includes the logistics organisation and logistics operations used to supply the end customer. This thesis focuses on the logistics flow related to the sales operations ranging from warehousing to foreign distribution to foreign sales markets.

Retail internationalisation: In this licentiate thesis, retail internationalisation is defined as "the expansion of a retailer's stores or outlets into other countries or territories outside of their country of origin" (IGI Global, n.d.). It can be seen as an ongoing process that includes one or several establishments into new foreign sales markets. This licentiate thesis focuses solely on the early stage of retail internationalisation, which includes about two to five establishments into foreign sales markets. In this thesis, the focus lies primarily on the establishment of physical stores within foreign markets; however, online stores are also studied to some extent because retailers typically establish online stores as an additional marketing platform.

Establishment process: The establishment process in this licentiate thesis is defined as the process of establishing sales operations in a new foreign country, ranging from the first action taken to enter a new market to full sales operations. 
Logistics characteristics: In this licentiate thesis, logistics characteristics are the distinctive characteristics of the logistics organisation and its operations that support retail internationalisation. This licentiate thesis focuses on identifying logistics characteristics that simplify the expansion of the logistics system into foreign markets in the early stage of retail internationalisation.

Supply-chain capabilities: In this licentiate thesis, supply-chain capabilities are defined as capabilities used by companies to efficiently coordinate important supply-chain resources, including internal logistics resources (e.g. logistics staff, warehouse operations) and external supply-chain resources (e.g. logistics providers). In the context of retail internationalisation, supply-chain capabilities are the capabilities required to coordinate supply-chain resources related to foreign sales operations, such as coordination of internal staff and distributors to foreign markets.

\subsection{Structure of the licentiate thesis}

In this last section, the structure of this licentiate thesis is presented. After this introductory chapter, the frame of reference and methodology are presented, followed by a presentation of the case companies. Thereafter, an overview of the three appended papers is presented. This is followed by a chapter answering the research questions, followed by the final analysis of the supporting role of logistics during the early stage of retail internationalisation. Thereafter, the conclusions of the licentiate thesis are presented, followed by the references and the appendices. 



\section{Frame of reference}

This chapter presents the frame of reference for the research conducted in this licentiate thesis. This chapter is divided into three main sections: Retail Internationalisation, Logistics in Retail internationalisation and Supply-chain Capabilities in Retail internationalisation. The first section presents the literature on retail internationalisation in terms of definition, motives and how an establishment into new foreign sales markets is performed. This section provides a basic understanding of retail internationalisation and how retailers enter new foreign markets, which is key in order to understand the context of this licentiate thesis and to identify establishment phases. The second section presents the literature on logistics in a retail internationalisation context. Previous research has focused on individual logistics characteristics from a general internationalisation perspective and this section aims to summarise the important logistics characteristics related to retail internationalisation. The third and final section presents the literature on resource-based theories related to supplychain capabilities in a retail-internationalisation context. This section provides a basic understanding of resource-based theories, which is necessary in order to identify supplychain capabilities that support retail internationalisation.

\subsection{Retail internationalisation}

Retail internationalisation has been studied since the 1990s (Alexander and Myers 2000) and is a well-researched topic. In contrast to internationalisation in general, retail internationalisation solely encompasses the foreign sales operations and not the foreign sourcing operations of a retailer. Furthermore, retail internationalisation can be described using numerous definitions. For instance, it can be defined as "the operation by a single form of shops, or other forms of retail distribution, in more than one country" (Dawson 1994 p. 26). Another definition is provided by one of the leading international academic publishers, IGI Global, which defines it as "the expansion of a retailer's stores or outlets into other countries or territories outside of their country of origin" (IGI n.d.). These two definitions are similar; however, the latter mentions expansion into new foreign markets, while the first refers to already-established foreign sales operations. The definition provided by IGI Global is used in this licentiate thesis because it studies the establishment of retailers into new foreign sales markets.

Furthermore, retail internationalisation is a critical success factor for many retailers and is mostly driven by growth incentives, saturated home markets (Alexander 1995) and ease of legal trading barriers (Assaf et al. 2012). However, retail internationalisation involves a considerable amount of uncertainty (Gielens and Dekimpe 2007) and should therefore be carried out in a stepwise manner (Cateora and Graham 1999). This provides more control and minimises the risks associated with internationalisation (Vahlne and Ivarsson 2014). In a similar vein, Johanson and Vahlne $(1977 ; 2009)$ describe internationalisation as a gradual learning process during which acquisition, integration and use of knowledge about the foreign markets and internationalisation occur over time (Johanson and Vahlne 1977; Johanson and Vahlne 2009). Furthermore, experiential knowledge gained during the internationalisation process can strongly influence the future commitment decisions and operations of a company (Johanson and Vahlne 1977; Johanson and Vahlne 2009). 
Previous research on retail internationalisation has focused on individual market-oriented issues. For instance, most of the literature covers market-oriented issues such as internationalisation motives (e.g. Hutchinson et al. 2007), foreign market selection (e.g. Sakarya et al. 2007), and retail market entry modes (e.g. Doherty 2000). However, how retailers actually establish themselves in a new foreign market, including for instance the decisions, activities and resources involved, is seldom described in full. For the purposes of this licentiate thesis, a good understanding of individual establishments into new foreign sales markets is important to gain an in-depth understanding of the supporting role of logistics during the early stage of retail internationalisation. Therefore, the process of establishment into new foreign markets will be further described in the following section.

\subsubsection{Establishment into new foreign markets}

The process of becoming established within foreign markets involves retailers in several important decisions and activities, which are necessary in order to plan, enter and operate in the new foreign market. In addition, retailers need both internal and external resources that can manage and perform activities during the establishment into a new foreign market. The following section presents a summary of the literature on the decisions, activities and resources involved in the process of establishment into new foreign markets. This summary is used as a base for mapping the establishment process as well as to identify the phases of the establishment into a new foreign market. Firstly, the decisions are presented, followed by the activities, and the internal and external resources.

\section{Establishment decisions}

A number of decisions have been identified that strongly influence a foreign establishment (Picot-Coupey, Burt, and Cliquet 2014). Elsner (2012) defines these decisions as marketoriented, which are determined for each foreign establishment. There are three marketoriented decisions: (1) foreign market selection, (2) retail market entry mode and (3) retail format transfer. These decisions are further described in the following sections.

Foreign market selection: This decision refers to the selection of foreign markets. The previous literature on market selection has presented numerous market-selection theories. Market selection is typically based on both market-specific and company-specific characteristics. One of the most well-known market-selection theories is Dunning's OLI paradigm, which describes market selection as being based on three strategic variables called ownership advantages, location advantages and internalisation advantages (Dunning 1988). The OLI paradigm considers both firm-specific resources and firm-specific experience, as well as market potential and market risk (Brouthers et al. 2009). Another well-known marketselection theory is presented by Johanson and Widersheim-Paul (1975), who argue that market selection is based on "psychic distance". Usually, retailers first enter foreign markets that are psychically close in terms of culture, language and business practices, before enter more psychically distant markets (Elsner 2012; Johanson and Widersheim-Paul 1975; O'Grady and Lane 1996). Furthermore, retailers usually choose to expand first within the domestic market and as the domestic market becomes saturated, then they enter foreign markets (Elsner 2012). This market selection approach is common among retailers in Europe (Swoboda et al. 2009) as well as in the USA (Vida 2000). When it comes to 
establishing online stores, the psychic distance has some impact on foreign market selection but not to the same extent as for traditional retailers (Sakarya et al. 2007).

Retail market entry mode: The selection of retail market entry mode refers to the entry approach used for expanding into a new foreign market (Root 1994; Elsner 2012) and includes a range of different modes, including full or shared-control entry modes that involve a varied level of risk, control and investment. For instance, wholly-owned subsidiaries and acquisitions involve a high degree of control, investment and risk, whereas franchises and joint ventures involve a low degree of control, investment and risk. For the successful selection of entry mode, Elsner (2012) stresses the importance of choosing a mode that matches the company's own resources. For instance, the establishment of physical stores requires large investments (including logistics investments) that in turn require large financial resources from the company. In a similar vein, Huang and Sternquist (2007) argued that both company-specific characteristics and market-specific characteristics (e.g. economic, regulations and culture aspects of foreign markets) need to be taken into account in the selection of entry mode.

Retail format transfer: Retail format transfer refers to the transfer of business concept and internal retail systems and processes (i.e. marketing and supply-chain operations) to a new foreign market (Goldman 2001; Swoboda and Elsner 2013). The importance of adapting the business concept has been stressed by several scholars (e.g. Johansson and Thelander 2009; Wigley and Chiang 2009) as it can help companies to operate better within foreign markets. In contrast to adaptation, other scholars highlight the importance of standardisation in order to achieve economies of scale (Gamble 2010). Between these two extremes, there are also scholars who argue that a combination of the two is the best approach (e.g. Jonsson and Foss 2011). For instance, in a study of the global Swedish retail chain IKEA by Jonsson and Foss (2011), a flexible replication of the retail business concept was identified, which included both standardised and replicated high-level features in terms of fundamental values and vision, alongside adapted low-level features in terms of product offerings and marketing efforts. This type of replication strategy has also been mentioned by other scholars as well (e.g. Bengtsson 2008; Winter and Szulanski 2001). So, a retailer can choose to transfer either a standardised, an adapted or a mixed retail format.

In terms of internal retail systems and processes, there is a lack of literature covering this part of the retail format transfer. According to Elsner (2012), it is not known which internal systems and processes are involved and the degree to which these are adapted during the establishment within a foreign market. However, previous research has recognised the importance of transferring internal retail systems and processes into foreign markets. For instance, Coe and Hess (2005) argue that infrastructure in terms of IT, logistics and finance is needed, which can be achieved either by standardisation or adaptation of systems and processes.

\section{Establishment activities}

To become established within a new foreign market, retailers need to perform a number of activities. These establishment activities depend on the chosen sales channel. For instance, the establishment of physical stores includes activities to locate store locations and hire store staff, while the establishment of an online store includes mainly IT activities in order 
to create online stores. The establishment of physical stores in foreign markets is seldom mentioned in the literature; however, there is literature that describes store establishment for domestic markets. For example, in a study of Swedish retailers, Sandberg (2014) provides a detailed description of the establishment of physical domestic stores, including activities such as the identification of site location, build the store and the education of store staff.

Similarly to the establishment of foreign physical stores, the establishment of foreign online stores is sparsely described in the literature. However, previous research has focused on individual key activities related to the establishment of foreign online stores. For instance, Liao et al. (2008) have identified content preparation, in terms of organising and presenting information on websites, as one of the key activities in establishing online stores. Furthermore, Liao et al. (2008) argue that local information preferences must be integrated into the development of international online stores in order to better serve local customers. In addition, Hwang et al. (2006) argue that adaptation to local market conditions such as the economy, infrastructure and culture, is important in order to become successful within foreign markets. In addition, Liao et al. (2008) argue that market adaptations such as only translating a domestic website are insufficient, due to local information and payment preferences.

\section{Establishment resources}

An establishment into a new foreign market requires considerable resources and usually includes both internal and external resources. Internal resources are defined by Barney (1991 p. 101) as "all assets, capabilities, organizational processes, firm attributes, information, knowledge, etc. controlled by a firm that enable the firm to conceive of and implement strategies that improve its efficiency and effectiveness", whereas external resources are obtained externally. For instance, a company can hire external support such as a consultant who performs activities during an establishment into a new foreign sales market. In this thesis, the focus has been on managerial resources in terms of the internal strategic company staff who coordinate company functions, and external support involved in foreign establishments.

The process of becoming established in a foreign market is typically driven by the top management team of the company, which coordinates both the internal and external resources involved. How retailers actually manage the process of establishing into a new foreign market is seldom mentioned in the literature. However, how the establishment of domestic stores is managed is found in previous literature (e.g. Sandberg 2014), which can be useful in the retail-internationalisation context. According to Sandberg (2014), the establishment of domestic stores is typically managed by an establishment team. This team integrates different company functions, such as sales, marketing and logistics during the process (Chen, Daugherty, and Roath 2009). In a similar vein, the establishment of domestic stores can be described as a cross-functional project that includes a number of projects involving several company functions (Sandberg 2014).

In addition, retailers can hire external support in terms of consultants and export promotion organisations (EPOs). For instance, EPOs can assist retail companies in the planning and preparation of a new foreign establishment as well as helping them to obtain expertise and 
know-how related to foreign markets. The range of activities that an EPO provides depends on the company's specific needs and which internationalisation stage the company is focusing on (Kotabe and Czinkota 1992). For example, during the pre-export phase, EPOs stimulate export initiation by providing standardised market information about foreign markets (Bell et al. 2001)

\subsection{Logistics in retail internationalisation}

Previous research has mostly studied logistics from a general internationalisation context has and seldom focused on retailers or how their logistics should be organised in order to successfully support retail internationalisation. In order to capture the logistics characteristics that support retail internationalisation, this section aims to summarise the diverse literature on logistics related to retail internationalisation.

As a starting point, the following section presents literature that describes the setting of logistics in the context of retail internationalisation. In retail internationalisation, marketing aspects (e.g. the business concept) are typically the main focus, whereas logistics is a supporting function that adapts to marketing-oriented conditions (Abrahamsson et al. 2010). To better understand the match between logistics and marketing in retail internationalisation, the first section describes the match between logistics and marketing in the given context. Thereafter, literature about how logistics should be organised in terms of organisation and operations to support the early stage of retail internationalisation is presented.

\subsubsection{The match between logistics and marketing in retail internationalisation}

Previous research related to retail internationalisation has recognised the importance of a successful match between how logistics is organised and operated on the one hand, and marketing-oriented decisions and operations on the other. For instance, Chen et al. (2009) studied capabilities related to logistics and marketing and emphasised the need for an "effective relationship" between the two functions in order to create value for end customers. In a similar vein, Schramm-Klein and Morschett (2006) argued that the establishment of an "effective coordination" between the two functions is crucial in order to avoid risking the overall company performance. Furthermore, a successful interplay between operational performance (i.e. logistics) and strategic market positioning is, according to several scholars (Abrahamsson and Brege 2004; Abrahamsson and Rehme 2010), of great importance for the profitable growth of a company. In the context of retail internationalisation, a similar observation is made by Swoboda et al. (2008), who claim that supply-chain processes (e.g. logistics operations and order management) and marketingoriented processes (e.g. sales promotion and customer relationships) are reciprocal and must be combined together in order to achieve both internal efficiencies (typically ensured by well-functioning logistics operations) and external effectiveness (represented by a marketing-oriented logic). 


\subsubsection{Logistics organisation and operations in retail internationalisation}

For retailers to successfully expand into foreign markets, logistics managers have to expand their logistics organisation and logistics operations in a way that supports the overall strategy related to the retail internationalisation. The logistics strategy plays a crucial role in managing internationalisation in general, because it sets the frame for the design of the logistics organisation and the logistics operations (Schmidt and Wilhelm 2000). Furthermore, most of the previous contributions have focused on individual characteristics of the logistics strategy (e.g. Jonsson et al. 2013; Melacini et al. 2011). There are also a few contributions that investigate several characteristics of logistics strategy in a general internationalisation context (e.g. Marchet et al. 2016; Straube et al. 2008). In order to identify key logistics characteristics that support retail internationalisation, the following section presents a wide set of logistics characteristics related to retail internationalisation. The section starts with the aspect of Centralisation in retail internationalisation, followed by Standardised processes and operations in retail internationalisation and Outsourced distribution in retail internationalisation.

\section{Centralisation in retail internationalisation}

Centralisation is a logistics characteristic that has frequently been discussed in previous logistics literature and is typically distinguished in terms of management and physical structure. In terms of the centralisation of management, a centralised logistics organisation is often called for in the literature (e.g. Creazza et al. 2010; Sandberg 2013; Swoboda et al. 2008). This is because centralisation offers an overview and leadership to efficiently and effectively coordinate the logistics resources needed in establishments into new foreign markets (Abrahamsson et al. 2003; Swoboda and Anderer 2008) as well as enabling costefficient operations due to better cost control (Abrahamsson et al. 2003). It also enables the logistics organisation to manage complexity, which typically increases when operating in multiple foreign markets. According to Chow et al. (1995), centralisation can be considered in terms of two dimensions. The first refers to the extent to which logistics decisions are made internally within the organisation, while the second refers to the degree of proximity between top management and strategic logistics staff. Centralisation in terms of close proximity between logistics decision-makers and top management is important in order to integrate logistics with marketing and other company functions (Abrahamsson et al. 2003). Furthermore, the more directly involved the logistics organisation is in decisionmaking, the better are the possibilities for logistics managers to seek conformity with overall strategy regarding the establishments into foreign markets (Swoboda et al. 2008). This also enables better forecasting and inventory planning (Rudberg and West 2008). In addition, it offers logistics managers a place on the project teams that manage the process of such establishments (Swoboda and Anderer 2008). In a similar vein, Straube et al. (2008) emphasise the importance of involving logistics managers in strategic decisions relating to internationalisation in order to better align the logistics. Furthermore, the involvement of logistics managers in the early stage of internationalisation is especially important in order to make sure that any opportunities and shortcomings of the logistics organisation and operations are considered (Straube et al. 2008).

In addition to the centralisation of management, the centralisation of the physical logistics structure (i.e. warehouse facilities) is also frequently mentioned in the literature. In terms of establishment into foreign markets, a centralised physical logistics structure is essential 
(e.g. Abrahamsson et al. 2003). It offers cost control (Burt et al. 2008; Sandberg 2013) as well as providing a better overview and leadership of the logistics organisation, which enables the efficient and effective coordination of logistics resources (Abrahamsson et al. 2003; Swoboda and Anderer 2008). According to Abrahamsson and Rehme (2010), a central warehouse enables cost-efficient operations upstream towards suppliers, which in turn creates proactiveness and responsiveness downstream towards end customers. Furthermore, the formalisation and standardisation of logistics operations are typically facilitated by the centralisation of the physical structure, which in turn enables the creation of advantages such as creating economies of scale and scope (Abrahamsson and Rehme 2010; Wood and Reynolds 2014).

\section{Standardised logistics operations in retail internationalisation}

Standardisation of logistics operations is another logistics characteristic frequently highlighted in the literature (e.g. Straube et al. 2008; Abrahamsson et al. 2003). Standardised logistics operations enable the creation of economies of scale and scope as well as enabling smooth adjustment to new conditions (Sandberg and Abrahamsson, 2010; Swoboda and Anderer 2008; Wood and Reynolds 2014) and giving the ability to cope with environmental and market uncertainty. Simultaneously, logistics managers have to balance standardised procedures with local adaptations in order to meet local requirements. To achieve the standardisation of logistics operations, routines for reporting and gathering information, as well as methods and information systems for planning, are crucial (Abrahamsson et al. 2003). These routines, methods and systems are also important in order to install wellfunctioning IT support within the logistics organisation. Furthermore, the combination of standardised logistics operations and centralised logistics structures facilitates the pooling of logistical resources, which in turn enhances flexibility (Abrahamsson and Rehme 2010). It also facilitates the up-scaling of logistics operations, which is especially important in the context of retail internationalisation. Furthermore, this combination allows the logistics organisation to serve as a source of growth as well as a platform for cost efficiency (Abrahamsson and Rehme 2010).

Furthermore, standardised logistics operations support efficient store replenishment, which strongly depends on efficient warehouse operations. Warehouse operations typically include operations for: (1) receiving, (2) put-away, (3) storage, (4) picking, (5) sorting, (6) packing, and (7) shipping (Kembro et al. 2018; Hellström and Saghir 2006; Zúniga and Martinez 2016). In addition, retailers usually also include (8) return operations. Return operations are typically more prominent for retailers with online stores, as such stores typically experience a larger number of returns (DeKoster et al. 2002; Kembro et al. 2018). Figure 2 illustrates the standard warehouse operations of retailers. When products are received at the warehouse, they are unloaded, labelled and verified with a quality check (Kembro et al. 2018). Thereafter, the products are put away into an assigned storage location (Bartholdi and Hackman 2008). Storage typically includes a picking zone and a reserve area (Frazelle 2002). A limited quantity of each product is kept in the picking zone in order to be easily retrieved by pickers (Rouwenhorst et al. 2000). As picking accounts for most of the labour costs, it is important to select an appropriate method that increases the picking efficiency ( $\mathrm{Li}$ et al. 2017). To further improve the picking efficiency, fast-moving products should be placed in the most accessible locations (Gu et al. 2007). Afterwards, the picked orders are packed and made ready for distribution (Gu et al. 2007). If the order 
involves products from multiple flows, these products are first sorted and merged into a complete order. Also, products can be directly transported from the inbound to the outbound terminal via cross-docking. Thereafter, the order is registered for departure and the distribution is made from an allocated gate during a scheduled time window (Bartholdi and Hackman, 2016). Returns typically include operations for receiving and sorting returned products before they are put away in storage (DeKoster et al. 2002).

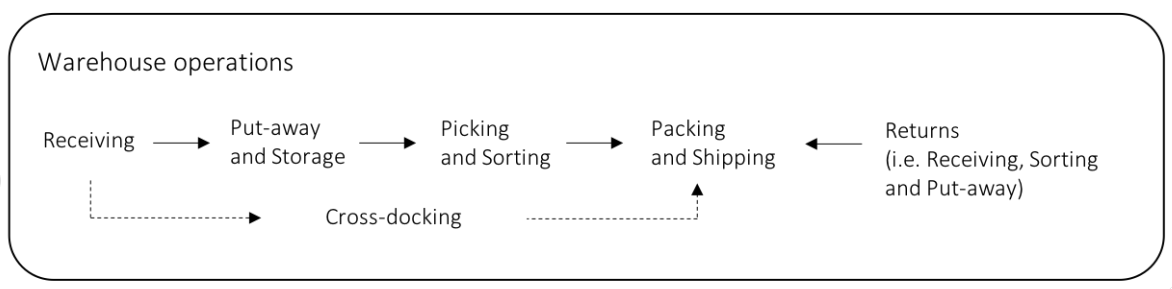

Figure 2 - The warehouse operations of retailers

In addition to the above, in order to establish efficient standardised logistics operations in a warehouse, a number of design aspects and resources need to be considered. For instance, Kembro et al. (2018) list: physical warehouse layout, storage and handling equipment, automation solutions, information systems and labour management. These design aspects are illustrated in Figure 3. To achieve design goals (e.g. improved capacity and resource utilisation) as well as avoid sub-optimisation, several of these design components should be considered (Baker and Canessa 2009). Furthermore, it is important to consider design aspects at an early stage while establishing warehouse operations, as changes later on can become costly and difficult to implement (Huertas et al. 2007).

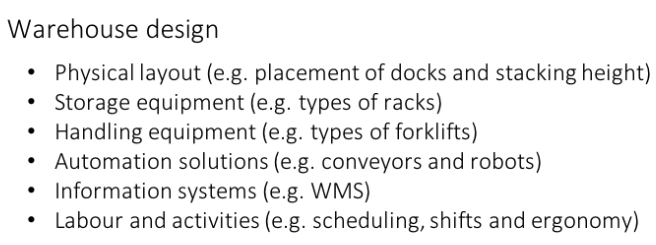

Figure 3 - Aspects of the warehouse design

\section{Outsourced distribution in retail internationalisation}

Foreign distribution is another important key aspect that is closely related to retail internationalisation. To successfully establish and operate in foreign markets, retailers have to establish efficient distribution in order to supply their foreign end customers. To establish efficient foreign distribution, transportation networks play a fundamental role in internationalisation because such networks enable cost control and logistics leverage in terms of customer satisfaction (Bygballe et al. 2012; Creazza et al. 2010). Furthermore, transport planning in terms of how to supply new foreign markets is of great importance in transportation networks (Marchet et al. 2016; Melacini et al. 2011). 
In contrast to warehouse operations, which are typically managed inhouse by most retailers (Swoboda et al. 2008), the planning and execution of transportation are usually outsourced and managed by a third-party logistics provider (Straube et al. 2008). To successfully operate in foreign markets, it becomes crucial to establish a relationship with third-party logistics providers that can operate and manage physical distribution in foreign markets ( $\mathrm{Li}$ et al. 2012; Straube et al. 2008). In a similar vein, establishing "territorial embeddedness" in which companies become rooted in local logistics networks in foreign markets, is crucial (Wood and Reynolds 2014; Wrigley et al. 2005). This embeddedness is key for logistics performance as well as for the timing of market entry. Furthermore, local networking is also a key ingredient for overcoming difficulties and challenges related to establishments into new foreign markets (Hutchinson et al. 2009).

\subsection{Supply-chain capabilities in retail internationalisation}

A starting point for this licentiate thesis is that, to become successfully established within foreign markets, retailers need capabilities enabling them to efficiently coordinate the different resources involved in retail internationalisation. Previous research has mainly described capabilities related to marketing issues; however, capabilities related to supplychain issues are also necessary for successful retail internationalisation. Retailers need supply-chain capabilities in order to efficiently coordinate supply chain resources to align them with the requirements of their retail internationalisation. To identify supply-chain capabilities that support retail internationalisation, this section aims to summarise the literature about capabilities related to the supply chain in a retail-internationalisation context. The section starts by considering the literature on resource-based theories in order to provide a basic understanding of resources and capabilities. Thereafter, literature on learning mechanisms and external network resources is presented.

\subsubsection{Resource-based theories in retail internationalisation}

Resource-based theory has been studied extensively since the 1990s and is one of the dominant perspectives in strategic management literature. In contrast to Porter's (1980; 1985) market position perspective, which argued that competitive advantage comes from the market position of a company, scholars such as Barney (1991) and Grant (1991) argued that competitive advantage is based on a company's resources and capabilities. According to Wernerfelt (1984), companies are "bundles of resources" that can be used to achieve competitive advantage. Company resources are typically defined as "all assets, capabilities, organisational processes, firm attributes, information, knowledge, etc. controlled by a firm that enable the firm to conceive of and implement strategies that improve its efficiency and effectiveness" (Barney, 1991, p. 101). Grant (1991) further developed the term by making a distinction between resources and capabilities. According to Grant (1991), resources are tangible (e.g. capital, equipment) and intangible (e.g. skills of employees, brand names and finance) inputs to the production process, while capabilities are the "cooperation and coordination of teams of resources" (Grant 1991, p. 119). Furthermore, Grant (1991) states that "while resources are the source of a firm's capabilities, capabilities are the main source of its competitive advantage" (Grant 1991, p. 119). However, not all the capabilities that a company possesses result in long-term competitive advantage, which makes it important to find the capabilities that actually do. To achieve a sustainable competitive advantage, Barney 
and Clark (2007), along with Sandberg and Abrahamsson (2011), argued that resources need to be valuable, rare and difficult to imitate. Otherwise, competitors can easily imitate and use them for their own advantage.

In addition to traditional resource-based theory, there are also other, parallel views in terms of different resource-based theories. One of these is the theory of dynamic capabilities (e.g. Teece et al. 1997), which is grounded in the view that the solution for today may not be the best solution for tomorrow and therefore resources and capabilities need to be continuously renewed and updated in order to ensure long-term competitiveness (Sandberg and Abrahamsson 2011). This is also assumed to apply to the supply-chain-oriented resources and capabilities involved in retail internationalisation, because retail internationalisation is a dynamic process.

There has been very little research covering capabilities related to the supply-chain aspects of retail internationalisation. However, there are a few studies (e.g. Cao 2011; Frasquet et al. 2018; Frasquet 2013; Lowe et al. 2012) that consider capabilities in the context of internationalisation that use the theory of dynamic capabilities. For example, Frasquet et al. (2013) identify general dynamic capabilities (e.g. knowledge acquisition, learning and adaptation capability) that are relevant to international companies in general, as well as retail-specific dynamic capabilities (e.g. channel management or location and store-design management) specifically relevant to retailers. These two types of dynamic capability are further studied by Frasquet et al. (2018), who investigate how these capabilities support the creation of market embeddedness. In a similar vein, Lowe et al. (2012) study how dynamic capabilities develop over time as retailers establish themselves in new markets. In addition, Cao (2011) presents three capability categories labelled sensing, shaping, and transfer and reconfiguration, which are found in unstable market environments.

\subsubsection{Learning mechanisms in retail internationalisation}

According to the logic of dynamic capabilities, the existing resource base needs to be continuously renewed and updated in order to achieve long-term competitiveness. To do so, organisational learning has been identified as an important prerequisite in order for companies to learn from previous experience and improve their resources and capabilities (Esper et al. 2007; Sandberg and Åman 2010; Zollo and Winter 2002). According to Zollo and Winter (2002), organisational learning includes three learning mechanisms: experience accumulation, knowledge articulation and knowledge codification. The first, experience accumulation, refers to experiential knowledge that is typically acquired by the company through trial and error. Retail internationalisation can be seen as a learning process including learnings from trial and error. The second, knowledge articulation, refers to when opinions and viewpoints are discussed and challenged by individuals or a group of individuals (Zollo and Winter 2002), which makes staff aware of company conditions and how the organisation (including the supply-chain organisation) is functioning and performing. This can include conditions as well as how retailers are functioning and performing in retail internationalisation. The third learning mechanism, knowledge codification, goes beyond the articulation of knowledge and refers to the codification of individuals' own understanding. For instance, logistics staff can codify how supply-chain operations are performed by creating blueprints and implementing different support systems (Zollo and 
Winter 2002). This knowledge codification can include codification of supply-chain operations relating to retail internationalisation.

\subsubsection{Network resources in retail internationalisation}

Previous research on resource-based theories has also mentioned a relational view (Dyer and Singh 1998; Lavie 2006), which relates to network resources, defined as "external resources embedded in the firm's alliance network that provide strategic opportunities and affect firm behaviour and value" (Lavie 2006, p. 638). So, in addition to internal resources, which are owned and controlled by the company, there are also external resources that are embedded between supply-chain members, which can contribute to a sustainable competitive advantage (Dyer and Singh 1998). In addition, Lavie (2006) argues that companies should be valued in terms of the resources created from their alliances, instead of only the value of their internal resources (Lavie 2006). In a similar vein, Dyer and Singh (1998) mention that relational rents are created by the joint idiosyncratic contributions of alliance partners (Dyer and Singh 1998). For instance, the investment of resources into an alliance, knowledge exchange between alliance partners, or a combination of complementary resources, as well as lower transaction costs, all contribute to relational rent (Dyer and Singh 1998).

In a contribution to the relational view based on dynamic capabilities, dynamic supply-chain capabilities in the setting of operations and logistics management have been identified as a source of competitive advantage (Beske 2012; Defee and Fugate 2010). The importance of inter-organisational relationships has been widely recognised in the supply-chain setting. From a retail perspective, logistics providers can play an important role in the creation of unique capabilities (Kembro et al. 2018). Furthermore, Defee and Fugate (2010) identified two dynamic supply-chain capabilities by combining literature on supply-chain orientation (e.g. Mentzer et al. 2001) and learning orientation (e.g. Zollo and Winter 2002). The first capability is knowledge assessing, which is the ability to understand where to gain access to resources held by two or more members of the supply chain. This capability only focuses on knowledge about where to obtain resources when they are needed. Co-evolving is the second capability, which refers to the continuous collaboration and the creation of joint resources. 



\section{Methodology}

This chapter presents the research methodology used in this licentiate thesis. First, the research approach to the explorative research is presented, followed by the research process. Thereafter, a detailed description of the research methods is presented.

\subsection{Research approach}

This licentiate thesis is written within the frame of the research project Geographical expansion of retail companies (Swedish: Geografisk expansion av detaljhandelsforretag). The purpose of this overarching project has influenced the research purpose, the research questions and the research approach of this thesis.

Because little research has been conducted on logistics in the context of retail internationalisation, an explorative approach has been used. Such an approach is appropriate for providing new knowledge about a specific problem area that lacks previous research (Patel and Davidson 2011). Furthermore, an abductive, multiple case-study approach has been used because it is an appropriate method for explorative research (Kovács and Spens 2005; Miles et al. 2014). An abductive case study combines both empirical data and literature in an iterative process (Kovács and Spens 2005), in order to understand the phenomenon under study (Alvesson and Sköldberg 1994). This approach was used to gradually improve the understanding of the supporting role of logistics during the early stage of retail internationalisation.

Furthermore, this licentiate thesis is a compilation thesis based on three papers. Each paper contributes to one of the three research questions. More specifically, Paper 1 answers the first research question and Paper 3 answers the third research question. Paper 2 partly answers the second research question; however, additional data and literature as well as a further analysis have been added. In Figure 4, below, the building blocks used to answer the purpose and research questions of the licentiate thesis are illustrated.

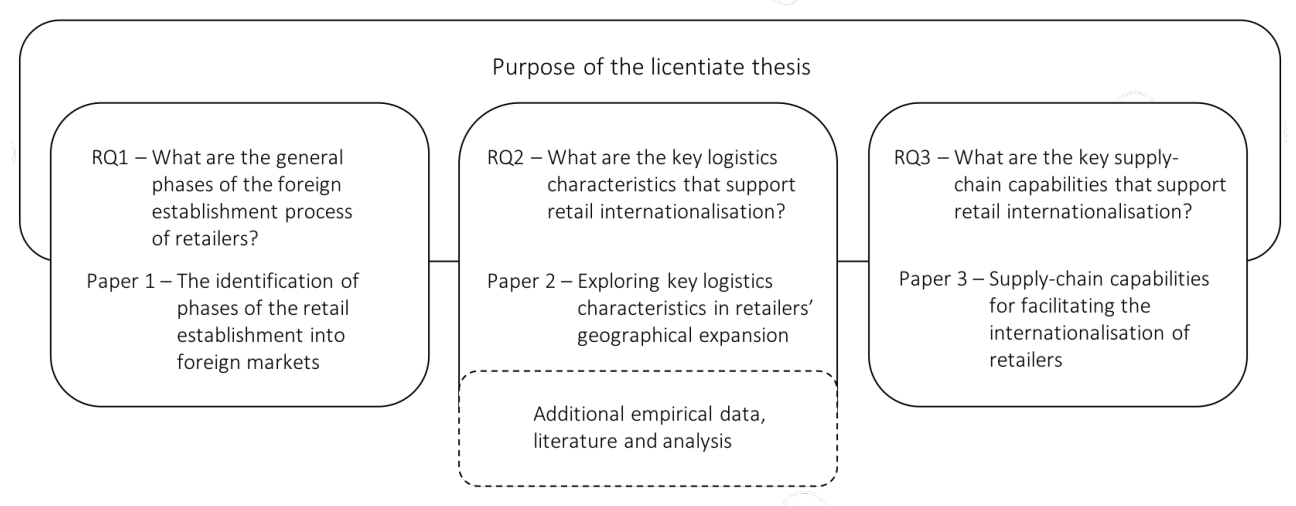

Figure 4 - The building blocks of this licentiate thesis 


\subsection{Research process}

This research has employed an iterative process, using mostly case studies and literature reviews in the different steps of the process. The research process includes 8 steps; it began in autumn 2016 and ended at the beginning of spring 2019. In Figure 5, the overall research process is illustrated.

\section{Research process}

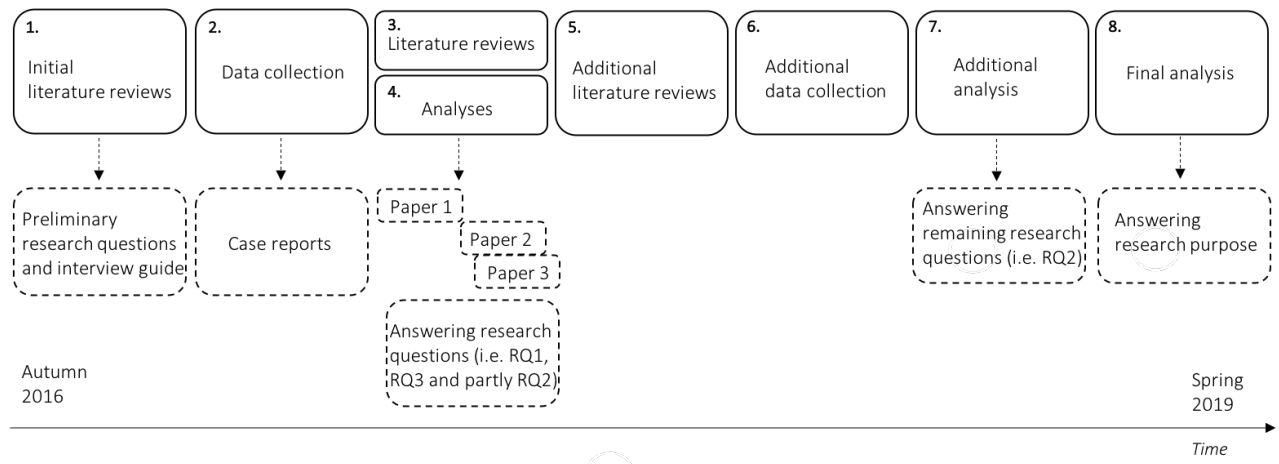

Figure 5 - The research process of this licentiate thesis

The research process started with (1) an initial literature review, in order to develop a basic understanding of logistics and retail internationalisation, which resulted in the formulation of preliminary research questions for the thesis as well as the creation of an interview guide for the empirical data collection. Thereafter, (2) data collection for the case studies, was performed, which resulted in empirical data that was summarised into three individual case reports, one for each case company. The case reports included all the empirical data used in the research. Afterwards, the three research papers were written individually, starting with Paper 1, followed by Paper 2 and then Paper 3, although the two latter papers were written somewhat in parallel. Each paper included (3) additional literature reviews and (4) analyses. The empirical data and literature were analysed by first performing within-case analyses and later a cross-case analysis. The within-case analyses codified patterns within the individual cases with inspiration from the literature in the literature reviews, while the cross-case analysis identified and compared common patterns among the case companies. The analyses answered most of the research questions (i.e. RQ1, RQ3 and parts of RQ2) in this licentiate thesis. Thereafter, (5) additional literature reviews, were performed in order to collect literature about operational logistics aspects that were necessary for answering the remaining research question (i.e. RQ2). Also, (6) additional data collection, about operational logistics aspects of the case companies, was performed, before the literature and empirical data were analysed in (7) an additional analysis, in order to answer the remaining research question. Thereafter, (8) a final analysis was performed by combining the findings from the research questions with the additional analysis to answer the research purpose. 


\subsection{Research methods}

The research methods used in this licentiate thesis are case studies and literature reviews. Case studies are appropriate for conducting empirical research, while literature reviews were necessary in order to obtain a solid theoretical base for analysing the empirical data. In the following section, the case studies are presented, including case selection, data collection, analysis of the case data and research quality of the cases. Thereafter, the performed literature reviews, including literature collection, analysis of the literature and research quality of literature reviews, are presented.

\subsubsection{Case studies}

This licentiate thesis is based on a multiple case study approach comprising three case companies. Case studies are empirical descriptions of a phenomenon (Yin 2003) and in this licentiate thesis the phenomenon of the supporting role of logistics during the early stage of retail internationalisation is studied.

\section{Case selection}

Case selection is identified as one of the key aspects of case-study methodology (Siggelkow 2007) because it ensures that the studied phenomenon can be researched in depth. In casestudy research, case companies need to be purposely selected with respect to the aim of the study (Patton 2014). As a means to facilitate and enable generalisability, the case companies were chosen using selection criteria that included a number of key characteristics. As a means to identify suitable case companies for the study, the researcher, together with colleagues, scanned the Swedish retail industry for potential candidates that could provide rich empirical data and covered several retail sectors, in order to ensure relevance to the retail industry in general. This study has focused on sectors that offers affordable everyday customer products (e.g. clothes as well as home and leisure products). A major selection criterion was retail chains with relatively recent experience of retail internationalisation, which have top management teams willing to share knowledge and data about their ongoing retail internationalisation. Another important selection criterion was retail chains that have been present in at least one of their new foreign markets for a minimum of three years in order to gain an understanding of the time and occurrences after the first establishment period. In addition, retailers that establish themselves with physical stores have been selected as this is the most common approach among large retail chains (Elsner 2012; PicotCoupey et al. 2014) and therefore is relevant to the generalisability of the findings. In addition, online stores have also been covered to some extent because the importance of having an online presence has rapidly increased in foreign sales markets (Picot-Coupey et al. 2014). Furthermore, large retail chains (e.g. see the definition at the European Commission 2009) were selected as they often have more resources enabling them to handle their own logistics, which is key in this research as it focuses on how retailers organise their logistics to support retail internationalisation. Large retail chains are appropriate for this study as they are likely to be more involved in designing their own logistics. This case selection resulted in the selection of three retail companies.

\section{Data collection}

Case studies are typically based on data from a variety of sources (Yin 2003) and the data collection for this thesis included semi-structured interviews, company visits and secondary 
data material such as annual reports, company website and newspapers. Interviews were primarily used to gain deeper insight into the case companies linked to the research questions, while company visits and secondary data were used to learn about the companies and their overall operations. All empirical data was gathered during the time period autumn 2016-spring 2018, with the exception of a small complementary data collection conducted during autumn 2018.

All the interviews were conducted by using a standardised questionnaire (i.e. an interview guide) including open-ended questions, which is found in Appendix 3. The questionnaire was based on literature gathered from the literature reviews and was divided into three sections; the first included marketing-oriented questions, the second included logisticsoriented questions and the third and last section included questions about the relationship between marketing operations and logistics operations in the context of retail internationalisation. Different informants at the companies answered different sections of the interview guide. For instance, a logistics manager answered most of the questions related to logistics from the second and third sections, while an establishment manager primarily answered market-related questions from the first and third sections. The interview guide was sent to the informants in advance in order to advise them about what was of interest in the study. Most interviews were face-to-face and took place on the premises of each retailer. The interviews usually lasted 50-120 minutes. In addition, phone calls and emails were also used to answer complementary interview questions. Furthermore, the informants for this study included key staff such as company managers and project managers who were closely involved in their companies' retail internationalisation, as well as logistics managers who were centrally responsible for the logistics organisation and operations involved in retail internationalisation. In general, a top-down approach was followed in terms of hierarchy level of the informants, starting with top executives. This approach ensured that the appropriate informants were found. In addition, two informants from two export promotion organisations (EPO) were interviewed to gain a greater overall understanding of how retailers enter new foreign markets, which was highly relevant to the first research question (RQ1) and Paper 1. In total, 21 interviews were performed throughout the research process. In Table 1, below, all the informants from each case company are presented, including the type of empirical data each informant provided in relation to the three sections of the interview guide. 
Table 1 - The informants and the type of empirical data collected in this licentiate thesis

(Note: A number of informants were interviewed more than once)

\begin{tabular}{|c|c|c|}
\hline $\begin{array}{l}\text { Company/ } \\
\text { organisations }\end{array}$ & Title of informant & Type of empirical data \\
\hline$A$ & Company founder & Marketing-oriented \\
\hline & $\begin{array}{l}\text { Project manager of the foreign } \\
\text { establishments }\end{array}$ & Marketing-oriented and logistics-oriented \\
\hline & Logistics manager & Marketing-oriented and logistics-oriented \\
\hline & Logistics developer & Logistics-oriented \\
\hline & Supply-chain excellence manager & Logistics-oriented \\
\hline & Warehouse manager & Logistics-oriented \\
\hline$B$ & Head of expansion & Marketing-oriented \\
\hline & Brand director & Logistics-oriented \\
\hline & Logistics manager & Logistics-oriented \\
\hline & Transport and customs manager & Logistics-oriented \\
\hline$C$ & Establishment manager & Marketing-oriented \\
\hline & Supply-chain director & Logistics-oriented \\
\hline EPO1 & Senior project manager & Marketing-oriented \\
\hline EPO2 & Business area manager & Marketing-oriented \\
\hline
\end{tabular}

All interviews were recorded and transcribed. Thereafter, the empirical data, including quotations and data from secondary data sources (e.g. reports and written documents) from each case company, were summarised into three case reports, one for each case company. All three case reports have a similar structure, starting with an overall company presentation, followed by a detailed description of the logistics organisation. Thereafter, the internationalisation journey of each case company is presented, including the foreign markets and the approach used to enter these new foreign markets. The case reports are found in Appendix 2.

\section{Analysis of the case-study data}

Analysing qualitative data is challenging and needs to be performed in an organised and logical manner (Stuart et al. 2002). To achieve structure and logic, the analysis was made using a stepwise approach. Each research question is answered individually and performed in two steps, starting with a within-case analysis of each case company individually, followed by a cross-case analysis (Yin 2014). The within-case analysis studied each company individually by coding different aspects related to each specific research question. The coding process was performed by carefully reading the data material for each case company with the specific research question in mind. Identified codes were marked with a yellow marker. To more easily capture relevant aspects of each case, literature (retrieved from the literature reviews) related to the specific research question had been read beforehand. In addition, before properly analysing the case data, the researcher had established some basic propositions inspired by the interviews or the literature that were later tested in the crosscase analysis. This provided a better structure for the analysis, which simplified the comparison between cases. While the findings of the licentiate thesis were starting to be formulated, the researcher presented the preliminary findings to her colleagues in a seminar (i.e. Förslutsseminarium) in order to receive feedback and input on the licentiate thesis. This contributed to improvements in the entire licentiate thesis, including the findings. For instance, the researcher improved the structure of the analysis as well as the argumentation about the findings, which improved the logic of the analysis. 


\section{Research quality of the cases}

In this section, the research quality in terms of reliability and validity are discussed. For the findings of a study to be trustworthy, both reliability and validity need to be carefully considered (Patel and Davidson 2011). According to Patel and Davison (2011), reliability and validity have a specific relationship because reliability is an important prerequisite for achieving validity. Reliability is about how trustworthy the performed measurements are (Miles et al. 2014). If the study were to be repeated, would the same results be achieved? In a qualitive study like this one, reliability is problematic to achieve; however, aspects such as data-quality checks (to avoid bias), peer or colleague reviews and clearly specified constructs can improve the reliability of a study (Miles et al. 2014). For this specific study, a standardised interview guide was used to collect the empirical data, which enabled smoother data-quality checks between the different answers of the informants from the same company and the fact that the answers corresponded increased the reliability of this study. Furthermore, in the search for informants, a top-down approach in terms of the hierarchy level of informants was used, which ensured that no important informants were missed. The reliability is improved by this systematic approach as it is easy to repeat and probably would result in the same type of informants if the study was repeated as the hierarchy levels within a company seldom changes. Furthermore, additional data-quality checks on the collected data were performed by sending the case reports to the informants for them to read. This ensured that the empirical data was correct and provided a solid empirical foundation for the analysis, which also improved the reliability of the study. In addition, the analysis of the empirical data was peer reviewed by the supervisors and the feedback was used to improve the logic of the analysis, which increased the reliability of the study.

Furthermore, there are three types of validity: construct, internal and external (Yin 2014). Construct validity refers to sufficient measures used to study relevant concepts in a study. This validity can be achieved by using multiple sources of evidence, creating a chain of evidence and having case study reports reviewed by informants (Yin 2014). The use of multiple sources of evidence, such as empirical data and literature, to describe a phenomenon is important to ensure that key concepts are studied in the study. For instance, both empirical data and literature confirmed a number of key constructs related to logistics that were important in retail internationalisation, such as centralisation. Furthermore, a chain of evidence was created by following a sequential research process in which analyses was made stepwise in order to ensure a logic and well-motivated findings. In addition, the case reports were read by the informants in order to ensure that concepts relevant for the study was considered, which increased construct validity.

Internal validity refers to whether findings make sense for a specific study. Internal validity can be achieved, for instance, by using context-rich, meaningful and comprehensive descriptions, by triangulation with complementary methods and data sources, and by logically motivating the findings (Miles et al. 2014). For this specific study, a greater level of data triangulation was achieved through the diversity of informants that helped to reduce the bias of informants. The fact that answers from the informants were mostly uniform, helped to ensure increased internal validity (Miles et al. 2014; Yin 2003). Also, observations have been performed at the case companies, which allowed method triangulation. Furthermore, context-rich, meaningful and comprehensive case descriptions (i.e. case 
reports) were created and used in the study, which increased the internal validity. Also, pattern matching (Yin 2014) was performed in which patterns between the case companies were documented and analysed. This helped to logically motivate the findings of the specific study.

In addition, external validity refers to the extent to which the findings can be transferred to other contexts and how far they can be generalised (Miles et al. 2014). For a qualitive study, it is useful to specify any limitations in the sample selection and critically examine the ability to generalise the results to different settings and contexts. This study is based on a few case companies that allows a more in-depth analysis of each case, which can provide more indepth knowledge and understanding of a particular phenomenon. One drawback can be limited external validity. Yin (2014), however, argues that two or more cases strengthen the findings considerably instead of having just one case. Additional case studies would have increased the validity further, but is not a requirement in order to generalise the findings. Furthermore, the external validity is improved by studying three case companies from three different retail sectors. Despite their differences (e.g. business offer, product range), there are a number of common traits (e.g. foreign establishment approach and logistics organisation) that increases the generalisability of the findings to other retail companies.

\subsubsection{Literature reviews}

To gain knowledge about specific research areas, literature reviews were appropriate (Bryman 2015). These literature reviews were important throughout the research process, especially in the formulation of the research questions and frame of reference. For the literature reviews, three strategies were used. The first acquired literature from several data sources, including recommended papers and books from supervisors and colleagues, as well as $\mathrm{PhD}$ courses such as International entrepreneurship (Swedish: Internationellt företagande). This strategy was particularly important during the initial literature review in order to gain a basic understanding of logistics and retail internationalisation. The second strategy sourced literature by using specific key words. This strategy was primarily used to find literature relevant to the specific research questions, such as literature related to logistics characteristics and resource-based theories. The third strategy was snowball sampling, which was used to find relevant references from other papers of relevance (Miles and Huberman 1994).

\section{Literature collection}

The literature collection was performed by using two databases; UniSearch and Google Scholar. UniSearch was used as the primary database because it includes a large range of databases, including Web of Science, Scopus and Business Source Premier. A database that covers a large range of databases is good in order to capture a larger number of relevant literatures in one search. In addition, Google Scholar was used as a complement to find recommended papers as well as to find full texts that were not accessible in the other database.

For the initial literature reviews, basic literature was collected in order to provide a basic understanding of logistics and retail internationalisation, as well as to establish the interview guide used in the data collection. During the other literature reviews, the focus was to 
collect in-depth knowledge related to a specific paper, research question or research aim. For the literature reviews, search terms were combined manually based on the specific goal of the review. For instance, for the literature collection related to logistics characteristics in retail internationalisation, search terms such as "retail", "logistics", "logistics aspects", "warehouse operations" and "retail internationalisation", were combined in different search strings. Also, synonyms of key words such as "supply chain", "distribution operations", "foreign expansion", "foreign establishment" and "internationalisation" were used in order to find relevant literature.

\section{Analysis of the literature}

After the literature had been collected, it was analysed. First, the collected literature was scanned by reviewing the titles of the papers. Titles that did not seem to relate to the focus at all were removed, while potential papers were kept for further analysis. Second, the abstracts of the remaining papers were carefully read. Third, if the abstract seemed relevant, the researcher scanned the entire paper and read relevant parts that might be of further interest. Usually, interesting parts of different papers were summarised in a separate document in order to save them in one place. This also reduced the risk of losing relevant literature during the research process.

\section{Research quality of literature reviews}

To improve the research quality of the collected literature, data triangulation was conducted using books and journal articles that increased the validity of the literature used in this study. Furthermore, to ensure a high standard among the collected journal articles, peer-reviewed journals were used to an extensive degree in the literature reviews. This approach ensures increased reliability as peer-reviewed journal articles are typically written with a good research manner. Furthermore, search terms including synonyms were used for the literature collection that increased the chance of finding relevant literature for this study, which in turn increased the research quality. 




\section{Presentation of case companies}

This chapter presents the case companies studied in this licentiate thesis. In Table 2, the overall information about the case companies is presented, followed by a presentation of each company.

Table 2 - Overall information about the case companies in the licentiate thesis

\begin{tabular}{|c|c|c|c|c|}
\hline Company & Retail sector & Sales channels & $\begin{array}{l}\text { Sales markets via } \\
\text { physical stores }\end{array}$ & $\begin{array}{l}\text { Sales markets via } \\
\text { online store }\end{array}$ \\
\hline$A$ & Home and leisure & Physical stores & $\begin{array}{l}\text { Sweden, Norway } \\
\text { and Germany }\end{array}$ & No online stores \\
\hline$B$ & Fashion & $\begin{array}{l}\text { Physical stores and } \\
\text { online stores }\end{array}$ & $\begin{array}{l}\text { Sweden, Norway, } \\
\text { Finland, Denmark } \\
\text { and Germany }\end{array}$ & $\begin{array}{l}\text { European Union } \\
\text { countries and } \\
\text { Norway }\end{array}$ \\
\hline$C$ & Hobby materials & $\begin{array}{l}\text { Physical stores and } \\
\text { online stores }\end{array}$ & $\begin{array}{l}\text { Sweden, Norway, } \\
\text { Finland, the } \\
\text { Netherlands and } \\
\text { Belgium }\end{array}$ & $\begin{array}{l}\text { European Union } \\
\text { countries and } \\
\text { Norway }\end{array}$ \\
\hline
\end{tabular}

\subsection{Company A}

Company A is a Swedish retailer that offers affordable home and leisure products to private customers. The company was founded in the mid-1980s and is a store-based company. To date, the company has about 1,700 employees. In 2017, the turnover was about EURO 253 million and the operating margin was $6.1 \%$. The headquarters of the company are located in the region of Stockholm and its central warehouse is located in the region of Norrköping.

Company A entered the international arena by establishing stores in Norway in 2014 and Germany in 2017. To date, company A has a total of 109 stores, 88 of which are located in Sweden, 19 in Norway and 2 in Germany. Figure 6 illustrates the retail internationalisation via physical stores of Company A. The main motivation for retail internationalisation was to achieve further growth as the company had started to experience saturation of the home market. The company runs a low-margin business and strives to offer products at a low price. To be able to keep prices low, the company needs to expand in a way that increases the economies of scale of its company operations. By expanding into foreign markets, the company can order larger quantities for a lower price per unit, which enables the company to reduce its product prices, which results in long-term competitiveness.

The establishment of Company A into foreign markets has been driven by the board, with the two company founders and the CEO in the lead. All strategic decisions related to foreign establishment have been taken at a centralised level by the top management team of the company. For all markets, the company uses a standardised business concept in terms of business offers, sales channels and product range.

Company A uses physical stores as its main sales channel with a complementary order assortment. The latter is delivered to the stores for all markets, with the exception of 
Swedish customers, who can also choose home delivery. The product range consists of about $25 \%$ market-specific products.

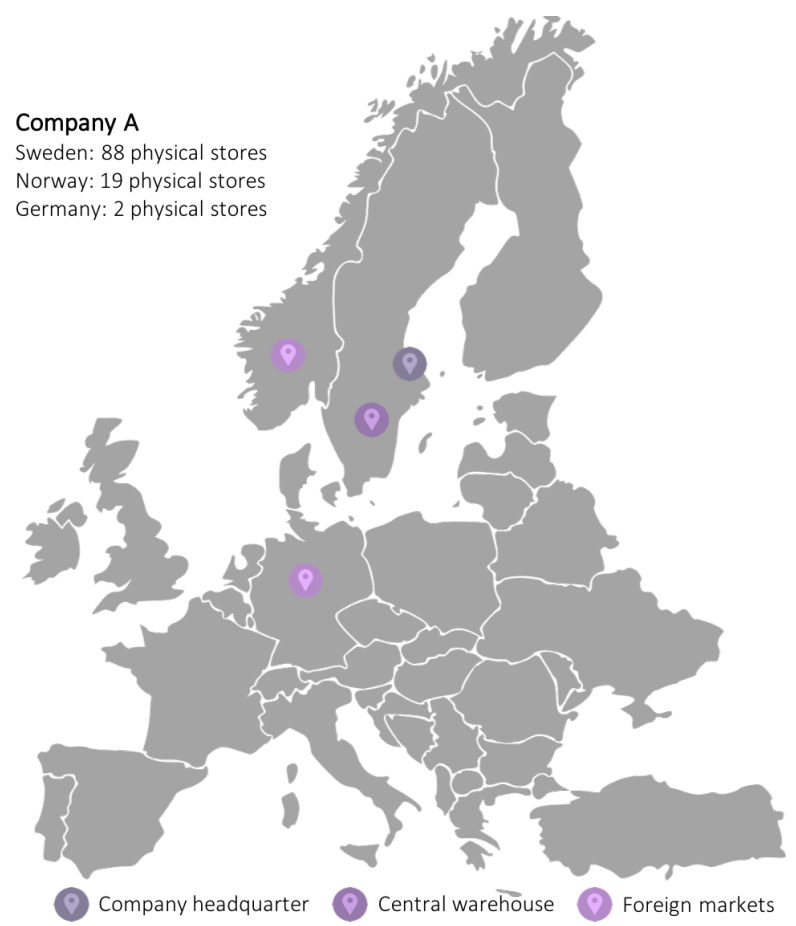

Figure 6 - The retail internationalisation via physical stores of Company A

\subsection{Company B}

Company B is a Swedish fashion retailer that offers affordable fashion to young women. The company was founded in the late 1990s and started out as a family-owned, store-based company. To date, the company has about 2,000 employees and a total of 183 stores in Sweden, Norway, Finland, Denmark and Germany, as well as online stores across the EU. Physical stores are the main sales channel and constitute the majority of total sales, while the online stores are used primarily as a marketing platform that offers additional services. The headquarters and central warehouse are located in Borås. In 2014, the company changed its management as a private equity investor became the majority shareholder of the company.

Since the first store opened in Sweden, Company B has established stores in Norway in 2007, Finland in 2007, Denmark in 2008 and Germany in 2010. The Swedish market accounts for half of the company's turnover while the turnover of the other markets is ranked: (1) Norway, (2) Finland, (3) Denmark and (4) Germany. Of the total of 183 stores, the company has 88 stores in Sweden, 38 in Norway, 24 in Finland, 20 in Denmark and 13 in Germany. Figure 7 illustrates the retail internationalisation via physical stores of Company B. 
During the years of establishments to foreign markets during the 2000s, Company B was very successful and enjoyed high economic profits. However, during the 2010s, the company has gone through some challenging years, as the global competition within the fashion sector has become more apparent with the company competing against other international fashion companies. In 2017, the turnover of the company was about EURO 97.5 million and the operating margin was $-0.36 \%$.

All strategic decisions related to retail internationalisation are made at a centralised level within the company, including marketing-oriented decisions and logistics-related decisions. The company uses a standardised business concept in terms of business offer, sales channels and product range for all markets. This to achieve economies of scale within company operations. A standardised business concept is also used because the fashion trends in western countries are quite homogeneous and are believed to work well internationally.

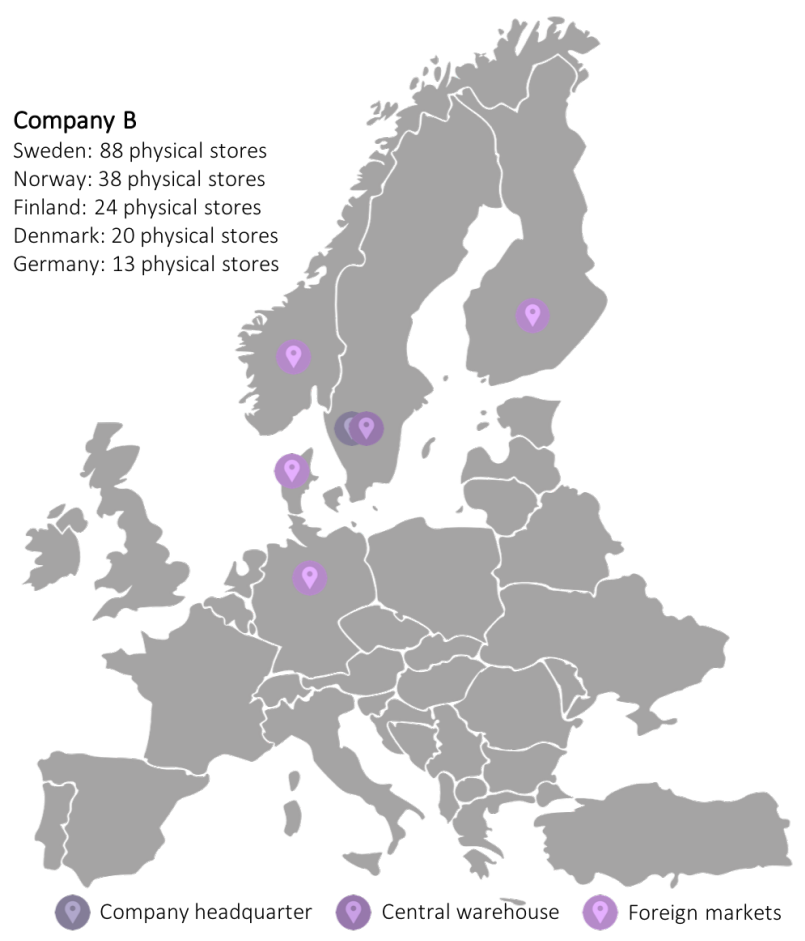

Figure 7 - The retail internationalisation via physical stores of Company B

\subsection{Company C}

Company $\mathrm{C}$ is a Swedish hobby retailer that offers a broad range of hobby materials, tools and DIY kits to private customers. The company was founded in the mid-1950s in Copenhagen as a family-owned, mail-order-based company. During the 1980s, however, the company started to expand via physical stores in order to achieve further economic 
growth. To date, the company has 131 physical stores in Sweden, Denmark, Norway, Germany, the Netherlands and Belgium, as well as online stores across the EU. The company also sells hobby products as a wholesaler. Physical stores are the main sales channel and account for about $75 \%$ of the annual sales, while online stores and wholesale account for $10 \%$ and $15 \%$ respectively. The company has about 600 employees and the both headquarters and central warehouse are located in Malmö. In 2017, the turnover was about EURO 79.4 million and the operating margin was $0.53 \%$.

Since the 1950s, the company has established itself in Sweden in 1962, Norway in 1986, Germany in 2010, and the Netherlands and Belgium in 2011. Company C has 38 stores in Sweden, 19 in Norway, 18 in Denmark, 3 in Germany, and 25 in the Netherlands and Belgium. Figure 8 illustrates the retail internationalisation via physical stores of the company. The first online stores were launched in Scandinavia in the late 1990s and have expanded to cover the entire EU. The company wants to increase its online sales further and therefore launched a new website in 2017 to improve the online shopping experience.

In Company C's retail internationalisation, all strategic decisions are made at a centralised level within the company. It has kept a fairly standardised business concept in terms of business offer, sales channels and product range for its foreign establishments in order to achieve economies of scale in its company operations. However, some minor market adaptations in terms of market-specific products have been added to better meet local customer demand and to create a more local feel to the brand.

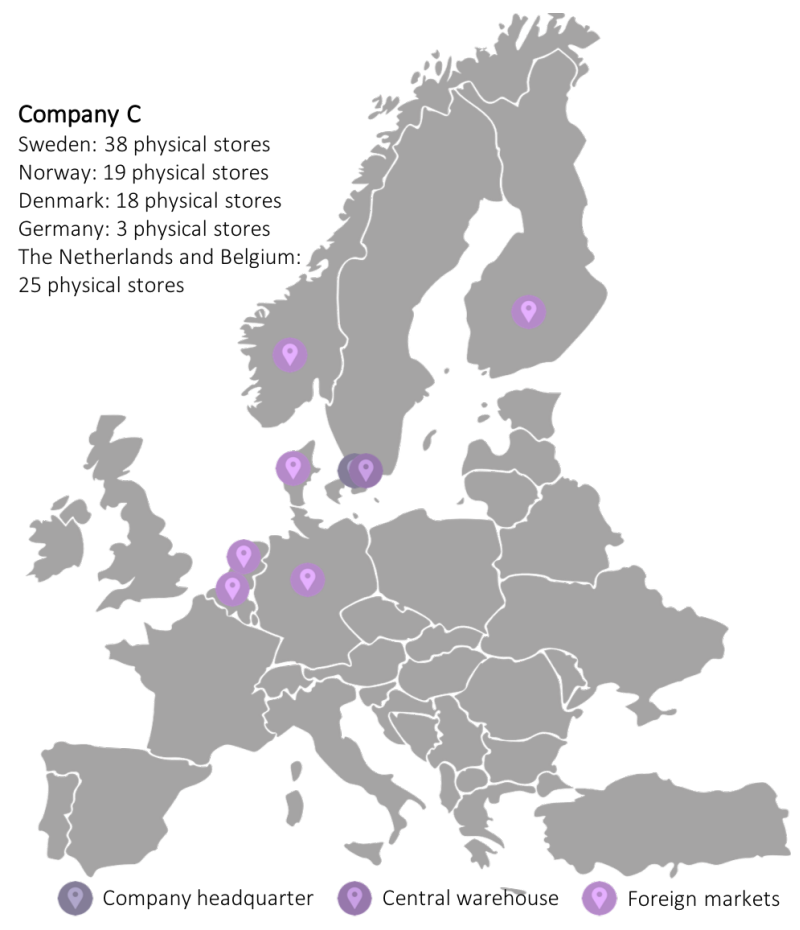

Figure 8 - The retail internationalisation via physical stores of Company $\mathrm{C}$ 




\section{Overview of appended papers}

In this chapter, an overview of the three appended papers is presented. The focus of this overview is to present the results of the papers in order to provide a better understanding of how they relate to the licentiate thesis. The full papers are also found in Appendix 1.

\subsection{Paper 1 - Phases of foreign establishment}

Previous research on retail internationalisation has mostly studied specific market-oriented aspects, such as motivations (Hutchinson et al. 2007) and market entry strategies (Agarwal and Ramaswami 1992; Doherty 2000), while the way in which retailers actually establish their sales operations into a new foreign market is not clearly described. The actual establishment process for retailers into a new foreign market is missing, as well as the phases that this process includes.

The aim of this paper is to explore the phases of the process of the retail establishment into new foreign markets, including the internal and external individuals/functions involved.

The paper was based on a multiple case study of two large-sized, Swedish retail companies, which had entered new foreign markets via wholly-owned stores and online stores. Also, managers within two export promotion organisations were interviewed in order to gain a fuller understanding of what the establishment process usually look like for retailers. From these two cases, the establishment process for each retailer was established. The analysis of the establishment process of the case companies identified three establishment phases: a market-analysis phase, an implementation phase and a follow-up phase. The marketanalysis phase includes activities for investigating potential foreign markets, during which both market-specific and company-specific characteristics were evaluated before the final market selection. Second, the implementation phase includes activities for establishing foreign sales operations such as physical stores and online stores. For instance, activities such as store location, store build-up, and the recruitment and education of store staff. Third and last, the follow-up phase includes daily monitoring of sales in the new stores to see whether they are following the expected sales curve. Throughout the establishment process, an internal establishment team, including the CEO, was involved, as well as external support in terms of export promotion organisations and informal business networks.

\subsection{Paper 2 - Logistics characteristics}

Logistics has been acknowledged as a key ingredient for the successful geographical expansion of retailers (Creazza et al. 2010; Marchet et al. 2016; Swoboda et al. 2008). Despite recognition of the impact and interdependence between logistics and geographical expansion, the way in which logistics supports retailers' geographical expansion has not been studied in depth. To better understand how logistics supports the geographical expansion of retailers, this paper identifies key characteristics that enable the logistics organisation and its operations to provide this support.

The purpose of this paper is to explore how the logistics organisation and its operations support retailers' geographical expansion. 
The paper was based on an inductive, multiple case study of three large-sized, Swedish retail companies. The case companies had expanded into neighbouring foreign markets via wholly-owned stores and online stores. The identification of logistics characteristics was made in two steps. The case companies were first studied individually in a within-case analysis, followed by a cross-case analysis. From the analysis, four logistics characteristics: (1) centralised logistics control, (2) centralised logistics structure, (3) standardised logistics operations and (4) continuous logistics learning and improvement were identified. Centralised logistics control refers to the central control of the logistics organisation whereby it is managed by a few strategic logistics staff who design the entire organisation. Furthermore, this central control is enhanced as the strategic logistics staff are located at the headquarters, in close proximity to top management, which allows short communication lines between the logistics organisation and top management. Centralised logistics structure refers to the centralisation of warehouse facilities into one central warehouse. A central warehouse simplifies foreign distribution and reduces logistics costs in relation to transportation and handling. The third important characteristic is standardised logistics operations. By using standardised operations for all markets, the complexity related to foreign markets can be reduced and economies of scale and scope can be achieved. Fourth and last, continuous learning and improvements occur within the logistics organisation. The strategic logistics staff frequently collected feedback from foreign stores and operational logistics staff in order to improve logistics operations. The logistics organisation also evaluates the distribution carried out by logistics providers in the foreign markets. Taken together, these four logistics characteristics were important for enabling a smooth establishment into new foreign markets in the geographical expansion of retailers.

\subsection{Paper 3 - Supply-chain capabilities}

According to previous scholars (e.g. Swoboda et al. 2008), a match between marketingoriented processes and supply-chain processes (e.g. logistics operations) is an important prerequisite for retailers to internationalise successfully. However, companies are struggling to align their logistics to support the companies' marketing-oriented objectives, such as establishing themselves in new, foreign sales markets (Straube et al. 2008). In contrast to marketing-oriented challenges, supply-chain challenges have been given sparse attention in previous research (Marchet et al. 2016). Hence, this paper focuses on the supply-chainoriented capabilities that are needed in order for retailers to successfully internationalise into foreign sales markets.

\section{The purpose of this paper is to explore the supply-chain-oriented capabilities that facilitate the process of retail internationalisation.}

This inductive, multiple case study of three large-sized Swedish retail companies takes it stance in the literature on resource-based theories, including the resource-based view of the firm (e.g. Barney 1991; Wernerfelt 1984; Peteraf 1993), dynamic capabilities (e.g. Winter 2003; Teece 2007) and the relational view (e.g. Dyer and Singh 1998). Resource-based theories were used to explore the supply-chain capabilities that support retail internationalisation. From the analysis, three categories of supply-chain capabilities were identified: (1) leadership capability, (2) integration capability and (3) learning capability. The first 
category (leadership capability) refers to central control of the logistics organisation in terms of hierarchy and location. This category includes two sub-capabilities: (a) company founder involvement and (b) top management control. Company founder involvement refers to the strong influence of a company's founder as he or she can help to prioritise logistics, whereas top management control refers to the top management team (including the supply-chain manager) that manages the logistics organisation. The second category (integration capability) refers to the integration between the top management team, company functions and external support involved in retail internationalisation. Integration capability included three sub-capabilities: (c) organisational integration, (d) functional integration and (e) external integration. Organisational integration refers to efficient coordination and collaboration between the top management team and the different functions needed in order to successfully coordinate the different resources involved. Functional integration refers to coordination and collaboration between internal company functions. For instance, collaboration between the logistics organisation and the marketing function is important for achieving efficient product flow in the foreign markets. External integration refers to coordination and collaboration between the retailer and external support, which is important in order gain new knowledge about foreign markets. The third and final category (learning capability) refers to learning within the supply chain during retail internationalisation. Learning capability included two sub-capabilities: (f) organisational learning and $(\mathrm{g})$ experiential learning. Organisational learning refers to a learning culture within the company and the logistics organisation in which feedback is frequently collected in order to improve company operations. Lastly, experiential learning refers to the trial-anderror approach used in retail internationalisation. Most of the knowledge obtained comes from personal experiences of previous foreign establishments, which are used to improve the organisation and its operations, including logistics operations.

\subsection{My contribution to the papers}

In this section, my contribution to the papers is presented, starting with Paper 1, followed by Paper 2 and ending with Paper 3.

\subsubsection{Paper 1 - Phases of foreign establishment}

The first paper is a conference paper that was written for the conference Recent Advances in Retail and Consumer Service, which took place in Madeira, Portugal, in 2018.

This paper was solely written by me. However, the idea for the paper originates from the research application that my supervisor Erik Sandberg wrote for my research project, which mentioned the lack of understanding of retailers' establishment of sales operations in foreign markets. During the writing process, I got frequent feedback on the paper.

\subsubsection{Paper 2- Logistics characteristics}

The second paper is a journal paper that has been submitted to a journal and is now under review. The paper was written by me and my supervisor Erik Sandberg. The paper is based on another conference paper, which took place at the NOFOMA conference in Lund in 2017. 
My contributions to this paper were mainly the methodology section, the case company descriptions and the analysis chapter.

\subsubsection{Paper 3 - Supply-chain capabilities}

The third paper is a journal paper that is under review at a journal. This paper is based on a conference paper that was written for the conference Nordic Retail and Wholesale Conference, which took place in Reykjavik, Iceland, in 2018.

This paper was written by me and my supervisors Uni Sallnäs and Erik Sandberg. My contributions to the paper were the introductory section, the methodology section, the case descriptions and analysis section. Also, I was closely involved in the writing of an extended abstract (including introduction, preliminary methodology and preliminary findings), which was sent as an application to the conference. 




\section{Answering the research questions}

This chapter presents the answers to the research questions of this licentiate thesis. It presents the findings of the cross-case analysis, starting with the first research question (RQ1), followed by the second (RQ2) and lastly the third (RQ3).

\subsection{The general phases of the foreign establishment process of retailers}

This section presents the analysis of the first research question (RQ1): What are the general phases of the foreign establishment process of retailers? The aim of this first question was to identify the general phases of the establishment into a new foreign market, which was done by first mapping the establishment process. In this licentiate thesis, the establishment process is defined as the process ranging from the first action taken to enter a new market, to full sales operations in that specific market. By identifying the phases of the establishment process, the supporting role of logistics in the process of establishing into a new foreign market can be explored in a more comprehensive setting and can be studied for each specific phase. This results in a more in-depth understanding of how logistics actually supports the establishment phases and the establishment process.

\subsubsection{The general phases of the foreign establishment process of retailers}

From the analysis presented in Paper 1, it was found that the establishment process encompasses three distinct establishment phases: (1) a market-analysis phase, (2) an implementation phase and (3) a follow-up phase. First, the market-analysis phase includes activities related to investigating potential foreign markets, typically including both market studies and economic evaluations. The market studies investigate demographic and cultural aspects, and the economic evaluations study the financial aspects of potential markets. The information retrieved from this phase worked as a base for the final market selection. Second, the implementation phase includes activities for establishing new foreign sales operations, including activities such as store location, build store, and recruitment and education of store staff. These activities are also typically involved in domestic store establishment (Sandberg 2014). Furthermore, market-oriented projects involving market adjustments (i.e. pricing, product range), as well as projects to adapt IT systems (e.g. business systems and warehouse management systems) were performed. For the establishment of online stores, activities such as website translation, payment solution adaptations, and the establishment of delivery solutions are performed, which have also been mentioned by previous scholars (e.g. Hwang et al. 2006). Third and last, the follow-up phase includes activities related to the daily monitoring of sales. From the store revenue of the new markets, the case companies evaluated whether the sales statistics followed a standardised sales curve, which confirmed whether or not their business concept was successful within the new foreign market. These evaluations were used to predict sales potential as well as to plan for further expansion into the market. Figure 9 illustrates the phases of the establishment process into a new foreign market. 
Establishment process of retailers into a new foreign sales market

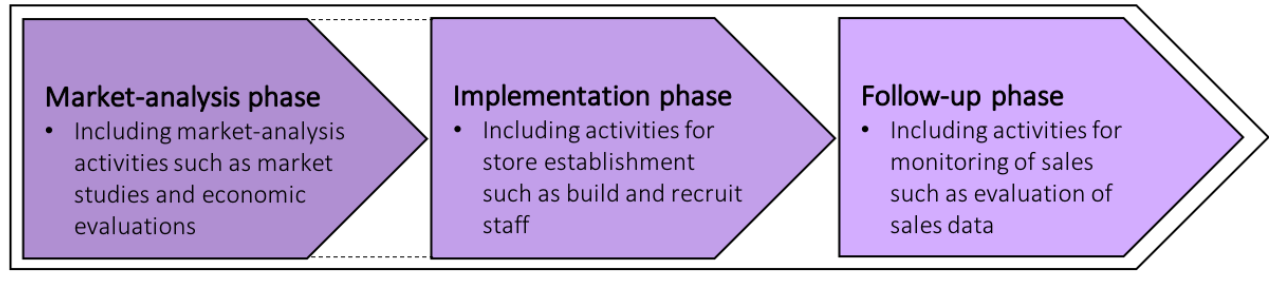

Time

Figure 9 - The phases in the establishment process of retailers into a new foreign sales market

Furthermore, from the analysis it was found that the different phases of the establishment process were inter-dependent, as the market-analysis phase initiated the implementation phase, which in turn resulted in the follow-up phase. Each phase had a specific purpose. For instance, the market-analysis phase focused solely on finding the best foreign market to enter, while the implementation phase focused on establishing physical stores and/or online stores. In some cases, the market-analysis phase and the implementation phase overlapped as activities such as finding store locations started during the market-analysis phase. The case companies tend to start searching for potential store locations early on during the market analysis phase, because this location search is typically challenging and time consuming. The informants from the case companies mentioned the difficulty of getting in contact with local property owners within the foreign markets and therefore they started earlier to ensure a smooth implementation phase. Consequently, this generates a small overlap between the first two phases. However, the follow-up phase does not overlap with the other two phases because it starts after the new foreign stores have opened, which requires that the other two phases have already been completed.

\subsubsection{Concluding remarks regarding the establishment process}

This section presents a few concluding remarks regarding the key decisions and management of the establishment process, which are worth mentioning due to the specific logistics focus of this licentiate thesis.

\section{Establishment decisions related to logistics}

From the analysis of establishment decisions, it was found that, of the three marketoriented decisions (i.e. foreign market selection, retail market entry mode, retail format transfer) listed by Elsner (2012), only the foreign market selection was included in the market-analysis phase of the establishment process and was conducted by the top management team. In the market selection, market-oriented aspects such as demographic and culture aspects were studied extensively. In terms of logistics, lead time for potential markets was also considered to be an important aspect of market selection, as the case companies wanted to establish themselves within nearby markets that allowed them to use their existing logistics resources (e.g. the warehouse). This logistics aspect limited the number of potential markets, but logistics did not, however, have a large impact on market selection, as the "psychically close" markets (e.g. Norway, Finland and northern Germany) were typically localised geographically close to the domestic market. So, the demographic 
and cultural aspects had a direct impact on foreign market selection, while logistics had an indirect impact on it.

When it comes to the selection of entry mode and retail format, these two decisions were made by the top management team before the actual establishment process began, and were a part of the overall company strategy. Despite these decisions not being directly included in the establishment process, they had an indirect impact on the establishment process because they set the frame for how these retailers entered foreign markets. A change in either of these two decisions is believed to strongly influence the resources involved, including logistics resources. In terms of entry mode, the case companies had decided to establish their own physical stores and online stores, which enabled them to have a high level of control over their foreign sales operations. This in turn required, for instance, hiring their own store staff as well as creating their own store routines. From a logistics point of view, having their own sales operations also required supporting warehouse systems and frequent store deliveries. This in turn set the logistics requirements for the logistics organisation in terms of lead time, warehouse capacity and delivery capacity in order to ensure high product availability. When establishing fully-owned stores, a retail company has more control over designing its own logistics than when utilising other entry modes. For instance, to establish oneself by franchise reduces the control and the overview of logistics (e.g. receiving logistics-oriented feedback from stores) as the franchisor and the franchisees are more disconnected.

The case companies kept a fairly standardised retail format, apart from a few minor adjustments in order to meet local regulations and local customer demand. According to informants in the top management team, the use of a standardised retail format simplifies the process of foreign establishment in terms of predictability and flexibility, as well as creating economies of scale and scope (e.g. Gamble 2010). Retail format includes both the business concept (e.g. business offer and product range) and the internal retail systems and processes (i.e. marketing operations and supply-chain operations) of a retail company (Goldman 2001). The case companies have used a fairly standardised business concept that has allowed some adjustments to the local market. This mixing of standardised and customised elements of the business concept has similarities with what Jonsson and Foss (2011) call a flexible replication. According to Jonsson and Foss (2011), the foreign replication of a business format includes standardised high-level features in terms of fundamental values and vision, as well as adapted low-level features in terms of product offerings and marketing efforts (Jonsson and Foss 2011). All case companies use standardised high-level features for all markets because the vision and overall business concept is standardised, while a few low-level features (e.g. parts of the product range and delivery time of seasonal products) are adapted to the specific market in order to better meet the local customer demand. Allowing some local adjustments to the business concept helps the retail company to better penetrate a new market (Johansson and Thelander 2009; Wigley and Chiang 2009) and for the case companies this has been necessary both for regulatory reasons and in order to better penetrate a foreign market. From a logistics point of view, the adaptations of product range and delivery time of seasonal products sets new conditions for the logistics organisation to be flexible in order to customise its local product range and store deliveries to the new foreign market. This required the logistics organisation to be able to separate market-specific products and delivery times between different markets. This also indirectly 
affects how internal retail systems and processes, such as supply chain operations (e.g. logistics operations), are performed. According to Coe and Hess (2005), retail systems and processes can either be standardised or adapted for foreign sales markets. The case companies use highly standardised logistics operations (e.g. warehouse operations), apart from a few market-specific operations, such as customs management. Also, distribution operations are fairly standardised, enabling the case companies to extend their foreign distribution network (e.g. Bygballe et al. 2012; Creazza et al. 2010) by using external logistics providers with experience of the new market. In terms of retail systems, the warehouse management system and the store replenishment system of the case companies have been transferred in a standardised manner during the establishment process. For the establishment process, the addresses of the new store locations as along with their distribution schedules are added into the warehouse system. Furthermore, the logistics organisation of the case companies has warehouse routines for preparing the first store replenishment in which products for the new store are set aside in the warehouse, starting about a month before the actual store opening.

From the previous section, it can be seen that logistics plays a reactive supporting role in the establishment process. Logistics serves as an operational performer that reactively adapts to new conditions by using mostly standardised logistics operations in order to supply a new foreign market. Furthermore, logistics was solely involved at the operational level of the individual foreign establishment, while it had a very small indirect impact on strategic decisions (i.e. foreign market selection, retail market entry mode and retail format transfer) related to the establishment process.

\section{Centralised management}

From the analysis of Paper 1, it was found that the establishment process has been managed by a small group from the top management team throughout all three phases. The case companies had assigned an establishment team, including the CEO and a few other top executives, in order to manage the establishment process. This small group of strategic, white-collar staff has a close resemblance to the domestic store establishment described by Sandberg (2014), which also includes an establishment team that is dedicated to the store establishment process. As stressed by Sandberg (2014), store establishment is a complex process involving several functions that need to be coordinated by the establishment team. In comparison, the establishment of foreign sales operations is even more complex as it involves additional complexities (e.g. foreign culture and foreign regulations) and therefore can require even more top management involvement to be managed. To better manage the establishment process, the case companies had assigned a project manager just under the $\mathrm{CEO}$, who was responsible for the overall coordination of projects during the establishment process. This project manager had a unique overall company knowledge and had close communication with the CEO throughout the establishment process. This enabled the project manager to more quickly communicate issues related to the establishment process, which helped to smooth things along. From a logistics point of view, a centralised management can enable logistics issues to be better considered during the establishment process, which in turn can enable a better strategic fit between logistics operations and other involved company operations. However, this requires an establishment team and a project manager who understands the advantages of efficient logistics and prioritises logistics during the establishment process. From the case 
companies, there are examples showing that top management teams with logistics competence prioritise logistics more during the process of establishment into a new market, while others with less or no logistics competence focus more on their core business during the establishment process. For instance, Company A prioritised logistics before the first establishment process and indirectly involved logistics organisation during the establishment process in the implementation phase and follow-up phase, while Company B solely focused on the marketing projects and outsourced its logistics during the establishment process due to a lack of logistics competence within the top management team. This further suggests that, for instance, a project manager or a CEO with logistics competence is better at involving logistics in the establishment process in order to enable logistics issues to be highlighted and communicated within the retail company. By prioritising logistics in the establishment process, the logistics organisation can be more integrated with other company functions throughout the process as well as giving the logistics organisation more time to prepare and establish a more efficient logistics solution. All this results in more proactive logistics that better support the foreign establishment into a new market. However, in contrast, a centralised management that does not value logistics is likely to exclude logistics from important decisions related to the establishment into a new foreign market. Then, logistics is only a reactive support in which the logistics organisation adapts to pre-set conditions set out by the top management team. This in turn can cause logistical problems later on. For instance, top management can decide to offer a large range of market-specific products within a new market, which consequently puts a lot of stress on the warehouse as these products must be kept separate in individual storage spaces. From a marketing perspective, offering a wide range of market-specific products is great for attracting local customers, but may not be logistically possible due to limited capacity of the logistics organisation.

\subsection{The key logistics characteristics that support retail internationalisation}

This section presents the analysis of the second research question (RQ2): What are the key logistics characteristics that support the early stage of retail internationalisation? This research question covers a wider scope than the first question as it aims to identify logistics characteristics that support overall retail internationalisation including several foreign establishments. From the cross-case analysis of Paper 2 and the additional analysis, four logistics characteristics (Centralised logistics control, Centralised logistics structure, Standardised logistics operations and Continuous learning and improvements) have been found, which together shape the logistics of the retail company in a way that supports the early stage of retail internationalisation. The logistics characteristics that support the early stage of retail internationalisation are illustrated in Figure 10 and are further described in the following sections. 
Retail internationalisation

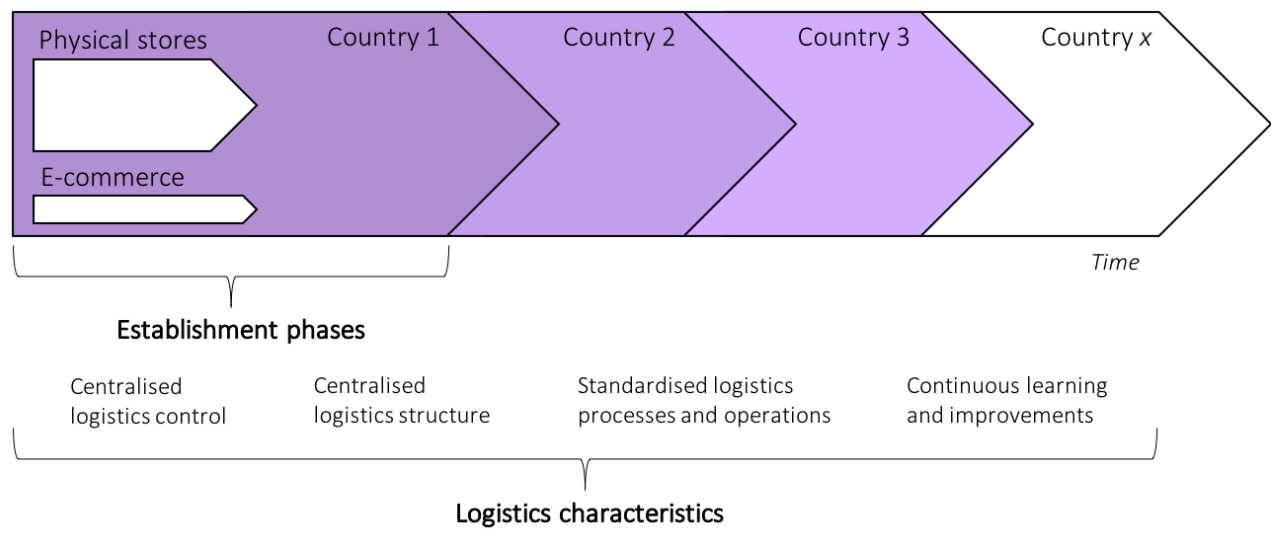

Figure 10 - The key logistics characteristics that support the early stage of retail internationalisation

\subsubsection{Centralised logistics control}

The first common logistics characteristic is a centralised logistics control. From the cross-case analysis, it was found that the logistics organisation is managed by a few strategic logistics staff, including a logistics manager, who are concentrated at the headquarters in close proximity to top management. The close proximity between the logistics organisation and the top management team allows short communication lines, which enables smooth communication (Abrahamsson et al. 2003). For instance, top management and other executives can more quickly communicate new logistics conditions to the logistics manager, which in turn increases the responsiveness of the logistics organisation. At the same time, the logistics manager can easily communicate information in terms of performance and limitations to the rest of the company. For retail internationalisation, fast communication is crucial in order for the logistics organisation to better cope with unforeseen challenges (e.g. lack of warehouse capacity or delivery problems) as well as supporting the retail company to take advantage of upcoming opportunities (e.g. supply a new market or improve customer service). For instance, if the warehouse capacity becomes too small due to increased product volumes, the logistics manager can quickly communicate this problem to the top management team, which can ensure that the problem is brought to the table and discussed by different company functions in order to solve the problem. This communication also works the other way around, as other functions can more easily communicate with the logistics organisation because the strategic logistics staff are located at the headquarters. For instance, when the sales function detected a missed sales opportunity, this information could quickly be communicated to the logistics organisation, which adjusted the deliveries of seasonal products to better match the local demand. This centralised logistics control helps to ensure that logistics is aligned with the overall company strategy (Abrahamsson et al. 2003; Swoboda et al. 2008). In addition, the centralised logistics control in retail internationalisation is further motivated by the fact that the supplychain manager is often represented on the top management team, who can also raise logistics aspects at a centralised level of the company. This is further motivated by Chow 
et al. (1995), who mentioned proximity between top management and strategic logistics staff as a dimension of centralisation. According to Swoboda and Anderer (2008), the close proximity between logistics managers and top management offers the logistics manager a place on the project teams that manage the process of foreign establishments (i.e. the establishment process). However, for the case companies, the involvement of the logistics managers in the establishment process has been very limited.

Beyond efficient communication with top management, centralised logistics control also provides an overview and distinct leadership of the logistics organisation. This in turn enables efficient decision-making and coordination of logistics operations within the logistics organisation. By having central control, the design process of the overall organisation and operations can be simplified, as there are fewer staff involved in the decision-making. Furthermore, distinct leadership is important in order to more quickly change the organisation when needed. This flexibility that central control provides (Abrahamsson et al. 2003) is highly prioritised by the case companies because retail internationalisation results in various changes (e.g. new market-specific products and extended foreign distribution networks) for the logistics organisation as new foreign markets (and foreign stores) are added.

Furthermore, centralised logistics control is further enhanced due to most of the logistics operations being performed in-house and by the company's own logistics staff, except for the actual foreign distribution. According to the informants, in-house planning and execution of logistics operations are important prerequisites in order to achieve control, which is in line with the literature (e.g. Rudberg and West 2008; Swoboda et al. 2008). In addition, Rudberg and West (2008) argued that centralised logistics control enables better forecasting and inventory planning. The logistics organisation of the case companies uses a standardised forecasting plan for the establishment into a new foreign market, which provides them with a clear preparation plan. However, the forecasting for a new market is challenging during the first year as it is unknown what the sales pattern will be. In terms of inventory planning, in-house planning enables better control of inventory levels as well as increasing flexibility within the warehouse. For instance, a specific order can be prioritised for a specific foreign market. This type of prioritising is more easily achieved for the case companies that control their own logistics planning.

In addition, centralised control of the logistics organisation was also a key priority among the case companies as it offers control of logistics-related costs (Abrahamsson et al. 2003). Cost control is particularly important in retail internationalisation as logistics costs typically increase, due to increased handling costs (e.g. warehousing and transportation costs). This is also confirmed by the case companies, which have seen a cost increase due to the foreign establishments. From the analysis, it seems that logistics costs increase less for the case companies with a high degree of in-house logistics. For instance, the case companies with in-house logistics measured the cost of logistics operations within the logistics organisation, which helped the companies to better keep track of the logistics costs throughout the process of retail internationalisation. It also helped the logistics manager to prioritise areas for improvement within the logistics organisation. For instance, the overall logistics cost of customs management could be reduced by performing parts of the customs management in-house. In contrast to inhouse logistics, the logistics costs for outsourced logistics can be 
harder to control or change. Outsourced logistics can be very cost-efficient due to large economies of scale and scope. However, when establishing into new foreign markets solely by using logistics providers, the logistics costs can rapidly increase as new conditions are added. For instance, Company B, with most of their logistics operations outsourced, experienced a massive increase in logistics costs when establishing into new foreign markets. When Company B later moved most logistics operations in-house, the logistics costs were reduced by $50 \%$ in the first year. This example shows that it is important to keep track of logistics costs, especially when using logistics providers to manage all logistics.

Furthermore, control of logistics costs becomes very important when the logistics operations are scaled up due to increased volumes. When up-scaling logistics operations, logistics inefficiencies become costlier and therefore should preferably be detected early on in the retail internationalisation. For instance, Company A detected before the actual retail internationalisation that the cost of operating with several warehouse facilities (i.e. decentralisation of warehouse facilities) increased the logistics costs drastically as both the handling and transportation costs increased. To prevent this inefficiency in the up-scaling, the warehouse facilities were centralised into one single central warehouse, which reduced the handling and transportation costs.

\subsubsection{Centralised logistics structure}

Second, a centralised, physical logistics structure has been identified. Centralisation of physical facilities is highlighted as a key priority by both the case companies and research scholars (e.g. Abrahamsson et al. 2003), because it enables better control and overview of the physical flows in the supply chain. Furthermore, it provides the case companies with a holistic overview of the different product flows to and from the central warehouse. In addition, a centralised structure simplifies the standardisation of warehouse operations (e.g. picking and packaging operations) as well as being able to erase side functions that otherwise need to be performed multiple times for the different warehouses.

According to the informants in the case companies, a central warehouse has been essential in order to expand smoothly and supply multiple markets. For instance, Company A centralised its warehouse facilities into one central warehouse before entering its first foreign market because this was considered to be a necessary prerequisite in order to create time- and cost-efficient logistics operations. In a similar vein, Company C emphasised costefficient operations by physical centralisation and argued that it enables resource pooling, which allows the company to better coordinate its logistics resources. For instance, the allocation of staff between different warehouse activities becomes much easier if they are all under the same roof. Furthermore, simplified staff allocation is a key ingredient in order for logistics organisations to be more flexible and to better respond to unforeseen events. For instance, if the actual demand in the store flow to a market was much higher than planned, staff from another warehouse flow (e.g. online flow) can be allocated to the store flow to meet the demand and vice versa. In contrast to the other companies, Company B used a logistics provider during its foreign establishments, which resulted in a less centralised logistics structure. However, the case company established its own central warehouse later on. This suggest that a central logistics structure is a key characteristic in the early stage of retail internationalisation. 
In a similar vein, responsiveness is enhanced by the strategic location of the central warehouse. All three case companies have located their central warehouse in southern Sweden in close proximity to neighbouring markets. This location enables sufficiently short lead times from the central warehouse out to the foreign sales markets. For the case companies, this lead time is about 1-3 days, depending on the location of the end customer (for stores as well as for online customers in nearby markets). For the more distant store locations, the case companies usually deliver less frequently but in larger volumes, as this keeps down the transportation costs.

In addition, if the case companies continue to expand into more distant markets and continents in line with global retail chains (e.g. IKEA and Zara), additional warehouse facilities can become necessary in order to retain short lead times. The logistics manager of the case companies speculated about the possible future of implementing a more decentralised logistics structure and its advantages. For instance, additional warehouse facilities could become necessary for supplying fast-moving products that need more frequent deliveries. Furthermore, local warehouse facilities can be used for supplying foreign markets with local products, instead of transporting local products to the central warehouse and back to the local market. Moreover, a more decentralised logistics structure can become necessary for distributing online orders to customers located in more distant EU countries. As online shopping is often associated with fast deliveries and short lead times, short lead times are an important factor in maintaining a competitive advantage for the case companies. Today, Company $\mathrm{B}$ and Company $\mathrm{C}$ have online stores for all the countries within the EU and the lead times for more distant markets, such as France, Austria and Spain, are usually longer than 3 days. At the moment, online sales account for only a small part of the case companies' total sales (about $5 \%$ and $15 \%$ for Company B and Company $\mathrm{C}$ respectively); hence, to date there is not a high incentive to reduce the lead times at the case companies.

\subsubsection{Standardised logistics operations}

The third logistics characteristic is the use of standardised logistics operations. According to the case companies, the use of standardised operations helps the logistics organisation to reduce the complexity related to managing multiple markets, and it also allows the logistics organisation to more easily scale up its operations. Standardised operations are used to a very great extent by the case companies. Furthermore, the case companies strive towards standardised logistics operations that are both independent of both the chosen sales channels (e.g. stores and online stores) and sales market. There are only a few logistics operations that are market-specific, such as customs management for deliveries to Norway.

For warehouse operations, the case companies use standardised operations for receiving, put-away, storing, picking and packing, which are identical to the warehouse operations presented in previous literature (e.g. Hellström and Sagir 2016; Kembro et al. 2018; Zuniga and Martinez 2016). In addition, customs management is performed as a warehouse operation for foreign distribution. Table 3 lists the standardised warehouse operations that are important in retail internationalisation. 
Table 3 - The standardised warehouse operations important in retail internationalisation (Note: The operations are presented in sequential order, starting with receiving)

Warehouse operation Importance in retail internationalisation

\begin{tabular}{l|l}
\hline Receiving & $\begin{array}{l}\text { The receiving operation (including the labelling of products) is an important } \\
\text { standardised operation in the context of retail internationalisation. Market- } \\
\text { specific products must be carefully labelled in order to separate products for } \\
\text { specific markets. Local regulations state that product categories such as } \\
\text { home electronics and food must be labelled in the local language in order to } \\
\text { be sold, and therefore the right product label is crucial. }\end{array}$ \\
$\begin{array}{l}\text { Put-away } \\
\text { Storing }\end{array}$ & $\begin{array}{l}\text { The storing operation is important for separating market-specific products } \\
\text { within the warehouse. Market-specific products are placed in individual } \\
\text { storage locations. This standardised operation is important in order to meet } \\
\text { both supplier conditions and local regulations within the foreign markets. }\end{array}$ \\
$\begin{array}{l}\text { Picking } \\
\text { Packing }\end{array}$ & $\begin{array}{l}\text { Customs managemens management is a mandatory operation for distributing products to } \\
\text { markets outside the EU (e.g. Norway). The logistics organisation of the case } \\
\text { companies performs customs management in-house by preparing a customs } \\
\text { declaration, which is sent with the logistics provider. }\end{array}$
\end{tabular}

Most of the standardised warehouse operations presented are not only important in the context of retail internationalisation, but also for retailers operating at a national level (Abrahamsson et al. 2003) as well as in other sectors (e.g. manufacturing). Most warehouse operations were already standardised before the retail internationalisation started. However, the handling of market-specific products in the receiving and storing operations, as well as customs management, became especially important due to retail internationalisation.

From a retail-internationalisation perspective, standardised warehouse operations simplify the establishment into new foreign sales markets (i.e. the establishment process) because the logistics organisation only has to scale up its existing operations, which in turn smooths the overall process of retail internationalisation. Without standardised operations, retail internationalisation would need more resources and both the logistics organisation and operations would become more complex and harder to manage. The risk of performing operations wrongly in the warehouse is likely to increase as warehouse staff has to keep track of several different operations. To achieve standardised logistics operations, the case companies emphasised the importance of implementing information systems for reporting and planning, which is also important in the context of retail internationalisation. This is also in line with the findings of Abrahamsson et al. (2003). The case companies have implemented both a business system and a warehouse management system for planning and managing the supply chain, including foreign sales markets. The informants emphasised the importance of designing the warehouse management system in such a way that it fits the company's specific needs. This design freedom of the warehouse management system allows the case companies to design their organisation and operations to suit themselves. For instance, the case companies adapted their warehouse management system so that it could handle market-specific products, which was key for supporting their retail internationalisation. 
In addition, the standardisation of logistics operations is simplified by using standardised product labels for all foreign markets. This simplifies warehouse operations because standardised labels allow the logistics organisation to distribute products freely to any market as well as enabling it to have only one storage location for each product. The case companies mentioned the great challenge of having market-specific products as this requires several storage locations as well as potentially causing inaccuracies in the inventory levels in the warehouse management system. For each new foreign market, there is a transition time while the product labels are standardised for the product range. Informants at Company A mentioned that this transition was a bit frustrating because the logistics organisation had just finished standardising its products for the existing markets when the top management decided to enter a new market and they soon found themselves with the same logistical problem again. To avoid such problems, Company B has labelled all its products in multiple languages from the start. However, the problem could also have been avoided by better communication between top management and strategic logistics staff about future establishments. This would have enabled the logistics organisation to add multiple languages all at the same time. However, this may also be problematic as future establishment plans can shift in just a few years and then some languages may never become useful. The standardisation of product labels may also be easier for some product categories than others. For instance, clothes typically carry a small label that can include several languages without taking too much space or attention from the product itself, while other packaging can only include a few languages before the product loses its local feel and packaging becomes too full. The case companies struggle to maintain a balance between establishing a local presence with market-specific product labels, while at the same time standardising product labels with multiple languages to simplify the logistics operations.

In terms of foreign distribution, the case companies have outsourced physical distribution to external logistics providers, while performing the transport planning in-house. This corresponds well with previous literature (e.g. Straube et al. 2008; Swoboda et al. 2008). This physical distribution is crucial, and the case companies carefully monitor the delivery performance in order to keep track of the foreign distribution. Furthermore, the case companies used different standardised approaches when selecting logistics providers to supply foreign markets. For instance, Company B has a principle of only using local logistics providers for its foreign markets, Company A uses about 10-15 Swedish logistics providers, and Company $\mathrm{C}$ uses a few specific logistics providers that are used to distributing to the specific foreign markets. Informants from the case companies argued that it is important to use logistics providers with local knowledge of the foreign infrastructure in order to ensure efficient distribution. This approach is closely related to the establishment of "territorial embeddedness", in which retailers become rooted in local logistics networks within the foreign markets (e.g. Wood and Reynolds 2014; Wrigley et al. 2005). This can be done efficiently by actively using local logistics providers for supplying foreign markets. To conclude, different approaches to selecting logistics providers can be used to supply foreign markets, but it is good to use logistics providers with experience of the local infrastructure of specific foreign markets.

Furthermore, the case companies use a high degree of standardisation as this enables costefficient logistics operations due to economies of scale and scope (Abrahamsson and 
Rehme 2010; Wood and Reynolds, 2014). Standardisation also enables the case companies to measure time and cost as a means of improving the cost efficiency of logistics operations. For instance, the case companies use key measurements such as cost per store order and cost per online order in order to identify time and cost savings in different product flows. As retail internationalisation results in higher logistics costs, it becomes important to have costefficient logistics operations, which ensures that the logistics costs do not multiply faster than the incoming revenues.

Paradoxically, standardised operations also simplify the adjustment to foreign markets. According to scholars (e.g. Sandberg and Abrahamsson 2010; Swoboda and Anderer 2008), standardisation enables a smoother adjustment to new conditions. For the case companies, standardisation has enabled them to make market-specific adjustments in order to better meet the customer demand within local markets as well as meeting local regulations. For example, Company A and Company C distribute a small part of their product flow via local suppliers instead of the central warehouse. Standardisation usually means that flexibility is to some degree lost; however, this example shows that a high degree of standardisation enables some local adjustments. Without standardisation, these adjustments would become more difficult to manage as the logistics organisation would be more unstructured from the start.

\subsubsection{Continuous logistics learning and improvement}

The fourth and final logistics characteristic is a common continuous learning and improvement behaviour within the logistics organisation of the three case companies. In the organisation of logistics, the ability to continuously learn and improve is crucial in order to develop efficient logistics (i.e. the right products at the right time and of the right quality to the right service). All three case companies emphasised rapid learning in order to improve their operations related to retail internationalisation. Learning typically originated in previous experiences and the collection of feedback by the case companies. The logistics organisation frequently collected feedback from within its own operations and from the stores, which was then used to improve warehouse operations and foreign distribution. For instance, feedback regarding delivery accuracy and lead times can be used to fine-tune logistics operations. For this type of learning approach, a trial-and-error ability is needed in order to establish efficient logistics solutions. Finding a perfect logistics solution is not the focus during the establishment into a new foreign market; instead, a decent solution is seen as a good start, while improvements are made over time as the logistics organisation becomes more familiar with the new market. Furthermore, continuous learning and improvements to logistics operations are also made between individual market establishments. For instance, the establishment process can be documented and codified in order to better plan for the next one. From a logistics perspective, documentation and codification can also provide a starting point for creating more efficient logistics support related to new foreign establishments.

\subsection{The key supply-chain capabilities that support retail internationalisation}

Beyond logistics characteristics, this thesis has also been based on a resource-based perspective in order to identify the major supply-chain capabilities that together shape the 
characteristics presented in RQ2. Whereas characteristics present a state, this third research question (RQ3) captures the capabilities involved in retail internationalisation. Capabilities shape resources into characteristics that create a competitive advantage over time. This licentiate thesis explores supply-chain capabilities that shape supply-chain resources into logistics characteristics that support during the early stage of retail internationalisation.

This section presents the analysis of the third research question, which was formulated as: What are the key supply-chain capabilities that support the early stage of retail internationalisation? The aim of this question was to describe the key supply-chain capabilities that support retail internationalisation that includes several foreign establishments. From the analysis in Paper 3, three supply-chain capability categories (leadership, integration and learning) were identified as common to all three case companies. Each supply-chain capability category includes a number of capabilities that together form the key supply-chain capabilities that support retail internationalisation. Figure 11 illustrates the supply-chain capabilities that support the early stage of retail internationalisation, and these are further described in the following sections.

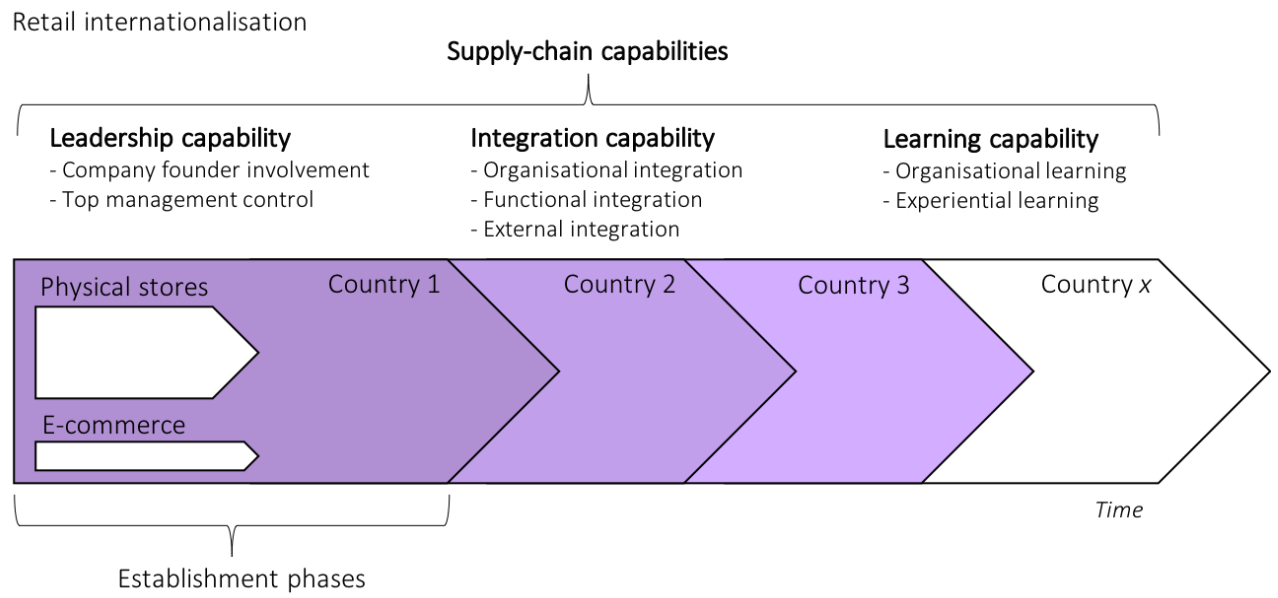

Figure 11 - The key supply-chain capabilities that support the early stage of retail internationalisation

\subsubsection{Leadership capability}

First, a common leadership-capability category was identified. For the case companies, leadership capabilities play an important role in centrally coordinating company resources, such as supply-chain resources, in retail internationalisation. More specifically, the involvement of company founders in supervising the retail Internationalisation (i.e. company founder involvement) as well as a tight top management team (i.e. top management control), have been highlighted as two important capabilities supporting retail internationalisation. 


\section{Company founder involvement}

The involvement of company founders in the case companies was apparent and played a key role in the retail internationalisation. The company founders have been a major driving force in the retail internationalisation by actively participating in the case companies' top management team. Due to their entrepreneurial vein, the founders have been involved in both strategic (e.g. initiating the retail internationalisation) and operational (e.g. foreign market studies) aspects. They have also been highly aware of the different company functions that need to be involved and prioritised to ensure successful retail internationalisation. For instance, efficient logistics have been strongly emphasised by the company founders in order to expand in a cost-efficient way. As the case companies sell low-margin products, the establishment of cost-efficient logistics operations is important, and the company founders are well aware of this from previous domestic operations. The company founders have ensured that important logistics aspects have been prioritised by top management and they have also been closely involved in different supply-chainoriented decisions (e.g. physical centralisation and the standardisation of logistics operations). Furthermore, most of the company founders have had a clear vision of how the logistics organisation should be designed to support further expansion, which relates to Frasquet et al.'s findings (2013), which highlighted entrepreneurial vision as one of the key aspects of retail internationalisation. Company founders with a vision of how the different company functions should be designed and aligned to support retail internationalisation are seen as a great advantage. Through having an overall understanding of all company functions, they can ensure that no function (such as logistics organisation) vital to retail internationalisation is missed. Due to the personal commitment of the company founders, they are able to communicate necessary priorities regarding retail internationalisation. They also contribute with their own wide expertise and guidance to the establishment and the project managers who are managing the foreign establishments.

\section{Top management control}

In addition to company founder involvement, the case companies share a top management control capability. The top management team of each case company includes a few individuals (e.g. the CEO and other top executives of the retail company) who make all the strategic decisions (e.g. strategic logistics decisions) related to retail internationalisation. A tight top management team enables fast decision-making, which in turn enables better responses to the opportunities and challenges that arise throughout the process of retail internationalisation. This leadership capability enables the structured delegation and supervision of responsibilities, in which the top management team members manage the different functions involved in retail internationalisation. For instance, the supply-chain manager in the top management team is responsible for delegating responsibilities as well as supervising the logistics organisation. From a supply-chain perspective, leadership capability is also an important prerequisite in order to determine what the actual supply chain should look like. For instance, the top management team is highly involved in strategic supply-chain decisions, ranging from sourcing to sales operations. Furthermore, the leadership "spirit" of the top management team is also transferred further down within the company functions. For instance, the logistics organisation is managed by a logistics manager, who manages the logistics organisation and delegates and supervises the logistics operations in order to ensure that strategic decisions are transferred to the operational level 
within the logistics organisation. This in turn enables faster adaptation of logistics to foreign markets during retail internationalisation.

\subsubsection{Integration capability}

Second, the category of integration capability was identified. Efficient integration between top management and internal company functions as well as external actors is of great importance in aligning resources to support retail internationalisation. From a supply-chain perspective, integration capabilities ensure that logistics is integrated in the retail company in such a way that it allows logistics and top management to efficiently communicate conditions and constraints, as well as for logistics to collaborate better with other internal company functions and external support, which in turn can support retail internationalisation. Figure 12 illustrates the three supply-chain capabilities.

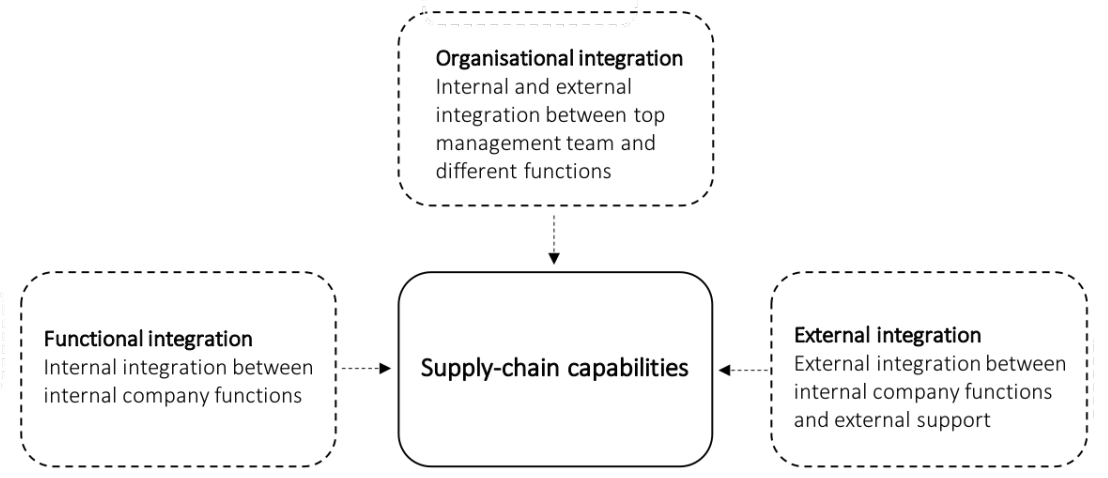

Figure 12 - The integration capabilities that support the early stage of retail internationalisation

\section{Organisational integration}

The first integration capability is organisational integration, which refers to the integration between top management and internal company functions as well as external support. The central control of the top management team allows efficient delegation and supervision of the different functions involved in foreign establishments. For instance, there are frequent top management meetings with top executives (e.g. the supply-chain manager) in charge of different company functions, in which retail-internationalisation-related issues are discussed. Furthermore, the top executives later communicate conditions and other information back to the company functions as well as reporting back on progress and challenges related to retail internationalisation. Furthermore, the top management team also collaborates with external support (i.e. export promotion organisations and both formal and informal retail networks) in retail internationalisation. Organisational integration is also seen in the establishment process, in which a project manager responsible for the establishment process centrally coordinates different company functions as well as identifying collaborations among the different functions involved.

\section{Functional integration}

In addition to organisational integration, a functional integration capability was also found among the case companies. This capability enables efficient integration between internal 
company functions involved in retail internationalisation. The company functions of the case companies frequently communicate and collaborate in order to ensure that their resources are aligned to support retail internationalisation. A good example of this integration is the frequent collaboration between the logistics organisation and the marketing function within the case companies, which share information in order to improve the product flow and product range in the foreign markets. For instance, the marketing function of Company B identified a sales opportunity in Norway if the logistics organisation could deliver white summer dresses a couple of weeks earlier than for the other markets. By communicating this finding to the logistics organisation, the logistics organisation adjusted its delivery in order to deliver the white dresses earlier to the Norwegian market. Furthermore, there is also communication between the logistics function and the purchasing function in order to adjust the incoming product flow to the warehouse.

Furthermore, the top management team encourages functional integration by frequently communicating with the various company functions and by identifying potential collaborations among these functions in order to solve problems related to retail internationalisation. Furthermore, efficient integration between company functions can result in new ways of using company resources, which in turn can result in new competitive advantages. It is important to frequently review how resources are used in order to develop efficient operations and this helps the case companies to improve their overall company knowledge as knowledge and experience are shared among the company functions. This knowledge sharing among company functions, according to Zollo and Winter (2002), can be described as knowledge articulation, which can facilitate learning within the retail company. From a supply-chain perspective, the integration between the logistics organisation and marketing function has resulted in a better understanding of each other's constraints. For example, the marketing function and logistics organisation can come to an agreement to adjust the store deliveries for specific markets to better meet customer demand.

\section{External integration}

An external integration capability, which refers to the integration with external support in retail internationalisation, is also shared among the case companies. External support is hired in order to improve the case companies' knowledge about internationalisation and specific markets, as well as enabling them to perform specific activities (e.g. market studies) related to retail internationalisation. From a supply-chain perspective, the case companies have hired external logistics providers to supply foreign markets. In agreement with Dyer and Singh (1998), competitive advantage does not necessarily have to be based on the case companies' own resources. Instead, relationships and collaboration with external organisations can result in new ways of using company resources. During retail internationalisation, the case companies have integrated external resources (e.g. knowledge and experience) from external support such as export promotion organisations and retail networks, which has increased their own knowledge about foreign markets and how to establish into a new market. Instead of reinventing the wheel, the case companies take advantage of existing external resources, without having to possess these resources themselves. At the same time, this also allows the case companies to focus on their core business to a greater extent. 


\subsubsection{Learning capability}

Third, a learning capability category was identified. The case companies all emphasised the importance of learning in order to improve the logistics involved in retail internationalisation. Specifically, learning within the logistics organisation and learning from previous experience were highlighted as two important learning capabilities.

\section{Organisational learning}

The case companies have an organisational learning capability in common. This capacity is based on a strong learning culture among the case companies, which encourages organisational learning in retail internationalisation. Experience and new knowledge from previous foreign establishments are gathered and processed by the top management team as well as by individual company functions (e.g. the logistics organisation), and this contributes to organisational learning. For instance, the logistics organisation collects and processes feedback from the staff of foreign stores as well from its own logistics staff.

Organisational learning capability enables the case companies to renew their resource base, which, according to Zollo and Winter (2002), is an important prerequisite for long-term competitive advantage. The learning culture allows the case companies to learn from previous foreign establishments and to adjust their resources to improve future establishments. For instance, supply-chain resources such as warehouse facilities and logistics operations have been improved based on learning from previous foreign establishments.

\section{Experiential learning}

In addition to organisational learning, the case companies share an experiential learning capability. Aside from learnings from external resources, most of the learning and knowledge gains actually originate from the case companies' own experiences of retail internationalisation. In these foreign establishments, the case companies have to a large degree used a trial-and-error approach, in which the establishment approach in terms of management or operations was changed if something did not work. Experiential learning is also found within the supply chain. For instance, the logistics organisation has gained various forms of experience from previous establishments, which have enabled improvements in their logistics operations related to retail internationalisation. For example, the logistics organisation has learned that market-specific products require a large amount of storage and therefore a key priority has become to keep as many products as possible standardised for all markets. In addition, the case companies experienced long lead times for the Norwegian market due to long handling times at the customs service. Customs management was improved by moving most of it in-house, which reduced the lead time from the warehouse to the Norwegian stores.

Similar to experiential learning, Zollo and Winter (2002) describe a learning mechanism called experience accumulation. In line with the empirical data, Zollo and Winter (2002) stated that experience is usually acquired by trial-and-error. Furthermore, Johanson and Vahlne (1977) also identified experiential learning in the context of internationalisation and argued that internationalisation can be described as a learning-by-doing process, which 
corresponds well with our empirical data from the case companies. In addition to experiential learning, Zollo and Winter (2002) mention two other mechanisms of learning, knowledge articulation and knowledge codification. However, these two mechanisms are not clearly seen within the case companies. The measuring and monitoring of logistics performance, along with dialogue about the logistics operations, indicates some sort of knowledge articulation, whereas knowledge codification has not been identified among the case companies. 




\section{Final analysis}

This chapter presents the final analysis of this licentiate thesis. This analysis focuses on the overall discussion about the supporting role of logistics during the early stage of retail internationalisation, based on the findings from the previous chapter. More specifically, two aspects of the supporting role of logistics are presented, starting with the section: The reactive and proactive supporting role of logistics in retail internationalisation, which describes two supporting roles of logistics. Thereafter, the section: The importance of logistics over time in retail internationalisation is presented, which covers the time perspective relevant to the supporting role of logistics in retail internationalisation.

\subsection{The reactive and proactive supporting role of logistics in retail internationalisation}

The purpose of this licentiate thesis was to "explore the supporting role of logistics during the early stage of retail internationalisation". The findings suggest that logistics can play both a reactive and a proactive supporting role during the early stage of retail internationalisation, and these are illustrated in Figure 13, below. First, the findings indicate that logistics serves mostly as an "operational performer" that is expected to reactively adapt to predetermined decisions made by the top management team. For instance, the project manager responsible for the establishment process at Company A states: "So, logistics at Company $A$ is more of a performer... Their questions are not raised on the strategic agenda... They do not dictate, they are more a victim of the conditions." Similar statements are found at the other companies as well, which indicates that the logistics organisations reactively adapt their operations in order to support the early stage of retail internationalisation.

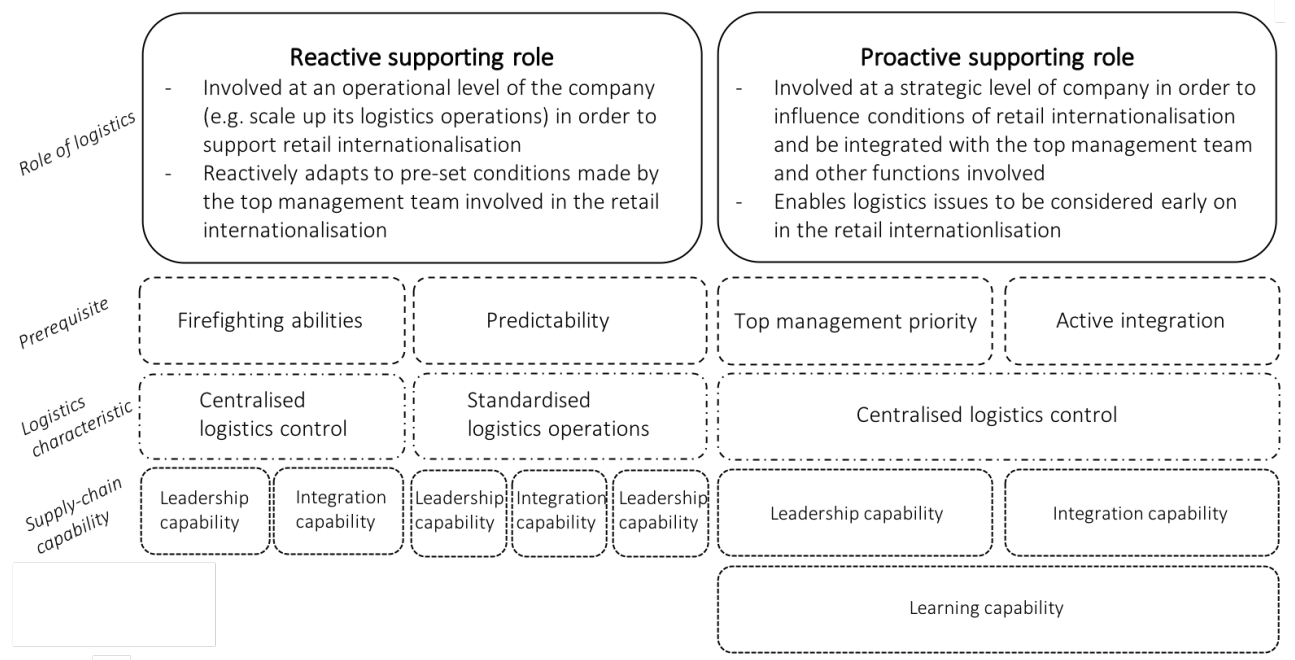

Figure 13 - The reactive and proactive supporting role of logistics during the early stage of retail internationalisation 
The reactive supporting role of logistics is mainly based on two important prerequisites, firefighting abilities and predictability, which need to be in place for the logistics organisation to reactively support retail internationalisation. First, the logistics organisation needs "firefighting abilities" that enable it to respond quickly to unforeseen challenges, to adapt to new conditions and to better prioritise different logistics issues related to retail internationalisation. These abilities are enhanced by the characteristic of centralised logistics control, which in turn is strongly related to supply-chain capabilities, leadership and integration. Leadership capability (i.e. top management control) enables efficient delegation and communication between top management and logistics managers during retail internationalisation. In addition, integration capability (i.e. organisational integration) supports collaboration and information-sharing between top management and the other functions involved in retail internationalisation. The logistics organisation needs to be predictable in the sense that it can inform the top management team about its logistics capacities (e.g. lead time and storage capacity). Predictability might also be a prerequisite for proactive logistics; however, the findings suggest that predictability is more of a significant prerequisite for reactive logistics. Predictability enables the top management team to better plan the logistics of retail internationalisation because the logistics capacities are known, which creates more realistic plans for the logistics organisation to reactively adapt to the retail internationalisation (e.g. the establishment process). Furthermore, predictability is enhanced by the characteristic of standardised logistics operations, which enable the logistics organisation to better estimate the time and costs required, for instance, to supply a new foreign market. The standardised logistics operations strongly relate to all three supply-chain capabilities (leadership, integration and learning) that have been identified as important for retail internationalisation. First, the leadership capability of the top management team and the logistics organisation enables the implementation of standardised logistics operations within the logistics organisation. Second, standardised logistics operations are typically developed in parallel with other functions (e.g. the top management team and the purchasing function), which is possible due to the integration capability. Third, standardised logistics operations are highly motivated by learning from previous experiences, which is supported by the learning capability.

The findings suggest that logistics has mostly been a reactive supporter; however, logistics can also be proactive because it can be involved in shaping the conditions of the retail internationalisation. For instance, Company A included logistics as a strategic aspect before establishing itself into its first foreign market by proactively designing a central warehouse that could manage the company's future expansion plans. In contrast, Company B did not emphasise logistics in its previous foreign establishments; instead, it became a strategic priority later on when the present foreign establishments had already been made and the complexity and logistics costs had increased.

In terms of proactive logistics support, close physical proximity between the top management team and the logistics organisation (i.e. the characteristic of centralised logistics control) is crucial in order to establish proactive logistics that supports retail internationalisation. However, proactive logistics support is not automatically established by including a supply-chain manager or a logistics manager in the top management team. Logistics must also be strongly prioritised by the top management team and be actively integrated with top management and other functions in order to proactively support retail 
internationalisation. Top management priority and active integration are two significant prerequisites for establishing proactive logistics, and these are made possible by the leadership capability and the integration capability respectively. The leadership capability enables logistics to be prioritised at a strategic level of the retail company, while the integration capability enables efficient communication and collaboration between the logistics organisation, the top management team and the other functions involved in the retail internationalisation. Furthermore, the findings suggest that retail companies typically learn the importance of proactive logistics from previous foreign establishments, as they typically started to involve the logistics manager when planning future establishments. Logistics managers were not included in the first establishments but became involved later on. This development towards proactive logistics is supported by the learning capability. In addition, to ensure that logistics supports retail internationalisation, logistics competence within top management is also found to be crucial in order to develop proactive logistics as part of the retail internationalisation. An understanding of the competitive advantages of efficient logistics can make it more natural to include and prioritise logistics in retail internationalisation. Furthermore, proactive logistics can enable the better use of logistics resources as they are integrated with other company resources in a more efficient and effective way. Also, proactive logistics helps to ensure that marketing-oriented decisions (e.g. business concept) and logistics are better aligned, which could otherwise result in logistical problems later on in the retail internationalisation. For instance, using a large number of market-specific products may not be logistically possible due to lack of storage capacity.

To conclude, logistics can play both a reactive and a proactive supporting role in order to support the early stage of retail internationalisation. Logistics is mostly a reactive supporter that supports retail internationalisation by reactively adapting to marketing-oriented conditions made by the top management team. The reactive logistics support is mainly based on fire-fighting abilities that allow the logistics organisation to better respond to unforeseen events and conditions and to prioritise logistics issues, as well as on predictability that helps the logistics organisation to better communicate the logistics capacities related to retail internationalisation. Beyond the reactive supporting role, logistics can also take a proactive supporting role in which it is involved in shaping the conditions of retail internationalisation. By proactively involving logistics, more efficient logistics can be established as the logistics organisation is involved in strategic decisions related to retail internationalisation. The proactive logistics support is based on a top management priority ensuring that logistics is prioritised in strategic decisions, as well as on an active integration that refers to the active integration of logistics with top management and other functions involved.

\subsection{The importance of logistics over time in retail internationalisation}

In the previous section, it was argued that logistics can play both a reactive and a proactive supporting role in retail internationalisation. These findings also suggest that the importance of logistics increases over time after several foreign establishments have been made. For instance, the importance of proactive logistics has been clearly emphasised after several foreign establishments. Also, logistics has been increasingly prioritised by top 
management throughout the retail internationalisation, which also suggests that the importance of logistics in the early stage of retail internationalisation increases over time.

During the first foreign establishments of a retail company, the prime focus of logistics is to quickly establish a decent logistics solution that meets the conditions of the new foreign markets. Establishing cost-efficient logistics is not the focus, and instead a reliable logistics solution that ensures on-time delivery and product availability is prioritised. Therefore, high logistics costs are justifiable at first as retail companies are focusing on marketing-oriented issues such as testing the business concept abroad and learning about the foreign markets. However, as retail companies continue to establish themselves into new foreign markets, both the complexity and the logistics costs increase, which in turn increases the importance of efficient and effective logistics in retail internationalisation. Furthermore, the findings suggest that the attention and competence of the top management team of retail companies increases over time. After the first foreign establishments, the top management team typically becomes more aware of the importance of logistics and starts to prioritise it. Also, logistics competence within retail companies becomes more important in order to create efficient and effective logistics. In particular, the logistics competence within the top management team is important in enabling logistics to be prioritised as an important strategic aspect that should be proactively involved in retail internationalisation.

Based on the findings above, it is believed that an ideal scenario in the early stage of retail internationalisation is to involve logistics as a proactive supporter from the start. By proactively involving logistics in the first establishments, it can become more effective and efficient from the beginning of retail internationalisation. This allows logistics to be involved in strategic decisions and to influence the conditions of the retail internationalisation, which in turn helps retail companies to avoid logistics mistakes in the early stage of retail internationalisation. Involving logistics in the early stage of retail internationalisation has also been emphasised by previous scholars (e.g. Straube et al. 2008) because it enables logistics to better align with the company strategy. In addition, it also ensures that the logistics complexity and costs are kept at a low level throughout the early stage of retail internationalisation. For logistics to serve as a proactive supporter, logistics competence within the top management team is important in order for it to be prioritised at the beginning of the retail internationalisation.

Furthermore, the importance of logistics over time can also be observed in the supply-chain capabilities (leadership, integration and learning), which shape logistics resources into logistics characteristics throughout the period of retail internationalisation. This shaping of logistics resources over time during retail internationalisation indicates the presence of dynamic capabilities (Defee and Fugate 2010), in which the resource base of the logistics organisation changes over time and enables a long-term competitive advantage in the retail internationalisation. In this study, logistics characteristics represent the present state of the logistics, including the logistics resources currently used by the logistics organisation, whereas supply-chain capabilities are continuously developing the logistics resources in order to ensure that logistics continues to support the retail internationalisation over time. Based on the theory of dynamic capabilities, the logistics characteristics and supply-chain capabilities are believed to change as new conditions arise over time during the retail internationalisation. Within the scope of this study, a specific set of logistics characteristics 
and supply-chain capabilities have been found that support the early stage of retail internationalisation. However, another set of characteristics and capabilities might be more suitable for supporting different stages of retail internationalisation. For instance, a later stage is believed to require logistics support based on another set of logistics characteristics and supply-chain capabilities. For instance, global retailers such as IKEA and Walmart need a multinational, decentralised logistics structure with several warehouses and hubs in order to supply distant foreign sales markets. This suggests that, for instance, the characteristic of having a centralised logistics structure is insufficient during a later stage of retail internationalisation. In terms of supply-chain capabilities, the capabilities of leadership, integration and learning are believed to also be valuable during later stages of retail internationalisation in order to centrally manage and coordinate resources as well as to learn and to improve operations involved in retail internationalisation. However, additional capabilities may be added. For instance, a cultural capability that enables retail companies to better understand and adapt to more distant cultures can become necessary in order to establish themselves into more culturally distant continents, such as Asia. From this, it is believed that logistics characteristics change more quickly than capabilities, with the latter being more stable because they can develop new characteristics and are not bound to specific states or conditions to the same extent as characteristics. 



\section{Conclusions}

This chapter presents the main conclusions of this licentiate thesis. First, the conclusions are presented, followed by the contributions made by the thesis and, finally, suggestions for further research.

\subsection{Conclusions}

The purpose of this licentiate thesis was to "explore the supporting role of logistics during the early stage of retail internationalisation". The findings suggest that logistics can play both a reactive and a proactive supporting role in the early stage of retail internationalisation. Logistics is mostly a reactive supporter as the logistics organisation reactively adapts to predetermined conditions set by the top management team. Logistics is typically involved at an operational level by scaling up its warehouse operations and expanding its distribution network in order to supply multiple, foreign sales markets. To be a reactive supporter, findings suggest that the logistics organisation needs "firefighting abilities" in order to respond quickly to unforeseen events and adapt rapidly to new conditions as well as prioritising different logistics issues related to retail internationalisation. Furthermore, the logistics organisation needs to be predictable in the sense that the top management team needs to know its capacity in order to better plan the operations involved in retail internationalisation.

Beyond its reactive supporting role, logistics can also play a proactive supporting role in the early stage of retail internationalisation. Proactive logistics enables the logistics organisation to influence the conditions of the retail internationalisation, which can result in efficient logistics that can cope with increased complexity (i.e. the increased number of markets) as well as keeping track of the logistics costs incurred by the retail internationalisation. Also, by becoming more proactively involved, the logistics operations can be better aligned with the marketing-oriented operations of retail internationalisation. For logistics to be proactive, strategic logistics staff (e.g. the logistics manager) need to be included at a strategic level of the company in close proximity to the top management team. This enables the logistics manager to participate in important strategic decisions related to retail internationalisation. Furthermore, the logistics organisation needs to be actively integrated with both the top management team and other involved functions in order to better align its operations with the rest of the company and to better support retail internationalisation. In addition, logistics competence within the top management team was found to be crucial in order to establish proactive logistics as top management enables logistics to be prioritised within the retail internationalisation.

It was also found that the importance of logistics increases over time in retail internationalisation. The more markets retailers enter, the more important efficient logistics becomes in order to deal with the increased complexity and to keep track of the logistics costs. Proactive logistics can enable retail companies to establish efficient logistics and to avoid costly logistical pitfalls in the early stage of retail internationalisation. Ideally, proactive logistics should be in place from the start of the retail internationalisation in order to support it in the best possible way. The findings presented above are based on the answers to the three research questions presented below. 
The purpose of this thesis has been addressed through three research questions. The first research question (RQ1) was formulated as: "What are the general phases of the foreign establishment process of retailers?" This question aimed to provide a better understanding of the supporting role of logistics during different phases of the establishment process into a new foreign market. The results showed that the foreign establishment process includes three phases: a market-analysis phase, an implementation phase and a follow-up phase. In terms of logistics, the logistics organisation was solely involved at an operational level in an individual foreign establishment. During the implementation phase, the logistics organisation scaled up its operations in order to prepare for the new foreign market, and these operations were later used to supply the new foreign market during the follow-up phase. Furthermore, logistics had an indirect impact on strategic decisions (i.e. foreign market selection, retail market entry mode and retail format transfer) related to the marketanalysis phase.

The second research question (RQ2) was formulated as: "What are the key logistics characteristics that support the early stage of retail internationalisation?' This question aimed to explore a set of comprehensive logistics characteristics spanning both the strategic and the operational level of logistics that support retail internationalisation. From the results, four logistics characteristics were identified: centralised logistics control, centralised logistics structure, standardised logistics operations and continuous learning and improvement. Centralised logistics control refers to the small group of strategic logistics staff who manage the logistics organisation. Centralised logistics structure refers to the physical centralisation of warehouse facilities into one central warehouse. The third characteristic refers to the great extent of standardised operations used by the logistics organisation. Fourth and last, continuous learning and improvement refers to the learning culture that enables the logistics organisation to constantly learn and improve.

The third and last research question (RQ3) was formulated as: "What are the key supply-chain capabilities that support the early stage of retail internationalisation?" This explored supply-chain capabilities that support retail internationalisation by using resource-based theories. The findings suggest that there are three supply-chain capabilities: leadership, integration and learning, that support retail internationalisation. Each supply-chain capability category includes a number of capabilities that together form the key supply-chain capabilities. The leadership capability category refers to the centralised coordination of company resources, including supply-chain resources (e.g. logistics resources) in retail internationalisation. More specifically, two capabilities have been highlighted. First, the involvement of company founders (i.e. company founder involvement) is important in order to prioritise logistics at a strategic level during retail internationalisation. Additionally, a tight top management team (i.e. top management control) is important for efficiently delegating and supervising the different functions (e.g. logistics organisation) involved in retail internationalisation. The integration capability category refers to efficient integration between top management and internal company functions (e.g. logistics organisation) as well as external support during retail internationalisation. There are three integration categories: organisational, functional and external. First, organisational integration refers to the integration between top management and both company functions and external support, which is important in order to efficiently delegate responsibilities and supervise the retail internationalisation. Second, functional integration refers to efficient integration between company functions, 
such as collaboration between the logistics function and the purchasing function related to retail internationalisation. Third, external integration refers to the collaboration with external support in retail internationalisation, such as the collaboration between the logistics function and logistics providers. The learning capability category refers to learning within the company during retail internationalisation. The learning capability includes two learning capabilities, organisational and experiential. Organisational learning refers to the strong learning culture within the company, which allows the logistics organisation to learn from the retail internationalisation. Experiential learning refers to the high level of learning from the trial-and-error approach used during previous establishments into foreign sales markets in retail internationalisation.

\subsection{Contributions}

This licentiate thesis makes both an academic and a practical contribution. Based on the previous literature, the main contribution of this licentiate thesis is to provide a deeper understanding of how logistics supports retail internationalisation. Below, the specific contributions of this licentiate thesis are presented. First, previous contributions related to logistics in retail internationalisation have focused on logistics within a general internationalisation context and not within a specific retail-internationalisation context (e.g. Marchet et al. 2016; Straube et al. 2008). Therefore, this research contributes by studying logistics from the context of retail internationalisation and summarises the literature related to retail internationalisation that is used, for instance, to identify logistics characteristics. Second, previous contributions have focused on logistics at a strategic level (e.g. logistics strategies), while neglecting the operational level. In contrast to previous studies, this research spans both the strategic and the operational levels of logistics, which provides a deeper understanding of how the logistics organisation and logistics operations support retail internationalisation. Third, logistics has often been studied as a static aspect that does not change over time. However, retail internationalisation can be seen as a dynamic learning-by-doing process that requires continuous logistics support, which suggests that this support changes throughout the process of retail internationalisation. Therefore, logistics is studied from a more dynamic perspective as the scope of this research extends beyond the establishment process of a particular country. Fourth, previous research has not studied the supply-chain capabilities that support retail internationalisation. This research identifies such capabilities based on resource-based theories. Fifth, previous contributions have mostly focused on global retail chains (e.g. IKEA and Zara) that have established themselves into a large number of foreign markets worldwide and have well-established logistics routines for supplying multiple markets. In contrast, this research focuses on the early stage of retail internationalisation in order to better understand how retail chains design their logistics when establishing into their first few foreign markets.

From a practical viewpoint, this licentiate thesis provides an improved understanding of the supporting role of logistics in retail internationalisation, which can support managers in making more informed decisions about how to adapt their logistics organisation and logistics operations. Furthermore, it can help retailers to better coordinate their logistics resources in terms of logistics staff, warehouse facilities and logistics providers, in order to better cope with complexity and adapt to the requirements of foreign markets. This licentiate thesis also clarifies logistics characteristics and supply-chain capabilities that 
support the early stage of retail internationalisation. In addition, this licentiate thesis can help practitioners to better prepare their logistics organisation and logistics operations for a future retail internationalisation as well as preventing retailers from making logistics mistakes in the early stage of retail internationalisation.

\subsection{Suggestions for further research}

As with any research, there is room for further studies. The literature on retail internationalisation has not focused on logistics aspects to any great extent, which means that more studies related to logistics can be conducted in future research. In the following are a few suggestions for further research:

- This licentiate thesis investigates the early stage of retail internationalisation, which means that retailers' logistics has so far just adapted to supply a few foreign sales markets. It would be interesting to explore how logistics develops further over time and to follow how it develops after a retailer has become established into a large number of markets. For instance, what does the logistics organisation look like after ten foreign establishments? Or after 20 establishments? An in-depth, longitudinal case study of how retailers' logistics organisation develops over time would be very interesting. Such a study could also be used to test the findings of this study and determine whether the characteristics and capabilities found in this study are also valid in later stages of retail internationalisation.

- Furthermore, it could also be fruitful to explore the supporting role of logistics in a specific retail sector in order to capture logistical differences among different retail sectors. As there is a wide range of retail sectors with unique characteristics, it is likely that these sectors have specific logistical needs and challenges. Moreover, it would be interesting to investigate retailers that use different entry modes.

- Another interesting research suggestion is to investigate the relationship between retailers and logistics providers in retail internationalisation. What does this relationship look like and what are the key factors for a successful collaboration? Logistics has been recognised as an important competitive advantage that needs to be in place to offer the right customer experience. Today, quality is not just measured in terms of the product itself, but through the whole shopping experience, which means that logistics is an important factor.

- In this licentiate thesis, it was also found that logistics should use standardised operations in order to support the early stage of retail internationalisation. However, at the same time, logistics should be flexible in order to adapt to foreign markets and to tackle unforeseen challenges related to them. These two logistical desires are quite opposed to each other and how to combine them is not really made clear in previous research. Therefore, a further investigation of the balance between standardisation and adaptation would be an interesting research topic for the future. 
- There has been a major shift in retail during the last couple of years as e-commerce has increased drastically. In 2017, online shopping grew by $94 \%$, while shopping in physical stores only grew by 6\% in Sweden (Arnberg et al. 2018). By establishing omni-channels, retailers can offer their customers a seamless shopping experience by combining both physical stores and online stores. In the literature, omni-channels have started to be studied. However, omni-channels in the context of retail internationalisation have seldom been mentioned. As traditional retailers (i.e. with both physical stores and online stores) are becoming more common and retailers are establishing omni-channels, it becomes important to study these channels in order to deepen our understanding of them. 



\section{References}

Abrahamsson, M, Aldin, N, and Stahre, F. 2003. "Logistics platforms for improved strategic flexibility." International Journal of Logistics Research and Applications 6 (3):85106.

Abrahamsson, M, and Brege, S. 2004. "Dynamic effectiveness-improved industrial distribution from interaction between marketing and logistics strategies." Journal of Marketing Channels 12 (2):83-112.

Abrahamsson, M, and Rehme, J. 2010. "The role of logistics in retailers' corporate strategy - A driver for growth and customer value." Supply Chain Forum: An International Journal 11 (4):14-23.

Agarwal, S, and Ramaswami, S N. 1992. "Choice of foreign market entry mode - impact of ownership, location and internalization factors." Journal of International Business Studies (1):1-27.

Alexander, N. 1995. "UK retail expansion in North America and Europe A strategic dilemma." Journal of Retailing and Consumer Services 2 (2):75-81.

Alexander, N, and Myers, H. 2000. "The retail internationalisation process." International Marketing Review 17 (4/5):334-53.

Alvesson, M, and Sköldberg, K. 1994. Tolkning och reflektion-vetenskapsfilosofi och kvalitativ metod. Lund: Studentlitteratur.

Arnberg, J, Bergh, E, Nevander, O, and Svensson, A. 2018. "Det stora detaljhandelsskiftet." In. Göteborg: Svensk Handel.

Assaf, A G, Josiassen, A, Ratchford, B T, and Barros, C P. 2012. "Internationalization and performance of retail firms: A Bayesian dynamic model." Journal of Retailing 88 (2):191-205.

Baker, P, and Canessa, M. 2009. "Warehouse design: A structured approach." European journal of operational research 193 (2):425-36.

Barney, J. 1991. "Firm resources and sustained competitive advantage." Journal of Management 17 (1):99-120.

Barney, J B. 2001. "Is the resource-based "view" a useful perspective for strategic management research? Yes." Academy of Management Review 26 (1):41-56.

Barney, J B, and Clark, D N. 2007. Resource-based theory: Creating and sustaining competitive advantage: Oxford University Press on Demand.

Bartholdi, J J, and Hackman, S T. 2008. Warehouse \& Distribution Science: Release 0.89. Vol. 2. Atlanta USA: Supply Chain and Logistics Institute.

Bell, J, McNaughton, R, and Young, S. 2001. "Born-again global firms: An extension to the 'born global' phenomenon." Journal of International Management 7 (3):173-89.

Bengtsson, M. 2008. "The art of replicating." Linköping University Electronic Press.

Beske, P. 2012. "Dynamic capabilities and sustainable supply chain management." International Journal of Physical Distribution \& Logistics Management 42 (4):372-87.

Brege, S, and Öjdemark, C. 2016. Internationalisering $i$ en global värld - frän innovation till marknadsledare. Lund: Studentlitteratur.

Brouthers, K, Mukhopadhyay, S, Wilkinson, T J, and Brouthers, L. 2009. "International market selection and subsidiary performance: a neural network approach." Journal of World Business 44 (3):262-73. 
Brouthers, K D, Brouthers, L E, and Werner, S. 2003. "Transaction cost-enhanced entry mode choices and firm performance." Strategic Management Journal 24 (12):1239-48.

Bryman, A. 2015. Business Research Methods. Vol. 4th edition. Oxford: Oxford University Press.

Burt, S, Davies, K, Dawson, J, and Sparks, L. 2008. "Categorizing patterns and processes in retail grocery internationalisation." Journal of Retailing and Consumer Services 15 (2):78-92.

Bygballe, L E, Bø, E, and Grønland, S E. 2012. "Managing international supply: The balance between total costs and customer service." Industrial Marketing Management 41 (3):394-401.

Cao, L. 2011. "Dynamic capabilities in a turbulent market environment: empirical evidence from international retailers in China." Journal of Strategic Marketing 19 (5):455-69.

Cateora, P, and Graham, J. 1999. International Marketing. 10 ed. New York: Irwin McGrawHill.

Chen, H, Daugherty, P, and Roath, A. 2009. "Defining and operationalizing supply chain process integration." Journal of Business Logistics 30 (1):63-84.

Chow, G, Heaver, T, and Lennart, H. 1995. "Strategy, structure and performance: A framework for logistics research." Logistics and Transportation Review 31 (4):285-307.

Coe, N, and Hess, M. 2005. "The internationalization of retailing: Implications for supply network restructuring in East Asia and Eastern Europe." Journal of Economic Geography 5 (4):449-73.

Commission, E. 2018. "What is an SME?" European Commission - Growth, Accessed 3 december.

Creazza, A, Dallari, F, and Melacini, M. 2010. "Evaluating logistics network configurations for a global supply chain." Supply Chain Management: An International Journal 15 (2):154-64.

CSCMP. n.d. "CSCMP Supply Chain Management Definitions and Glossary." In. cscmp.org: Council of Supply Chain Management Professionals.

Dawson, J. 1994. "Internationalization of Retail Operations." Journal of Marketing Management 10:267-82.

Defee, C, and Fugate, B. 2010. "Changing perspective of capabilities in the dynamic supply chain era." The International Journal of Logistics Management 21 (2):180-206.

DeKoster, R, Brito, M, and Vandel, M. 2002. "How to organize return handling: An exploratory study with nine retail warehouses." Econometric Institute Report 11 (1):118.

Deloitte. 2017. "Global powers of retailing 2017 - The art and science of customers." In. United Kingdom: Deloitte Touche Tohmatsu Limited.

Doherty, A M. 1999. "Explaining international retailers' market entry mode strategy: internalization theory, agency theory and the importance of information asymmetry." The International Review of Retail, Distribution and Consumer Research 9 (4):379-402.

. 2000. "Factors influencing international retailers' market entry mode strategy: Qualitative evidence from the UK fashion sector." Journal of Marketing Management $16(1-3): 223-45$.

Dunning, J H. 1988. "The Eclectic Paradigm of International Production - A Restatement and Some Possible Extensions." Journal of International Business Studies 19 (1):1-31. 
Dyer, J H, and Singh, H. 1998. "The relational view: Cooperative strategy and sources of interorganizational competitive advantage." Academy of Management Review 23 (4):660-79.

Elsner, S. 2012. Retail Internationalization Wiesbaden: Springer Gabler.

Esper, T, Fugate, B, and Davis-Sramek, B. 2007. "Logistics learning capability: Sustaining the competetive advantage gained through logistics leverage." Journal of Business Logistics 28 (2):57-81.

Frasquet, M, Dawson, J, Calderón, H, and Fayos, T. 2018. "Integrating embeddedness with dynamic capabilities in the internationalisation of fashion retailers." International Business Review.

Frasquet, M, Dawson, J, and Mollá, A. 2013. "Post-entry internationalisation activity of retailers: An assessment of dynamic capabilities." Management Decision 51 (7):151027.

Frazelle, E, and Frazelle, E. 2002. World-class warehousing and material handling. Vol. 1: McGraw-Hill New York.

Gamble, A. 2010. "The political consequences of the crash." Political Studies Review 8 (1):314.

Gielens, K, and Dekimpe, M. 2007. "The entry strategy of retail firms into transition economies." Journal of Marketing 71 (April 2007):196-212.

Goldman, A. 2001. "The transfer of retail formats into developing economies: The example of China." Journal of Retailing 77:221-42.

Grant, R. 1991. A Resource Based Theory of Competitive Advantage. Vol. California Management Review. Berkeley: University of California.

Gu, J, Goetschalckx, M, and McGinnis, L F. 2007. "Research on warehouse operation: A comprehensive review." European journal of operational research 177 (1):1-21.

Hellström, D, and Saghir, M. 2007. "Packaging and logistics interactions in retail supply chains." Packaging Technology and Science: An International Journal 20 (3):197-216.

Huang, Y, and Sternquist, B. 2007. "Retailers' foreign market entry decisions: An institutional perspective." International Business Review 16 (5):613-29.

Huertas, J I, Díaz Ramírez, J, and Trigos Salazar, F. 2007. "Layout evaluation of large capacity warehouses." Facilities 25 (7/8):259-70.

Hutchinson, K, Alexander, N, Quinn, B, and Doherty, A M. 2007. "Internationalization motives and facilitating factors - Qualitative evidence from smaller specialist retailers." Journal of International Marketing 15 (3):96-122.

Hutchinson, K, Quinn, B, Alexander, N, and Doherty, A M. 2009. "Retailer internationalization: Overcoming barriers to expansion." The International Review of Retail, Distribution and Consumer Research 19 (3):251-72.

Hwang, W, Jung, H S, and Salvendy, G. 2006. "Internationalisation of e-commerce: a comparison of online shopping preferences among Korean, Turkish and US populations." Behaviour \& Information Technology 25 (1):3-18.

IGI Global. 2018. "What is retail internationalization?" Idea Group Inc, Accessed 12 October.

Johanson, J, and Vahlne, J E. 1977. "The internationalization process of the firm - A model of knowledge development and increasing foregin market commitments." Journal of International Business Studies. 
2009. "The Uppsala internationalization process model revisited: From liability of foreignness to liability of outsidership." Journal of International Business Studies 40 (9):1411-31.

Johanson, J, and Wiedersheim-Paul, F. 1975. "The internationalization of the firm - Four swedish cases." Journal of Management Studies 12:305-23.

Johansson, U, and Thelander, $\AA$. 2009. "A standardised approach to the world? IKEA in China." International Journal of Quality and Service Sciences 1 (2):199-219.

Jonsson, A, and Foss, N. 2011. "International expansion through flexible replication: Learning from the internationalization experience of IKEA." Journal of International Business Studies 42:1079-102.

Kembro, J H, Norrman, A, and Eriksson, E. 2018. "Adapting warehouse operations and design to omni-channel logistics: A literature review and research agenda." International Journal of Physical Distribution \& Logistics Management 48 (9):890-912.

Kotabe, M, and Czinkota, M R. 1992. "State government promotion of manufacturing exports: A gap analysis." Journal of International Business Studies 23 (4):637-58.

Kovács, G, and Spens, K M. 2005. "Abductive reasoning in logistics research." International Journal of Physical Distribution \& Logistics Management 35 (2):132-44.

Lavie, D. 2006. "The Competitive Advantage of Interconnected Firms: An Extension of the Resource-Based View." The Academy of Management Review 31 (3):638-58.

Li, D X, and Kang, T W. 2012. "A Study on Logistical System and Operational Models of Franchise Store Retailing in China." 프랜차이즈경 영 연구 3 (1):130-43.

Li, J, Huang, R, and Dai, J B. 2017. "Joint optimisation of order batching and picker routing in the online retailer's warehouse in China." International Journal of Production Research 55 (2):447-61.

Liao, H, Proctor, R W, and Salvendy, G. 2008. "Content preparation for cross-cultural ecommerce: a review and a model." Behaviour \& Information Technology 27 (1):43-61. doi: 10.1080/01449290601088424.

Lowe, M, George, G, and Alexy, O. 2012. "Organizational identity and capability development in internationalization: transference, splicing and enhanced imitation in Tesco's US market entry." Journal of Economic Geography 12 (5):1021-54.

Marchet, G, Melacini, M, Perotti, S, and Tappia, E. 2016. "Shaping the international logistics strategy in the internationalisation process." International Journal of Supply Chain and Operations Resilience 2 (1):72-93.

Melacini, M, Creazza, A, and Perotti, S. 2011. "Analysis of supply chain planning centralisation for multinational companies." International Journal of Logistics Systems and Management 9 (4):478-500.

Mentzer, J T, DeWitt, W, Keebler, J S, Min, S, Nix, N W, Smith, C D, and Zacharia, Z G. 2001. "Defining supply chain management." Journal of Business Logistics 22 (2):1-25.

Miles, M, Huberman, M, and Saldana, J. 2014. Qualitative Data Analysis. Vol. 3. Thousand Oaks: Sage Publications.

Miles, M B, and Huberman, A M. 1994. Qualitative data analysis. Vol. 2nd. Thousand Oaks: Sage Publication.

Patel, R, and Davidson, B. 2011. Forskningsmetodikens grunder. Lund: Studentlitteratur.

Patton, M Q. 2014. Quantitative Research \& Evaluation Methods - Integreting Theory and Practice. Vol. Fourth edition. USA: Sage Publications. 
Picot-Coupey, K, Burt, S L, and Cliquet, G. 2014. "Retailers expansion mode choice in foreign markets: Antecedents for expansion mode choice in the light of internationalization theories." Journal of Retailing and Consumer Services 21 (6):976-91.

Porter, M. 1980. Competetitive strategy: New York: Free Press.

-1985. The Competitive Advantage: Creating and Sustaining Superior Performance: New York: Free Press.

Root, F R. 1994. Entry strategies for international markets. Lexington: Lexington Books.

Rouwenhorst, B, Reuter, B, Stockrahm, V, van Houtum, G-J, Mantel, R, and Zijm, W H. 2000. "Warehouse design and control: Framework and literature review." European journal of operational research 122 (3):515-33.

Rudberg, M, and West, B M. 2008. "Global operations strategy: Coordinating manufacturing networks." Omega 36 (1):91-106.

Sakarya, S, Eckman, M, and Hyllegard, K H. 2007. "Market selection for international expansion: assessing opportunities in emerging markets." International Marketing Review 24 (2):208-38.

Sandberg, E. 2013. "Understanding logistics-based competition in retail - A business model approach." International Journal of Retail and Distribution Management 41 (3):176-88.

- 2014. "Coordination mechanisms in the store opening process." International Journal of Retail and Distribution Management 42 (6):482-99.

Sandberg, E, and Abrahamsson, M. 2011. "Logistics capabilities for sustainable competitive advantage." International Journal of Logistics Research and Applications 14 (1):61-75.

Sandberg, E, and Åman, P. 2010. "Logistics learning mechanisms and capabilities: Towards an understanding of sustainable competitive advantage." Logist. Res. Springer-Verlag 2:97-108.

Schmidt, G, and Wilhelm, W E. 2000. "Strategic, tactical and operational decisions in multi-national logistics networks: a review and discussion of modelling issues." International Journal of Production Research 38 (7):1501-23.

Schramm-Klein, H, and Morschett, D. 2006. "The Relationship between marketing performance, logistics performance and company performance for retail companies." The International Review of Retail, Distribution and Consumer Research 16 (2):277-96.

Siggelkow, N. 2007. "Persuasion with case studies." The Academy of Management Journal 50 (1):20-4.

Straube, F, Ma, S, and Bohn, M. 2008. Internationalisation of logistics systems: Springer.

Stuart, I, McCutcheon, D, Handfield, R, McLachlin, R, and Samson, D. 2002. "Effective case research in operations management: a process perspective." Journal of Operations Management 20 (5):419-33.

Swoboda, B, and Anderer, M. 2008. "Coordinating the international retailing firm: Exploratory models and evaluations of structural, systemic, and cultural options." Journal of Retailing and Consumer Services 15 (2):104-17.

Swoboda, B, and Elsner, S. 2013. "Transferring the Retail Format Successfully into Foreign Countries." Journal of International Marketing 21 (1):81-109.

Swoboda, B, Foscht, T, and Cliquet, G. 2008. "International value chain processes by retailers and wholesalers - A general approach." Journal of Retailing and Consumer Services 15 (2):63-77. 
Swoboda, B, Foscht, T, Maloles, C, and Schramm-Klein, H. 2009. "Exploring how garment firms choose international sourcing- and sales-country markets." Journal of Fashion Marketing and Management: An International Journal 13 (3):406-30.

Swoboda, B, Schwarz, S, and Hälsig, F. 2007a. Towards a conceptual model of country market selection: Selection processes of retailers and C\&C wholesalers. Vol. Distribution and Consumer Research.

- 2007b. "Towards a conceptual model of country market selection: Selection processes of retailers and $\mathrm{C} \& \mathrm{C}$ wholesalers." International review of retail, distribution and consumer research 17 (3):253-82.

Teece, D J, Pisano, G, and Shuen, A. 1997. "Dynamic capabilities and strategic management." Strategic Management Journal 18 (7):509-33.

Vahlne, J E, and Ivarsson, I. 2014. "The globalization of Swedish MNEs: Emperical evidence and theoretical explanations." Journal of Business Studies 45:227-47.

Vida, I. 2000. "An empirical inquiry into international expansion of US retailers." International Marketing Review 17 (4/5):454-75.

Wernerfelt, B. 1984. "A resource-based view of the firm." Strategic Management Journal 5 (2):171-80.

Wigley, S, and Chiang, R C L. 2009. "Retail internationalisation in practice: per una in the UK and Taiwan." International Journal of Retail \& Distribution Management 37 (3):25070. doi: doi:10.1108/09590550910941517.

Winter, S G, and Szulanski, G. 2001. "Replication as Strategy." Organization Science 12 (6):730-43.

Wood, S, and Reynolds, J. 2012. "Establishing Territorial Embeddedness within Retail Transnational Corporation (TNC) Expansion: The Contribution of Store Development Departments." Regional Studies 48 (8):1371-90.

Yin, R K. 2003. Case Study Research: Design and Methods. Vol. 3. Thousand Oaks: Sage Publications.

Yin, R K. 2014. Case Study Research: Design and Methods. Vol. 5. Thousand Oaks: Sage Publications.

Zollo, M, and Winter, S G. 2002. "Deliberate learning and the evolution of dynamic capabilities." Organization Science 13 (3):339-51.

Zúñiga, R, and Martínez, C. 2016. "A third-party logistics provider: To be or not to be a highly reliable organization." Journal of Business Research 69 (10):4435-53. 


\section{APPENDIX 1}

Appended Papers

The papers associated with this thesis have been removed for copyright reasons. For more details about these see:

http://urn.kb.se/resolve?urn=urn:nbn:se:liu:diva-155027 
APPENDIX 2

Case reports 



\section{Company A}

Company $\mathrm{A}$ is a retail company that offers home and leisure products. The company targets a broad customer group with a wide range of products within six categories: interior design, gardening, Christmas, DIY, consumption and leisure. The product range changes depending on trends and seasons, where Company A has four seasons. Company A uses physical stores as the main sales channel with a complementary range of products available to order, with the latter being delivered to the stores for all markets, with exception of Swedish customers who can also choose home delivery.

Company A was founded in the mid 1980s in Sweden. The company grew rapidly during the 1990s and its expansion has continued until now. In 2014, Company A took its first steps into the international arena by establishing five stores in Norway. After a successful entry into the Norwegian market, Company A entered the German market in 2017. In total, Company A has about 110 stores, with 88 stores in Sweden, 19 stores in Norway and 2 stores in Germany. 82\% of its turnover comes from Sweden, 16\% from Norway and 2\% from Germany. For all markets, physical stores are the main sales channel, and Company A also offers an additional order assortment. The products available to order are delivered to stores for pick-up, and for the Swedish market Company A offers home delivery.

The retail internationalisation of Company $\mathrm{A}$ is due to experienced saturation in the home market, and therefore the focus on growth abroad has increased. In 2017, Company A had net sales of MSEK 181. In Table 1, turnover, net sales and the number of stores for the last six years are presented.

Table 1 - Turnover, net sales and number of stores for the period 2012-2017 for Company A

\begin{tabular}{|c|c|c|c|c|c|c|}
\hline & 2017 & 2016 & 2015 & 2014 & 2013 & 2012 \\
\hline Turnover (MSEK) & 2,65 & 4,52 & 3,98 & 3,59 & 3,04 & 2,69 \\
\hline Net sales (MSEK) & 154 & 185 & 79 & 99 & 220 & 118 \\
\hline Number of stores & 109 & 101 & 90 & 83 & 72 & 68 \\
\hline
\end{tabular}

Company A has more than 1,700 employees in seven countries, and its headquarters are located in Stockholm. The two company founders are still active as major shareholders and board members. In Figure 1, the organisation chart for Company A is presented. The management team consists of the CEO, the CFO, the Environment and Quality Manager, the Human Resources (HR) Manager, the Business and Product Range Manager, the Sales Manager, the Marketing Manager and the Supply Chain Manager. Each manager, other than the CEO, is responsible for one department.

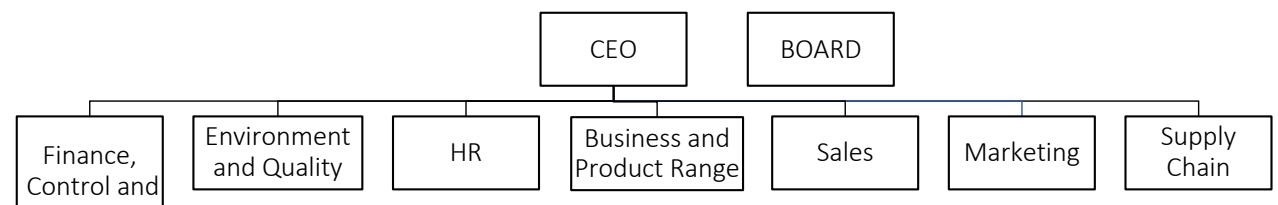

IT

Figure 1 - Organisation chart for Company A

The main departments presented in the organisation chart above are divided into smaller departments. In this study, the logistics of Company A is investigated, which is incorporated 
into the Supply Chain department. In the next section, the overall Supply Chain department will be described.

\subsection{Supply Chain}

The overall Supply Chain organisation encompasses five divisions, which are illustrated in Figure 2 First, the Sourcing division is responsible for the identification of and negotiation with suppliers in the sourcing countries in Asia and Europe. Second, the Transport division is responsible for the transportation of goods from manufacturers in Asia to the central warehouse, and distribution from the central warehouse to all stores. Third, the Logistics division is responsible for the warehouse operations in the central warehouse. Fourth, Outbound Planning is responsible for store restocking for all markets. Fifth and last, Supply Chain Excellence performs supply chain projects, in order to actively improve the flow of goods throughout the supply chain.

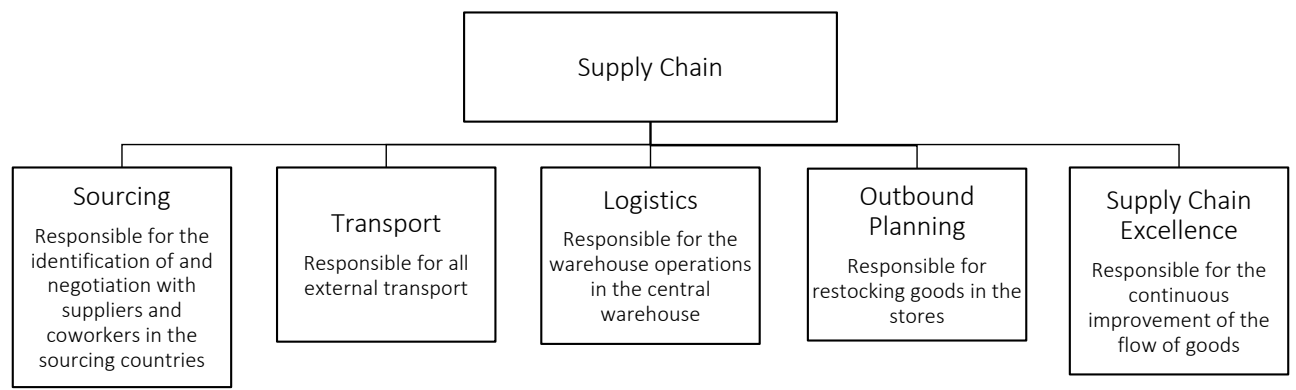

Figure 2 - Organisational chart for the Supply Chain Department

The Supply Chain department, managed by the Supply Chain Manager, encompasses the entire supply chain of Company A, including sourcing activities, warehouse operations, transport and store restocking. As the Business and Product Range department purchases products, the Supply Chain department acts as an organiser that organises the flow of goods with respect to stock turnover in the central warehouse and varying lead times for different products. The border between the two departments is a little blurred, as both are involved in the product flow, especially in the sourcing operations. Supply Chain identifies suppliers and manages the transportation, storage and distribution of the product flow, while Business and Product Range is responsible for the product range including operational purchases, which encompasses the types of products to order, the quality and quantity, and the time of delivery. There is close, continuous collaboration between these two departments to ensure the right quality and quantity are delivered on time.

This study investigates the internationalisation of sales operations into foreign markets. Therefore, the flow of goods closest to the foreign sales operations will be studied, ranging from warehouse to distribution out to stores, as this part of the supply chain changes considerably as retailers expand abroad, as the warehouse operations and distribution are directly affected. Therefore, the Logistics and Transport divisions are further described below. 


\subsubsection{Logistics}

The Logistics division is managed by the Logistics Manager, who is also site manager for the warehouse facilities (e.g. central warehouse and external warehouse). The Logistics division encompasses the warehousing (i.e. warehouse facilities and warehouse operations) and logistics development functions, of which the latter develops logistics operations performed in the supply chain. Figure 3 presents the organisation of the Logistics division. Beyond these two main functions, Logistics also includes an HR function and a financial controller.

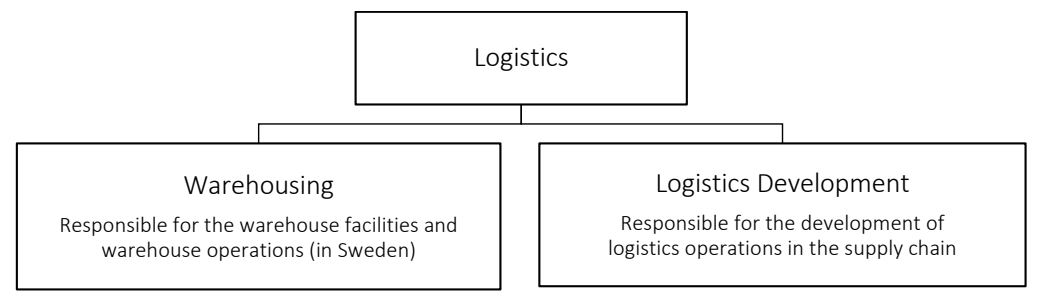

Figure 3 - Organisational chart for the Logistics Division

The main goal of the Logistics division is to ensure stock capacity and adjust to the flow of products, with the latter being determined by the Business and Product Range department. The Logistics division interacts with many company departments. For instance, the product packaging is designed by the Business and Product Range department with support from Logistics Development. Business and Product Range decides what products to sell, and the Sourcing division identifies suitable manufacturers. The Logistics division has contact with the Marketing department to keep track of what products are featured in the flyer to be able to plan the warehouse operations and the picking of campaign products. Furthermore, Logistics communicates daily with Outbound Planning about upcoming and delivered orders. According to the Logistics Manager, the interaction with other departments is crucial for a well-functioning logistics organisation. There are also dedicated forums within the company that aim to improve the supply chain. Moreover, the Logistics division communicates regularly with the top management about capacity in the supply chain, operating costs and other logistics-related issues.

Logistics Development is mainly based at HQ in Upplands Väsby, but also has a presence in Norrköping. The function develops IT systems relating to the product flow, such as the warehouse system and the business system. There are dedicated staff that work with different parts of the supply chain. For instance, one employee works with packaging originating from Asia and one works as a systems expert, optimising the systems in the supply chain.

Below the site manager are a warehouse management group of three people who are responsible for the warehouse operations: the Inbound Manager, Outbound Manager and Coordination Manager. The Inbound Manager is responsible for activities related to the inflow of products, including unloading, quality and environment. The Outbound Manager is responsible for the outflow, including picking lines, marshalling and loading. The Coordination Manager is responsible for production planning and the allocation of personnel between inbound and outbound, and can be seen as a support function for inbound and outbound.

The overall warehousing organisation consists of warehouse facilities, warehouse operations, key figures and IT systems, which are described below. 


\section{Warehouse facilities}

The warehouse facilities consist of a central warehouse located in Norrköping and an external warehouse located in Linköping. The warehouse facilities are located in the Norrköping region in order to be close to important infrastructure, such as harbours, railways and a European highway, as well as potential markets such as the Mälaren Valley. The warehouse location also needs to be large enough to handle further expansion, in terms of building additional ports and picking slots, and sufficient space was available in Norrköping. The central warehouse was built in 2014 by Company A and has been operating since 2015. The construction of the central warehouse has taken place in two stages; first a warehouse of $72,000 \mathrm{sq} \mathrm{m}$ and thereafter an expansion of 46,000 sq $\mathrm{m}$. At the end of 2018, the second stage of the expansion will be finished and the total area of the central warehouse will be $118,000 \mathrm{sq} \mathrm{m}$. Company A initially owned the warehouse in Norrköping, but has rented it since 2017. However, Company A still administers the warehouse via its own property manager. The external warehouse in Linköping is being rented temporarily until the expansion of the central warehouse is complete. The external warehouse is only used for intermediate storage of off-season products.

All markets are supplied by the central warehouse in Norrköping, and the main flow of products goes through the central warehouse, except for a small percentage that goes directly via the suppliers. For instance, large brands such as Coca-Cola and AGA Gas distribute directly to all market stores. Also, other products (e.g. paint) are delivered directly from the supplier.

Before the central warehouse in Norrköping was established, the logistics organisation rented two larger warehouses and 10 smaller hubs, all located in Småland. However, this former structure meant a lot of coordination and handling as goods were sent back and forth, due to a lack of storage space in the two warehouses. The strategic purpose of centralising the warehouse facilities was to simplify the situation and get a better overview of the product flow, as well as gaining better control of the Logistics division, and also to eliminate side functions such as quality control, which was previous performed in several locations. The centralisation resulted in less handling and transportation of products, as well as a staff reduction of about 30 people. In the light of entering the Norwegian and German markets, the centralisation process simplified the distribution of products to all stores as well as reduced the logistics costs.

\section{Warehouse operations}

The warehouse operations include standardised operations performed at all warehouse facilities. About 250 employees work in the warehouses and about $85-90 \%$ of them are inhouse staff. An external firm is hired for container unloading and additional external staff are hired for the two peak seasons, summer and Christmas. The staff work in two shifts per day.

The product flow in the central warehouse usually starts when products are delivered to the warehouse by truck or container. When the products arrive, the receiving process starts including unloading, reporting, quality check and labelling. After the products have been received, the products are put away in the storage area by a truck driver. The inventoryplanning function of the logistics organisation decides were the specific product should be placed and the location is reported in the WMS. The location depends on the product type. For example, fast-moving products are logically placed in more convenient areas to reduce 
the transportation time inside the warehouse. Also, market-specific products are placed in individual storage locations. The picking operation starts as an order in the business system is transferred into the warehouse system. Usually, voice pick is used but picking lists are also available, with latter is being used for pre-picking orders for upcoming seasons. Furthermore, to reduce truck time the staff always pick two trays simultaneously along the picking line. Pickers pick products for one store at the time and normally all product segments are picked every day. The layout of the picking line in the central warehouse is the same as the store layout. In other words, the staff first pick the goods that appear first in the store and so on. Thereafter, the packaging operations starts including sorting and packing of store pallets and boxes. Sometimes the store pallets are sorted and consolidated into fewer pallets in order to achieve better fill rate in the trucks. The logistics organisation has packaging guidance (e.g. maximum height) that help them pack with high fill rate on each pallet. When the products are packed and labelled, the logistics provider receives information about the delivery, in order to check that the right number of packages are loaded and distributed. Thereafter, the orders are distributed to the physical stores.

The orders for the next season are usually received 3-4 weeks before the actual season starts. The forecasts for the next day on the picking lines are limited and the workload varies significantly. As the demand for goods to the stores varies throughout the year, there is high pressure on the warehouse staff to be flexible. According to the Project Manager, the warehouse organisation has a large capacity and is very service oriented and therefore works harder when necessary. Furthermore, the orders for a new store opening is picked separately and starts 4-5 weeks before the actual store opening.

\section{Key figures}

The logistics organisation uses a number of key figures to measure the performance of the warehouse operations. The main key figures are warehouse turnover, fill rate and total logistics cost in relation to total sales, which can be broken down into smaller key figures. For instance, key figures can measure the performance of a specific warehouse operation or employee. The Logistics Manager together with a financial controller from the Logistics department, keeps track of the key figures and communicates these to the board.

\section{IT systems}

The logistics organisation includes a number of IT systems that are crucial for large-scale, standardised logistics operations. The most important IT system is the warehouse management system (WMS) called EPIX. The WMS manages the overall warehouse operations and is connected to the business system as well as other warehouse systems, such as the crane inventory.

Before the warehouse centralisation Company A used an older version of EPIX, but changed to a newer version in connection with the centralisation and the expansion into Norway. A new warehouse system was needed as the previous system could not handle different market products, warehouse automations, customs and the new business system. The EPIX software is developed in-house to customise warehouse operations in a way that suits Company A.

"The system is based on how we want to work." 
The development of EPIX has been highly prioritised as it supports more time-efficient handling of goods. From the beginning, the Logistics Manager had a clear view of what the new EPIX should include to support the warehouse operations, and in an initial development phase had created a list of criteria based on requirements, "nice-to-haves" and future needs. According to the Logistics Manager, it was crucial that the system should support the activities that the logistics organisation chose to perform and should be a flexible system that could be adjusted over time if needed.

\subsubsection{The role of the Logistics division}

The Logistics division can be seen as a performer that adapts to conditions set by the top management and makes sure that the stores are supplied. The Logistics Manager makes sure that the logistics organisation adapts to the current conditions to ensure inventory capacity.

"So, logistics at Company $A$ is more of a performer, be flexible, they don't create strat... Their questions are not prioritised on the strategic agenda in that way. They don't dictate, they are more a victim of the conditions."

(Project Manager responsible for the establishments into foreign markets)

According to the Project Manager, the flexibility of the logistics organisation is an important prerequisite for the strategy of Company A that enables the company to expand. The logistics organisation adapts warehouse facilities and operations in order to make store restocking more time-efficient. The logistics organisation has daily contact with the Outbound Planning department, which is responsible for store restocking, including keeping track of cover times, fill rates and minimum and maximum storage levels in the stores. Logistics receives product orders and gets feedback on previous deliveries from Outbound Planning. This feedback is used to improve operations. According to the Logistics Manager, Company A's strategy is about minimising total costs. Therefore, the company operations, including logistics operations, are designed in such a way that cost and time reductions are created for the entire company.

"We can take a higher cost in the warehouse if it simplifies the work in the store."

(Logistics Manager)

Overall, Company A aims to design its activities to reduce the company's total costs. Logistics Development designs its warehouse operations to reduce costs for the overall organisation. For example, the logistics organisation picks the product in a way that simplifies restocking for store staff. The goods are picked according to the store layout in order to reduce the time spent restocking the stores. The Logistics Manager describes this holistic way of thinking as a way to achieve an overall cost reduction and improve efficiency throughout the supply chain. Operations are designed in such a way that they save time for the overall organisation and work on a large scale. Logistics Development continuously investigates new solutions in order to streamline the flow of goods. For example, display pallets are being investigated as these pallets are already prepared for the store at the manufacturer as the manufacturer manages picking, which results in minimum handling in the warehouse. However, this solution has not yet been implemented by Company A. 


\section{Transport}

The Transport department is managed by the Transport Manager, who is responsible for the planning and purchasing of transport from the sourcing countries to the central warehouse, as well as distribution from the warehouse to all stores for all markets. The transport planning is performed in-house while the physical transport of goods is outsourced. For store distribution, Company A uses about 15 Swedish hauliers. For the Norwegian market, two Swedish hauliers are used, while for the German market a Swedish branch of a German haulier is used.

Products arrive at the central warehouse on trucks or in containers. $60 \%$ of the volume of goods comes via containers, while $40 \%$ comes by truck. However, trucks transport $60 \%$ of the value, while $40 \%$ of the value is transported by container. Goods from Europe are transported by trucks and goods from Asia are transported by container ships.

Store deliveries occur mainly on weekdays and the delivery frequency depends primarily on the store size. Swedish stores get deliveries 3-5 times a week, Norwegian stores get deliveries 2-3 times a week and German stores get deliveries three times. About 17\% of the delivered goods (including empty pallets and damaged goods) are returned to the central warehouse. However, returns from the Norwegian market stay in Norway due to customs, as it is not profitable to return the goods from the Norwegian market, according to the Logistics Manager. For the small amount that needs to be stored in Norway a 3PL provider is used.

\subsection{Retail internationalisation}

Company A started its retail internationalisation to achieve further growth. By expanding the Company A concept into foreign markets, economies of scale could be increased and the company's total costs could be reduced. In turn, this enables Company A to set better, more competitive prices.

In 2014, the company entered the Norwegian market, where the company currently has about 18 stores. Company A entered Norway mainly because the company was able to take a desirable price position on the Norwegian market. Also, the Norwegian market was considered to be similar to the home market regarding customer preferences.

In 2017, the company entered the German market by opening two new stores in Northern Germany. Company A entered Germany with the ambition to take a leading market position within the home and leisure sector in Europe, for which the German market is crucial.

\subsubsection{International strategy}

The international strategy is developed by the board of Company A, who make the strategic decisions concerning retail internationalisation. Company A aims for a flexible strategy for its expansion into foreign markets to be able to adjust as the internationalisation progresses. The international strategy centres around three key ambitions: standardised business concept, centralised store network and central control of foreign sale operations. Figure 4 below visualises the key ambitions in the international strategy, and these are described further in the following sections. 


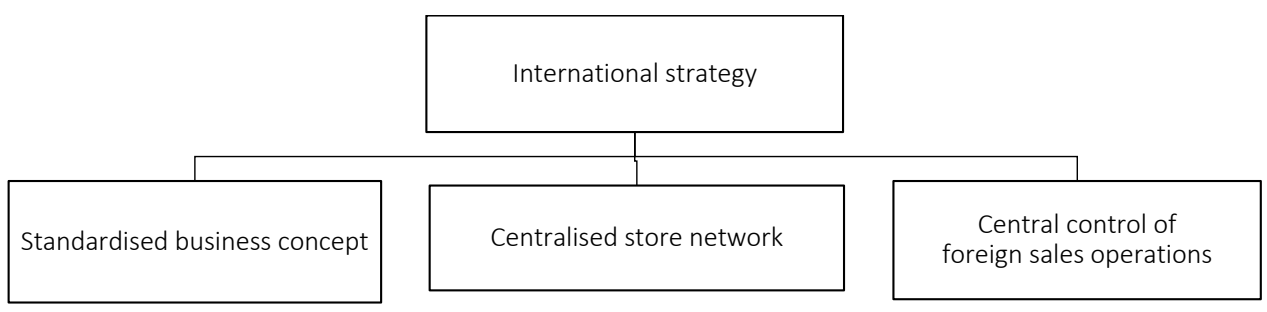

Figure 4 - Key ambitions of Company A's international strategy

The cornerstone of the international strategy is to use a standardised business concept (i.e. standardised store layout, product range, marketing and company image) for all markets, which is based on the Swedish market. Central operations, such as marketing, sourcing and concept development, are managed at a central level, as the company strives to achieve standardised operations. For example, flyers are used for marketing and a standardised store concept is used for all markets. For the foreign market operations, some adjustments to the product range have been necessary. About $25 \%$ of Company A's product range is marketspecific and mainly consists of fast-moving consumables, such as shampoo and detergent, from larger suppliers such as Procter and Gamble. Company A strives to use a standardised business concept to achieve economies of scale, especially to win advantages in purchasing and handling large volumes. According to the Project Manager, it is important to consider cultural differences between the foreign and domestic customers in the development of the business concept. However, Company A adapts as little as necessary as there is a strong belief within the company that the current offering can be used in all markets.

"We believe that the best guess is our current offer. We start with that. Then we meet the reality and adapt. There is an inherent desire for wanting to change in this regard. There is a feeling that we must change when entering Germany. We are holding back quite a lot. If you don't know, why change?"

(Project Manager responsible for the establishments into foreign markets)

To be able to have a similar product range for all markets, Company A chose markets with similar cultures to the Swedish market. For the Swedish market, summer and Christmas are the two most important seasons for Company A as these seasons account for the majority of the company's revenue and this model therefore needs to work for the foreign markets as well.

Company A aims to establish a centralised store network in the foreign markets, where the stores are located in the same geographical region. The centralisation of stores simplifies many aspects. For example, marketing costs are reduced as flyers need to be distributed for a smaller region.

The international strategy is feasible through central control of foreign sales operations. For each foreign market, Company A has a country organisation that is managed by a country manager, who manages the country organisation based on directives from the top management team. Each country organisation has a small organisation for managing local staff. 


\subsubsection{The role of logistics in the retail internationalisation}

The logistics is a vital part of the overall business of Company A that enables strategical moves and low prices, of which the latter is crucial as Company A is a discount business. For the retail internationalisation, however, logistics has been a minor issue and an increase in logistics costs has not been a major issue.

"For Company $A$ as a whole, for our strategy and concept, logistics has been more important than it has been in the expansion plans."

(Project Manager responsible for the establishments into foreign markets)

"In our establishments, logistics costs have not been a major issue."

(Project Manager responsible for the establishments into foreign markets)

The logistics costs account for a small part of the company's total costs (approximately $2.5 \%$ ). A $10-30 \%$ increase in logistics costs can be expected in the early stage of the retail internationalisation. When expanding into a new country, logistics calculations are carried out to estimate the logistics cost. In the domestic market, reducing logistics costs is highly prioritised as the domestic operations have been established for several years and are constantly being improved.

"As we consider whether or not to expand abroad, or which country to choose, the questions concerning logistics have are of fairly minor importance. We assume that we can have effective logistics abroad."

(Project Manager responsible for the establishments into foreign markets)

The main focus in when establishing in a new market has been to quickly establish a decent solution. According to the Project Manager, the establishment into foreign markets have not been about developing an optimum solution from the start. If Company A had focused on achieving the optimum solution, the establishments could have easily taken twice as long, the Project Manager argues. A budget for a new establishment is established to estimate the logistics costs. The prime focus has been to establish operating stores and to advertise in the local market. Creating efficient operations becomes important later as the company expands further into the new market.

"When you are up and running, like in Sweden where we have full activity, then it is a matter of chasing costs and becoming more effective. But priority one when we look at Norway and now in Germany is: Will we sell?"”

(Project Manager responsible for the establishments into foreign markets)

The retail internationalisation has resulted in some adaptations to the logistics operations. Before actually entering the Norwegian market in 2014, Company A had decided to centralise its warehouse facilities into one central warehouse. In parallel with the entering Norway, the new central warehouse in Norrköping was established and started operating in 2015. According to the Logistics Manager, the centralisation into one central warehouse simplifies the logistics operations for the foreign operations, but is not necessary for expanding abroad. Yet, the centralisation of the warehouse facilities is a prerequisite for effective logistics, the Logistics Manager argues. According to the Logistics Manager, a logistics organisation of several warehouses is not justifiable in terms of costs and by 
centralising the warehouse facilities, money is saved that can be invested in strategic company moves such as foreign market expansion.

"It is possible to operate an organisation of many warehouses, but it becomes very costly. If we had not carried out the centralisation, we would not have had as much money to invest with, for example for the expansion."

(Logistics Manager)

The implementation of the central warehouse in Norrköping has taken time as a new organisation has been established that includes new routines and side functions (i.e. human resources). The warehouse operations are standardised for all markets, so the warehouse operations are performed in the same way for all markets, despite for a few operations for market-specific products that are handled by local suppliers.

"For us it does not matter if the store is in Germany or in Sweden. We pick it all and there is a departure time from here. We get our orders ready."

(Logistics Manager)

When receiving products, it is important to keep the market-specific products apart. The market-specific products are labelled with specific labels and are put away in market-specific picking slots in order to hold the products apart. Due to the multiple markets with marketspecific products, there has been a shortage of picking slots in the central warehouse. Instead of just having one picking slot for the Swedish market, there were suddenly three picking slots for each market. This increased demand for picking slots resulted in a lack of storage space. Company A solved this problem by standardising product labels and instructions for its own brand and other brands to be able to sell these brands in all markets, which means that only one picking slot is needed. However, the same problem reoccurred for each new establishment and it took about a year to establish standardised product labels.

"We strive to keep everything standardised, but for every new market this problem occurs. It took about a year to convert the warehouse to have only swe/ no labels and the market-specific batches and picking slot could be removed. However, directly after we were done it was decided (by the top management team) to move into Germany and we were forced to the same journey again."

(Warehouse manager)

Furthermore, suppliers of famous brands still require separate picking slots for each market, due to different prices for the different markets. The logistics organisation can ensure transparency for its suppliers via its warehouse management system EPIX, which can distinguish market-specific products. The project to standardise labels and instructions will take time as non-standard products gradually have to be phased out.

Company A sources products from Europe and Asia, and the sourcing strategy is to purchase goods when products are cheapest to manufacture. This can result in early deliveries of goods to the central warehouse, which then need to be stored for longer than necessary, resulting in a high stock level and low turnover. Turnover has been especially low during the retail internationalisation due to increased volumes. According to the Project Manager, it is important to increase turnover to finance further expansion, and one of the prime focuses of the logistics organisation is to reduce the stock level. 
Most of the products are distributed from the central warehouse in Norrköping to the stores. Also, some suppliers of famous consumable brands deliver directly to the stores from the local market. Furthermore, there are different lead times for store distribution to different foreign markets as it depends on the location of the store. For instance, Northern Norway have a lead time of two to three days, while Southern Norway or Germany can be reached on one day. For any return shipments, products from the German market can be transported back to the central warehouse as Germany is a part of the EU. Since Norway is not a member of the EU, all goods distributed to the Norwegian stores go through customs, requiring customs clearance. Customs declarations are carried out partly by the logistics organisation and partly by an external party called TullXperten. The logistics organisation prepares custom declaration, which is sent with the distributors. This preparation enables faster custom management and has been implemented to reduce the lead time to Norway. Furthermore, the goods that have been sent to Norway do not return to the central warehouse due to high administrative costs. Instead, the small volume of remaining goods is stored by a logistics provider in Norway.

"So, the entire output principle for Norway is that what is in Norway, stays in Norway. Then you just have to find local solutions to get rid of it... It is simply too complicated administratively to transport it home again."

(Project Manager responsible for the establishments into foreign markets)

Company A has considered a duty-free warehouse in Norway, but this has not been considered to be economically feasible in the present circumstances. If the Norwegian market increases, the incentive for a duty-free warehouse increases. The duty is approximately $1-2 \%$ of the margin. According to the Project Manager, it is easier to implement a duty-free warehouse if the logistics operations are well-organised. Since the centralisation, the logistics are better organised and this would simplify the implementation of a duty-free warehouse in the future.

\subsubsection{Establishment process into foreign markets}

The main motivation for retail internationalisation has been growth. According to the Project Manager, growth is a prerequisite for long-term competitiveness and Company A strives to grow in a way that increases the economies of scale which in turn can enable the company to reduce its prices and become more competitive compared to other discount businesses.

"It is not only that we sell more from the contribution we get from Germany and Norway, but we also create the conditions to lower the prices of everything we sell in Sweden."

(Project Manager responsible for the establishments into foreign markets)

Company A can grow in two ways: either by increasing sales at its existing stores or by opening new stores in new markets. As the home market is becoming more saturated, the company has chosen to expand to nearby foreign markets.

According to the Project Manager, the retail internationalisation of Company A was possible thanks to the strong commitment of the CEO, who has been one of the main driving forces for both the market entries. The establishment projects have been driven 
mostly by the gut-feeling of the board and economic evaluations have had a minor impact on the decisions to enter a specific market. Company A uses an emergent ad hoc approach, whereby the establishment process emerges as the company establishes and expands abroad. The company learns by trial and error from previous establishments, and adjusts its establishment activities according to previous experiences. One of the main guiding principles in the establishment into foreign markets has been the word "courage", which originates from the two company founders encouraging the company to take risks to advance further.

All decisions concerning retail internationalisation are made by the board and the establishment process was monitored by an operational staff group that consisted of a few individuals, including the $\mathrm{CEO}$, one of the founders, the Marketing Manager and the Project Manager. During the establishment process, the board and the operational staff group had meetings to follow up on the establishment every third month. Also, the operational staff group had monthly debriefings from the key staff involved in the establishment projects.

The retail internationalisation started when the board instructed the CEO to begin the retail internationalisation of Company A. The CEO assigned a Project Manager from the staff function to be responsible for the establishment project abroad. The Project Manager worked as a facilitator, bringing relevant employees from the top management together in order to facilitate the expansion. Parts of this establishment team have differed for the two foreign market entries, mainly because some of the employees had country-specific knowledge that is valuable for a specific market establishment. The Project Manager was responsible for both the market entries. However, he is also involved in other company projects. The Project Manager works closely with the CEO. According to the Project Manager, he had an overall role in the organisation as he has a good insight and understanding of the company as a whole.

Moreover, several departments are involved in the retail internationalisation. For instance, the Business and Product Range division decides which products should be sold in each market, the Supply Chain department manages the flow of goods from manufacturers to company stores, and the Sales department manages the sales organisation for each market. Several departments are also involved in the establishment process in new foreign markets, and this process is described in greater detail later in this chapter.

In this study, the establishment process is defined as the process starting from the first market entry initiative to an operating store(s) that has been open for at least a year. Figure 5 visualises Company A's general establishment processes for a new foreign market, including projects, important decision points and key staff. The figure is based on an establishment plan established by Company A. The establishment process lasts between 21 and 28 months. The overall establishment process encompasses three main phases - market analysis, implementation and follow-up - including several projects. 


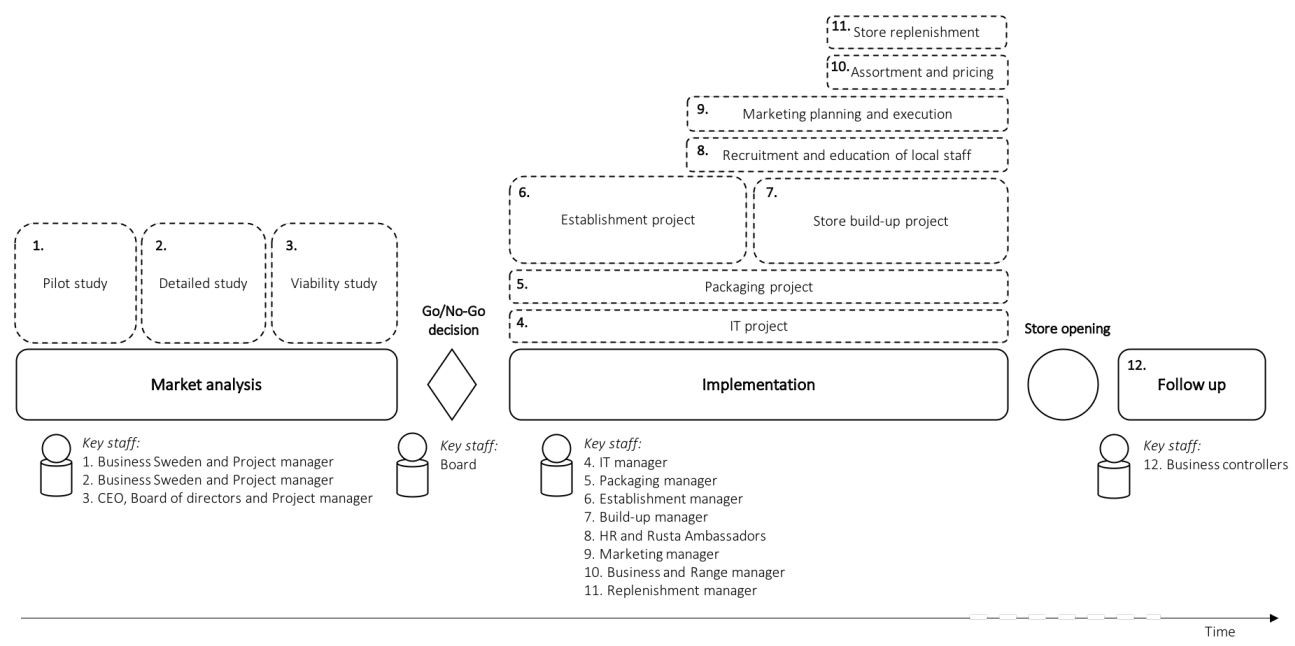

Figure 5 - Establishment process for Company A

In addition to the establishment process, initial preparations need to be made for the retail internationalisation. In the following section, the initial preparations are described, followed by the phases of Company A's general establishment process, including the content of each phase, the phase duration and the functions/individuals involved in each phase.

\section{Initial preparations}

Before Company A could establish itself in foreign markets, the company had to adapt the organisation to be able to go international. In this section, the main international adaptations are presented.

Adaptation of business system: To establish in foreign markets, a new business system needed to be in place that could manage product information for several marketing channels (e.g. signs and website) for multiple languages and also include multiple currencies. A multicurrency business system is a crucial requirement for conducting foreign sale operations, and needs to be in place before opening foreign stores. The adapted business system was in place two weeks before the actual store opening in Norway and was also adapted for the German market, which needed fewer adjustments as the most effort was put into the first establishment into foreign markets.

Obtain knowledge about foreign markets: To learn about the foreign markets, Company A obtained valuable information from external organisations/individuals before the market entry was completed. Company A obtains most of its market information, with some exceptions, from a few forums on making practical progress when entering a new market.

For the Norway establishment, Company A recruited two individuals with experience of the Norwegian market and who had participated in market entries to Norway by two other Swedish companies. They had valuable connections with property owners and lawyers, and had a good understanding of the Norwegian infrastructure and general legal knowledge. The two individuals were hired during the implementation phase when searching for store locations. Company A also hired an additional export promotion organisation called 
Business Sweden, which performed an extensive market analysis as the organisation possesses knowledge about the Norwegian market.

For the German market entry, Business Sweden performed the market analysis. As Company A had no internal staff with previous experience of Germany, the GermanSwedish Chamber of Commerce was hired, which is part of an international network to promote international trade. For the implementation phase, Company A contacted one of the offices in Sweden to identify store locations and deal with legal issues as the GermanSwedish Chamber of Commerce had valuable contacts with property owners and possessed both market and legal knowledge.

\section{Market analysis}

The initial step in the market entry was a market analysis including a pilot study, a detailed study and a viability study, which are described in the following sections.

Pilot study: The establishment process started with a pilot study that consisted of an overall desktop study. The pilot study was performed by Business Sweden for the Norwegian market and the German-Swedish Chamber of Commerce for the German market. These external organisations are described later on in this chapter. The study comprised nine countries, and the goal of the study was to narrow down the choice from nine to five countries. When doing so, various variables including demographic, geographic and socioeconomic criteria were used. These market criteria included market size (macroeconomics), BNP, unemployment, similar concepts in the market, purchasing power per capital, market growth in the current segment and sourcing purchasing power.

The pilot study lasted two months and provided information about both direct and indirect competitors of Company A, and their position and sales in the foreign market.

The CEO, one of the company founders and the Project Manager were the main people involved from the company, and they decided which four markets to investigate further. In addition to these, staff with previous foreign market experience participated.

Detailed study: When only four markets remained, a detailed study was performed by Business Sweden and the German-Swedish Chamber of Commerce. This study included economic calculations, making contact with property owners and comparing Company A against potential rivals. Company A's most important products were compared with similar products on the foreign market and this resulted in a price index, which gave Company A an idea of which products the company would be a price leader for. This material was then discussed and compiled, before being presented to the board.

The second phase lasted for about 3 months.

The market analysis phase was performed by the team from Business Sweden and the Project Manager from Company A. Business Sweden performed the actual market analysis. The Project Manager and Business Sweden reported to the operational steering committee.

Viability study: After the market analysis had been carried out, Company A performed an internal viability study, in which the market analysis was analysed. Additional information was also gathered, before making the final decision. According to the Project Manager, Company A needed time to think about the options. Also, the study conducted by Business Sweden was not enough to select a market as Company A also needed to investigate the markets itself in order to get its own impression of the market situation. 
This part took about 5-6 months and was carried out with low intensity.

\section{Decision point 1. Go/no-go decision}

After the market analysis, a go/no-go decision was made by the board. According to the Project Manager, this decision was one of the three most important fix points in the establishment process. The decision initiated the beginning of an implementation phase that included several market entry projects, which are described below.

\section{Implementation}

The implementation encompassed several projects: an IT project, a packaging project, an establishment project, a store build-up project, a recruitment and training of local staff project, a marketing planning and execution project, a product range and pricing project and lastly a store replenishment project.

IT project: The IT project involved the testing and adaptation of IT systems, such as the business system and EPIX. Company A established a new business system to handle different currencies. The most time-consuming adjustments to the business system and EPIX were mainly carried out during the establishment in Norway, and similar adjustments were made for Germany. Also, the website was established and launched at the same time as the stores opened.

The IT Manager was responsible for this project.

The packaging project: The product packaging and product labels were adjusted. Before the expansion into foreign markets, all the text on packaging, instructions and safety instructions were written in Swedish. The use of country-specific packaging was reduced as much as possible for logistical reasons. The product packaging included all languages for all the markets, which enables a product to have one item number for all markets. This resulted in one picking slot per item number in the warehouse, instead of one for each market. Company A decided to have the main heading in English with subheadings in Swedish, Norwegian and German. There is also space for additional languages for future market entries.

The packaging project took place in parallel with the establishment project.

The packaging project was managed by an internal packaging Project Manager from the Marketing department.

The establishment project: The establishment manager identified store locations, contacted property owners and signed store contracts. The contract signing was the second of the three most important fix points as it had a significant impact on the progression of the establishment process. The third and last fix point was when Company A got access to the location and could start the build-up phase.

The establishment manager was responsible for the establishment project and was part of the Sales department.

Store build-up: When the contract was signed for a store location, the construction of a Company A store began. The company has its own construction team that converts department stores into Company A stores according to the specific store concept, including specific walls, colour scheme and lighting. 
Approximately 6-8 weeks before store opening, products were requested in order to build up the store.

The build-up manager was responsible for this project.

Recruitment and training: New store staff were recruited locally and trained by experienced staff, so-called ambassadors, from Company A. These ambassadors transferred routines and work culture to the local staff.

The project took about 3-4 months.

HR was responsible for the recruitment and training of staff. The ambassadors were usually regional managers from an established market.

Marketing planning and execution: In this project, Company A learned how to advertise in the local market by contacting local PR agencies and advertising agencies. For instance, Company A learned how to produce newspaper adverts and how to create marketing events for local journalists and bloggers.

This project was run by the Marketing Manager at Company A, who was one of the members of the steering group for the establishment project.

Product range and pricing: The product range is defined for each market, as minor local adjustments are needed due to regulations. For instance, there can be stricter regulations for a fire alarm in Germany than in Sweden, and therefore the fire alarm need to be adapted to meet the German regulations.

The Business and Product Range Manager was responsible for this project.

Store replenishment: Planning and execution of replenishment for the foreign stores.

The Replenishment Manager was responsible for this project.

\section{Store opening}

As the implementation phase was completed, the first store opened in the foreign market.

\section{Follow-up}

The market performance of Company $\mathrm{A}$ is analysed via continuous evaluations and debriefings. The product range for every season is carefully analysed to adapt it for the local market. This type of analysis is performed continuously for each market for every season. More extensive analyses are performed for new markets, but this process is quite informal.

The follow-up occurs continuously throughout the year.

This project is performed by business controllers from the Control department, which is part of the Business and Product Range department. The controllers perform analyses of sales parameters for each market, and these sales parameters are reported to the top management. 


\section{Company B}

Company $\mathrm{B}$ is a fashion retailer that offers feminine fashion to young women. The company aims to transform trends into commercially viable products and to offer customers a new and exciting shopping experience at an affordable price. According to Company B, fashion should be exciting and fun yet affordable. Company B designs all items in-house and creates complete collections that include everything from the latest fashion trends to the best-selling basics.

Company B was founded in 1997 in Borås. Since the first store opened in Sweden, the company has expanded to Norway in 2007, Finland in 2007, Denmark in 2008 and Germany in 2010. The main sales channel for these markets is physical stores with complementary e-commerce. Company B also has online sales in 23 other countries in Europe. In total, Company B has about 180 stores with 88 stores in Sweden, 38 in Norway, 24 in Finland, 20 in Denmark and 13 in Germany. The Swedish market accounts for half of the company's turnover, while the turnover of the other markets is ranked as follows: (1) Norway, (2) Finland, (3) Denmark and (4) Germany.

During the years of retail internationalisation in the 2000s, Company B was very successful and recorded high profits. However, during the 2010s the company has gone through some tough years, as the global competition has become more apparent due to the company competing against other international fashion companies. In 2017, Company B had net sales of MSEK -0,364. Table 2 below presents the development of the company over the last six years.

Table 2 - Turnover, net sales and number of stores for the period 2012-2017 for Company B

\begin{tabular}{l|llllll} 
& 2017 & 2016 & 2015 & 2014 & 2013 & 2012 \\
Turnover (MSEK) & 1,02 & 958 & 1,19 & 1,64 & 1,63 & 1,80 \\
Net sales (MSEK) & $-0,36$ & -188 & -125 & -20 & -152 & -21 \\
Number of stores & 183 & 185 & 185 & 183 & 181 & 177
\end{tabular}

The company has about 2,000 employees and its headquarters are located in Borås, Sweden. In 2014, the private equity investor Nordic Capital became the majority shareholder of the company. The company has had a new CEO since 2017. The organisation chart for Company B is presented in Figure 6. The management team consists of the CEO, the CFO, the Human Resources (HR) Manager, the Sourcing Manager, the Establishment Manager, the Business and Product Range Manager, the Sales Manager, the Marketing Manager and the Corporate Social Responsibility Manager. Each manager, except for the CEO, is responsible for one department.

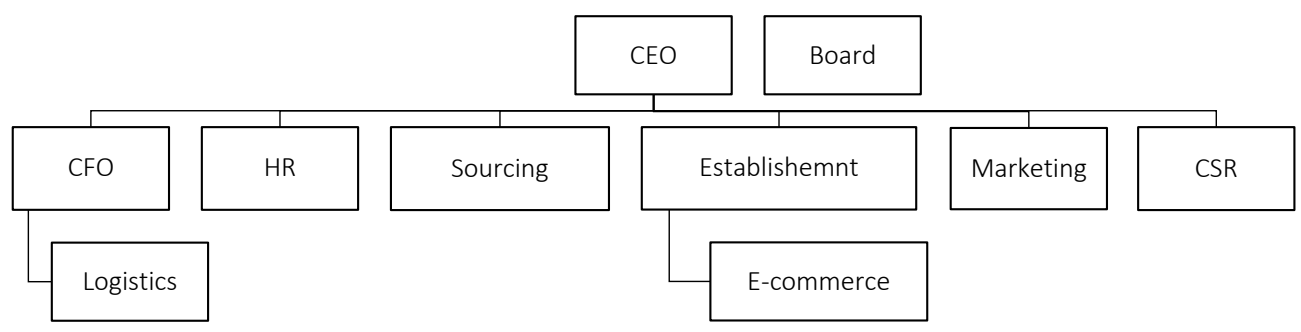

Figure 6 - Organisation chart for Company B 
The main departments presented in the organisation chart are divided into smaller departments. In this study, the Logistics department of Company B is investigated, which is incorporated into the CFO department. In the next section, the Logistics department is further described.

\subsection{Logistics}

The Logistics department encompasses three divisions: Warehousing, Customer Service, and Transport and Customs, which are illustrated in Figure 7. First, the Warehousing division is responsible for the warehouse facility and warehouse operations. Second, Customer Service is responsible for customer service and developing delivery offerings for customers. Third, the Transport and Customs division is responsible for planning and purchasing external transportation of goods from manufacturers in Asia and Europe to the central warehouse, and distribution to stores and end customers.

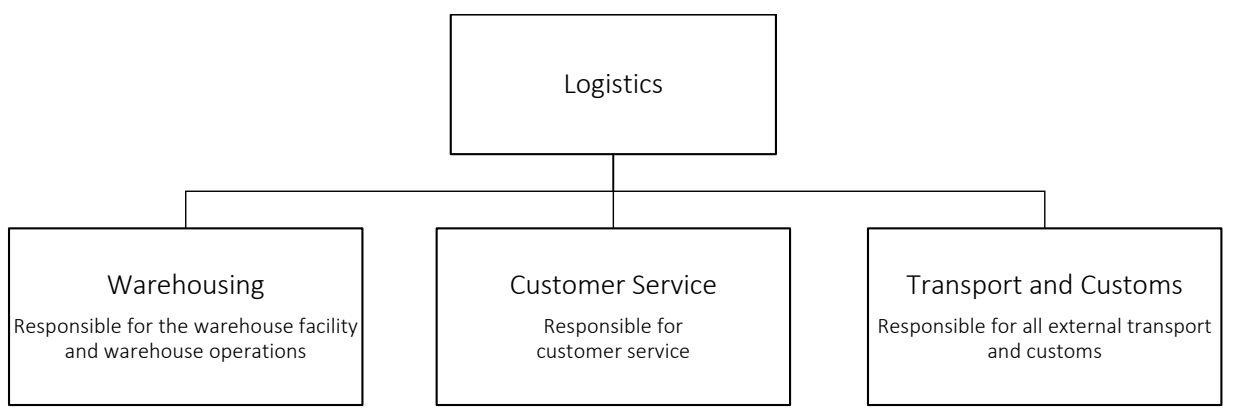

Figure 7 - Organisational chart for the logistics organisation

The Logistics department is managed by the Logistics Manager, who is also responsible for the Warehousing division (i.e. the warehouse facility and warehouse operations) and the Customer Service division. The Transport and Customs division is managed by the Transport and Customs Manager. The Logistics department collaborates with other departments within the company. For instance, the Warehousing division has close interaction with the Sourcing department, which purchases the garments from manufacturers in Europe and Asia. The Logistics department also has close communication with the stores to ensure store restocking.

This study investigates the internationalisation of sales operations into foreign markets. Therefore, the flow of goods closest to the foreign sales operations will be studied, ranging from warehouse to distribution out to stores, as this part of the supply chain changes considerably as retailers expand abroad since the warehouse operations and distribution are directly affected. Therefore, the Warehousing division and the Transport and Customs division are further described below. 


\subsubsection{Warehousing}

The Warehousing division is managed by the Warehousing Manager, who is responsible for the planning and coordination of operations at the central warehouse. Below the Warehousing Manager, there are function managers who are responsible for individual warehouse functions such as goods receipt, returns, e-commerce, wind tunnel, and picking lines. There is also a distribution group that keeps track of different categories of garments that come in and out of the central warehouse.

The Warehousing division encompasses warehouse facilities (i.e. a central warehouse and a duty-free warehouse), warehouse operations and internal transport, which are described below.

\section{Warehouse facilities}

The warehouse facilities encompass a central warehouse in the Borås region in Sweden and a rented duty-free warehouse in Norway. The central warehouse has been operating since 2013 and is managed by the company, which also owns the central warehouse. The central warehouse has an area of $13500 \mathrm{sq} \mathrm{m}$. The location of the central warehouse ensures proximity to all customer markets, as all markets are supplied by the central warehouse in Borås.

The central warehouse is today divided into two parts, one for store goods and one for e-commerce goods. As the company starts to use more single packs (i.e. a package including one item) instead of assortment packs (i.e. package including several items of different sizes), there are plans to merge the two warehouse parts to increase stock flexibility.

"An assortment pack is a bag with twelve garments including the entire size range, two XS, three $S$ and 4 $M$ and so on."

(Logistics Manager)

As Company B expanded into foreign markets in the 2000s, logistics costs rose. To reduce these costs and gain better control of the warehouse operations, Company $\mathrm{B}$ moved the logistics in-house in 2012 and reduced more than half of the logistics costs from MSEK 133 to 59. According to the Logistics Manager, the company waited before carrying out insourcing because of the high profits during 2000s. However, as sales increased, so too did logistics costs and it then become important to take control of logistics costs by bringing logistics in-house.

"As the sales increased, logistics costs increased equally and then we thought logistics was such an important aspect for us so we bave to bave it in-house."

(Logistics Manager)

The Logistics Manager argues that the cost reduction of MSEK 70 comes equally from import improvements, warehouse improvements and staff improvements, as well as distribution improvements.

\section{Warehouse operations}

The warehouse operations feature standardised operations for all markets. About 30 employees work at the central warehouse in one shift. The warehouse organisation consists of staff hired by the company itself. The Logistics Manager mentions that the logistics organisation 
has a policy of not hiring staff from staffing agencies, as the Logistics Manager argues that hiring its own staff increases the quality and the service level in the warehouse operations.

The picking staff uses hand-held terminals, where goods are picked by category into separate boxes for each store.

"We have separate jeans boxes, separate tricot boxes and so on by category."

(Logistics Manager)

There are weekly forecasts of the volumes of goods that need to be distributed to the stores for the upcoming week. The picking flow for the stores tends to vary, while the picking flow for e-commerce is considered to be constant.

"The problem for us is that the volumes vary a lot. So, one day there might one box to a store or two. Then the volumes become too small to split up."

(Logistics Manager)

The store goods for the next season are received about 3-4 weeks before the actual season starts. The picking staff pick for one store at a time, and packages are placed on pallets for a specific store. As long as Company B keeps the packages together country by country, PostNord manages the consolidation of packages for a specific store.

"So, there can be 4-5 flows to a store from the warehouse. However, this is not something that we need to keep together as long as we keep everything together country by country. PostNord deals with the actual consolidation for the last mile."

(Logistics Manager)

Company B delivers assortment packs to all stores, while for e-commerce single packages are used. For the first store replenishment, $70 \%$ of the assortment packs are used and the last $30 \%$ are used for the second replenishment.

Company B sources goods from Europe (Turkey and Italy) and Asia (Bangladesh, Pakistan, India and China). In a more uncertain market situation with varying customer demand, the company relies on nearby sourcing countries because of shorter lead times which make it possible to postpone decision-making.

From the sourcing countries, the goods are transported to the central warehouse. The goods come in boxes of assortment packages. The goods are unpacked in the same order as they are packed in the boxes and are placed on hangers. After every assortment package an orange marker is placed. Then, the goods go on to the wind tunnel, where the goods follow a track through the wind tunnel in which garments are polished and prepared before store distribution. The wind tunnel has a maximum capacity of 35,000 garments per week. The sourcing department plans a schedule, week by week, for which garments should go through the wind tunnel. The Logistics division acts as a gate keeper as the division inspects the garments before the wind tunnel and if garments do not need polishing, the logistics organisation contacts the sourcing department and reschedules. After the wind tunnel, the goods are packed into plastic bags and into assortment packages again. For distribution to the stores, specially made boxes are used in which the garments are placed on hangers within the boxes to avoid becoming wrinkled. 
The company uses standardised labels (including laundry instructions and content description) for all goods and markets. The labels are written in Swedish, Finnish, Danish and German, where the company has physical stores, and also in English for e-commerce within the EU. The standardisation of labels simplifies the warehouse operations as goods can be distributed to all markets.

For newly established stores, the warehouse operations are the same as for other stores, expect that the packages to be sent to a new store are labelled with a "new" sign and are usually put aside until the store is ready for its first delivery. Fifteen weeks before the opening of a new store, the logistics department needs to be informed to be able to prepare the goods in time. The picking of garments is done continuously until the last week. One week before the actual store opening, the goods are delivered to the new store for store build-up.

"In order for there to be a full product range at the store opening, we need to start picking in the warehouse 15 weeks before."

(Logistics Manager)

\section{Key figures}

The logistics department uses various key figures for both inbound and outbound flows. One of the main key figures is PostNord's delivery precision. This key figure is an external measurement but it is very important, because PostNord is responsible for the store delivery and delivery to 2,000 e-customers annually. The logistics organisation also uses key figures for the warehouse operations. For example, the Logistics division measures the costs for different warehouse operations such as the cost of blowing a garment in the wind tunnel. Labour-related key figures are also measured such as the picking rate for e-goods and store goods, as well as delivery reliability in the warehouse operations.

\section{IT systems}

The logistics organisation has a number of IT systems. The logistics organisation uses a warehouse system and an ERP system, both of which process purchase orders and sales orders in the warehouse operations.

"We work with our logistics and the warehouse operations in our ERP system."

(Logistics Manager)

The ERP system is connected to the business system IFS, which sends orders to the ERP system, which in turn enables the Logistics division to process the incoming orders.

"IFS sends our files including purchase orders and sales orders. Thereafter we pick."

(Logistics Manager)

The ERP system was developed to use real time updates, so as goods are picked in the warehouse, the stock balance goes down accordingly and the WMS system detects and confirms the actual stock balance in real time. Real time updates were not previously possible, but the implementation of the new ERP system has led to increased efficiency and quality in the picking lines. 
"We have achieved efficiency but above all quality."

(Logistics Manager)

\section{Customer Service}

The Customer Service division is managed by the Logistics Manager, who is responsible for customer service and developing delivery offerings. The Logistics Manager is passionate about developing delivery offerings and making logistics a sales pitch. For instance, if Swedish customers order their products before a certain time of day, the company delivers the products the following day.

"Write: Order before 16:00, get it tomorrow. That is a better selling pitch."

(Logistics Manager)

The Logistics Manager argues that it is not so efficient to deliver small orders, but wants the Logistics division to promote sales as much as possible.

"Is it efficient for us to send out several orders until 16:00? No. We could have been more efficient if we sent them in one single delivery, but I want to sell more and I want the company to be successful.

Therefore, we explore how logistics can contribute."

(Logistics Manager)

The Logistics division also processes orders on Sundays to even out the workload during the week, which according to the Logistics Manager is also a good way to create an attractive offering.

"By processing the order on the Sunday, we increase the workload that day and decrease the workload during the week, while also creating an attractive offering for customers."

(Logistics Manager)

The company also offers customers the option to return products purchased from its online store to a physical store.

\section{Transport and Customs}

The Transport and Customs Manager is responsible for all transport and customs relating to goods sent to and from the central warehouse. For store delivery, Company B prefers to use local distributors. For example, Company B uses PostNord in Sweden, Post in Finland, Bring in Norway, PostNord in Denmark and DHL in Germany. FedEx is used for delivery of e-goods to the rest of the EU. Previously, PostNord was used for distribution to all markets, which for instance worked well in Sweden but not in Germany. One example was when PostNord delivered goods to Germany and did not work together well with PostNord's partner in Germany, which exposed Company B to severe problems as there were several days when the German stores were not receiving deliveries on time. Due to this experience, the company hires only local distributors for the foreign markets.

"It was a catastrophe and there were several days where our stores did not get their deliveries and there were goods missing."

(Logistics Manager) 
The company delivers to all stores every weekday, thus five times a week.

"All stores get a delivery every day."

(Logistics Manager)

There is however discussion on differentiating the frequency of store delivery based on demand. For example, smaller stores have less demand and revenue than larger stores and therefore might not need deliveries every day.

"But of course, we have started to discuss, I mean there is a large difference in revenue between the store at the Mall of Scandinavia and the store in Löddeköpinge. We have decreased costs all the time, but what is the next step. And then we might ask, should Löddeköpinge have deliveries five times a week? Is that essential? At the same time, it might be easier for the staff management if we say: No, you get delivery two times a week instead. And for the Mall of Scandinavia, five times a week might not be enough, and six or seven times might be needed. We have to learn how to differentiate size and revenue."

(Logistics Manager)

According to the Logistics Manager, this question of differentiating store delivery is becoming more relevant and in the next stage of reducing logistics costs, this question will be investigated further.

"We have reduced costs continuously, but this will be the next step... We have to learn to differentiate size and sales."

(Logistics Manager)

The garments are not bulky and a truck filled with garments can easily fill an entire store. All transport costs are package-based, so the company pays for each package regardless of size. Previously, the suppliers and the logistics organisation delivered all assortment packs in separate boxes to the stores. However, small garments resulted in a large number of very small boxes, which were inconvenient for both loading and sorting. Instead, Company B decided to transport the goods in larger industry-specific standard boxes where packages are packed together with other packages, and these are used for both inbound and outbound deliveries.

"We have changed the delivery packaging from small boxes to larger standardized boxes."

(Logistics Manager)

The change in delivery packaging resulted in increased labour for the picking staff but reduced the number of packages delivered to the stores from 3,000 to 800, which simplified unloading and sorting operations in the stores. Overall, the total transportation cost decreased as the number of packages decreased.

"So, we have gone from an average of 25-30 filled boxes to the stores, down to an average of 7-8 boxes, but kept the same cost per package from PostNord."

(Logistics Manager) 
Norway is not a member of the EU and therefore the distribution to the Norwegian stores goes through customs. The distribution goes first to Norway where Bring delivers to the stores. Bring also helps the Logistics division with customs declarations, which are sent to the logistics organisation. The customs process is not considered to be time-consuming and does not have a significant effect on the lead time from warehouse to store. Company B has established a duty-free warehouse in Norway, which means that returns from ecommerce are handled by a Norwegian store, instead of being shipped back to the central warehouse. According to the Logistics Manager, it is too complicated to transport the Norwegian goods back to Sweden.

\subsubsection{The role of the Logistics division}

The Logistics division adapts to conditions set by the top management and works to reduce logistics costs. The logistics organisation informs the top management about the logistics capacity and the costs of current operations and alternative operations. The Logistics division examines logistics-related issues to make the delivery of goods as good as possible, and the division receives a lot of feedback from the stores if something is not working. The Logistics division also collaborates with other departments to reduce logistics costs. The increase in single packs instead of assortment packs is a good example of communication with other company functions. Before the transition, only assortment packs were delivered to stores, which caused a surplus of some sizes which were not in demand and were hard to sell. The Logistics Manager argues that it is not right to restock with assortment packs if only one specific size is missing. Therefore, the Logistics division communicated to the Sourcing department that assortment packages should only be bought for the initial stocking of the stores, and separate size packages should be bought for restocking.

"From now on, Company B will start to work in a different way. Until now, we have worked with assortment packages, which is right for the first replenishment to a store for offer the entire size range. The sourcing department has bought 100\% assortment packages and later kept 30\% for the second restocking. However, it is not right to restock with an assortment package if only one size is missing."

(Logistics Manager)

The change in packages has resulted in a higher picking intensity, as instead of picking ten garments at once, each garment will be picked separately for restocking the stores. However, the Logistics Manager argues that this change is necessary despite the increase in logistics costs. The Logistics Manager says that both the logistics organisation and the Sourcing department have agreed that this change in packages is needed and the change has been on the agenda for a long time. However, due to a change in management the implementation has been postponed for many years.

"Everyone has agreed on this."

(Logistics Manager)

The company was recently nominated for the PostNord Logistics Award, which is a prize to acknowledge and reward successful logistics solutions. The company was nominated for taking a holistic approach to its logistics operations and for achieving great positive effects 
in terms of lower logistics costs and reduced environmental impact in a short period of time, while also increasing the service level.

\subsection{Retail internationalisation}

The company has expanded internationally for the last eleven years, starting with Norway and Finland in 2007, Denmark in 2008 and Germany in 2010, where the company first established physical stores followed by e-commerce. Since 2012, Company B has also operated e-commerce in an additional 23 countries in Europe. The company entered these markets to achieve further growth. All market entries have been initiated by the CEO.

The establishments into foreign markets were made during a period of extreme success in the 2000s. The expansion into new foreign markets during the 2010s has been put on hold due to a low growth rate, and Company B has instead focused on expanding further in existing markets.

\subsubsection{International strategy}

The international strategy is developed by the board of Company B, which makes the strategic decisions concerning the internationalisation of the company. The international strategy is to keep a standardised business concept that centres around the three key ambitions: standardised product range, centralised store network with complementary ecommerce, and central control of foreign operations. Figure 8 below visualises the key ambitions in the international strategy, and these are described further in the following sections.

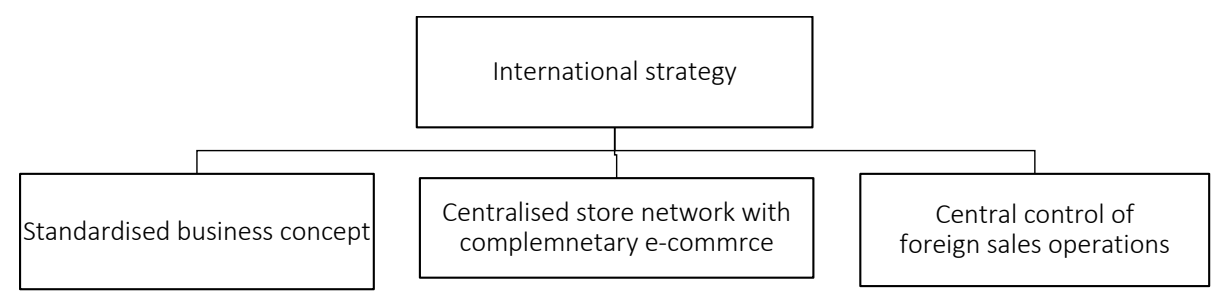

Figure 8 - Key ambitions in the international strategy of Company B

The company uses a standardised business concept for all markets that is based on the Swedish customer. The company only sells its own-designed clothing. The Establishment Manager considers the company offering to be global in the same way as H\&M and Inditex, and argues that the company's products are viable in different markets without extensive market adjustments. According to the Establishment Manager, the international media flow (e.g. fashion and pop culture) trends have become relatively homogenous, especially in Western countries, which allows for a standardised product range.

"It is a Swedish company with a Swedish focus. However, with today's fashion scene and especially the international fashion scene... the big product mass should have such an international impression that it can handle all markets. Otherwise, H\&M, Zara, Mango and VeroModa would not make it."

(Establishment Manager) 
Company B makes some adjustments to its product range to adapt to major international trends and international phenomena such as Black Friday and Christmas, which are the same for all markets. Also, time adjustments have been made to better meet the customer demand for specific markets. For example, in Norway there is a higher demand for white dresses in April in connection with confirmations, instead of May or June in connection with school graduations as in Sweden. In order to take advantage of a major sales opportunity, the sale of white dresses starts earlier in Norway. There are discussions within Company $\mathrm{B}$ about making more local adaptations. In particular, the country managers for the different foreign markets believe there is a need for more customisation according to the local market.

"Country adaptations are an ongoing discussion, as the country managers are never satisfied and always or often think that it is too Swedish."

(Establishment Manager)

However, the country managers have little decision-making power over individual stores and local product ranges as the Marketing department decides on the overall sale offering.

As Company B expands into foreign markets, the company aims to keep its store network centralised to a specific region in the new market before expanding further. Also, the company establishes itself in regions that have similar customers to Sweden. For instance, for the establishment in Germany, the company is still concentrated in the western part of the country as it is more like Sweden.

"Before, the CEO and I used to visit the potential markets and investigate the market and the style of the women on the spot. From these visits, the CEO and I got an idea of the potential foreign market and if the concept could work."

(Establishment Manager)

The business concept of Company B is based on physical stores located in larger cities with complementary e-commerce. For the company to establish in a new foreign market, the Establishment Manager argues that it is necessary to establish physical stores, as the company has a pronounced business concept that centres around attractive stores, where the majority of sales take place in the physical stores. Company B is discovered via its physical stores and its e-commerce provides additional services and works as a marketing platform for the company. At same time, the Establishment Manager believes that physical stores are the main sales channel, arguing that Company B will expand via e-commerce portals such as Zalando, Brandos or Amazon, as e-commerce finds new markets faster than physical stores. However, the competition between different e-commerce companies is fierce today, as there are a number of well-established e-commerce companies in the fashion industry, such as Boost, Zalando and Asos. Company B has discovered the impact of the internet due to bloggers who compare different brands in terms of quality and price. This exposure can lead to massive accessibility to many new customers with very little advertisement by the company. The Establishment Manager describes this new form of establishment as unattainable as it has a force of its own. 
The Establishment Manager argues that it is important to enter a market with physical stores, as potential customers do not discover Company B through e-commerce if no market-specific adaptations (e.g. language) are made.

"It is not like people discover the company because there is e-commerce for the Czech Republic. It is not like that. That approach does not work, because in that case you need to make an adjustment, for example in terms of language, so people truly feel that this really is a brand that likes the Czech Republic."

(Establishment Manager)

"It is very important for the customers, who want to feel that this is a brand that wants to be with us."

(Establishment Manager)

For the establishment in Norway, Finland and Denmark, the stores were established before the e-commerce. For the German market entry, stores and e-commerce were established in parallel with the opening of the first store. The company started its first e-commerce in 2009 and since 2012 has had shared e-commerce for 23 European countries. Language adaptations for e-commerce have been made for the markets with physical stores, while the shared e-commerce for the rest of Europe is in English.

All retail internationalisation decisions are made at a centralised level by the board at HQ. All markets are managed by local country managers, and below them are local regional managers and lastly individual store managers. The Establishment Manager says that these managers are solely responsible for the store operations and have no strategic mandate in the retail internationalisation. The establishment manager has overall knowledge of the development of sales areas and makes sure that new stores are opened in attractive areas.

The company has Swedish country managers for all markets, who report back to headquarters. The Establishment Manager mentions that there are ongoing discussions about the management of the local markets and the advantages and the downsides of having Swedish country managers versus local company managers, who have extensive market knowledge.

For the Danish and German market entries, the company hired local country managers with a strategic mandate, who were not managed by the top management. The company believed that the Danish and German markets were difficult to penetrate and were advised to hire local country managers. Unlike the previous market entries, the Expansion Manager only acted as an adviser in the market entries for Denmark and Germany. For the other market entries, the Expansion Manager was in charge.

"We must have someone from the country, someone who knows Denmark."

(Establishment Manager)

The company believed that a local manager who knew the local market from the inside was needed to succeed. However, the local country managers caused problems and within two years these managers had been replaced. 
"Everyone warned us about how hard Denmark was, that we needed a Dane... Then we hired one, and it was a catastrophe like no other."

(Establishment Manager)

Both the Danish and the German country managers have shown identical behaviour and made the same mistakes.

"Both the Danish and German country managers had the same behaviour and made the same mistakes in our opinion."

(Establishment Manager)

According the Establishment Manager, the country managers have not wanted to implement their market knowledge within the company and have not been interested in getting to know the company brand. Instead, they have relied on previous experience with other companies that has not suited Company B. The country managers have lacked an understanding of the brand and the spirit of the company.

"Their knowledge about the country, about the locations, rent and staff, that is country knowledge, they have not been interested at all in implementing what this company stands for."

(Establishment Manager)

"They have been the same and I do not know if it is a personality trait that we searched for before, but the German country manager, he was not at all interested in being here and getting to know how the product range worked and travelling with me."

(Establishment Manager)

The Establishment Manager does not know if the establishments in Germany and Denmark would have gone better if the company had hired Swedish country managers from the start. The local German country manager did a good job at finding good locations, but had no desire to learn about the company, which was his downfall and the reason why he is no longer with the company.

"This is a relatively young company that has not had a specific organisational structure, where you have different levels of hierarchy. We are very much 'bands on' and there has been a lot of gut feeling."

(Establishment Manager)

Today, Company B has no country managers with a strategic mandate in the foreign markets. Instead, the company has retail country managers who are only responsible for the local store operations.

\subsubsection{The role of logistics in the retail internationalisation}

The internationalisation has resulted in some adaptations to the logistics operations. In 2012, Company B decided to establish its own in-house logistics organisation instead of using a 3PL provider. The reason for this change was to gain better control over logistics costs as these had increased considerably during the major expansion in 2007-2008. As sales increased so too did logistics costs, and it became important for the company to bring the logistics in-house. 
"As sales increased, logistics costs increased and then it was thought that logistics was such an important aspect for us, so we had to have it in-house."

(Logistics Manager)

Today, the Logistics Manager estimates that logistics costs account for 2-3\% of the turnover of the company. At the end of 2013 and the beginning of 2014, the company started its in-house logistics and this transition resulted in a $50 \%$ reduction in logistics cost in the first year. The Logistics Manager believes that Company B waited to bring logistics in-house because during the major expansion period the company had high profits (MSEK 300-400 each year) and did not pay much attention to logistics costs. During that time, logistics was not as much of a key question as it is today. According to the Logistics Manager, during the period of outsourced logistics, the company probably lacked logistics competence and because of the fast expansion into foreign markets the logistics just had to work. During the major expansion period, Company B came up with new customer requirements and the $3 \mathrm{PL}$ provider delivered according to new requirements. For the company, it was very important that the logistics worked and that the 3PL provider could meet the new requirements fast. There was very little focus on logistics costs at that time.

"It is just like: 'fix this', 'no matter what the cost', 'it has to go fast!"'

(Logistics Manager)

Today, logistics is one of the main key success factors for Company B. According to the Logistics Manager, logistics is important from a sales perspective as it can work as a sales pitch, where the customer is offered fast delivery.

As mentioned earlier, for the past establishments into foreign markets logistics were not in-house and logistics costs were not an important cost item. According to the Logistics Manager, the Logistics department will have a more prominent role in the next market entry, as the department will make assessments of logistics aspects in the expansion into foreign markets. However, it is believed that logistics will not have a crucial role in the choice of market.

"There is no way that we would not question the logistics cost and perform in the most cost-effective manner, and I would probably be given an assignment from the CEO and management to investigate how it would be performed in the best way for the next market."

(Logistics Manager)

The central warehouse in Borås is located close to the present markets. However, if the company were to expand further in Germany and neighbouring countries, the Logistics Manager says that there might be a need to establish another warehouse closer to those markets to have shorter lead times to those markets.

"But now when we have not had that increase in turnover in Germany, we have not encountered this problem."

(Logistics Manager) 
When establishing new stores, logistics costs are taken into account to ensure cost-efficient logistics. According to the Logistics Manager, the Logistics department has the capacity to allow retail internationalisation into new countries. The central warehouse has the capacity to manage a huge expansion.

"Actually, we have facilities that are too large so we have the capacity to double our sales without any problems."

(Logistics Manager)

"The warehouse is also customised for twice as many employees."

(Logistics Manager)

"Of course, we also have the capacity to expand quite quickly."

(Logistics Manager)

However, establishment activities such as store location have little to do with logistics, and more to do with marketing. In Sweden, as well as in other countries, Company B does not need to actively search for store locations. Instead, the property owners make contact with the company. The company investigates which other retail stores will be present in the area, as Company B often has a positive mindset if other competitors are located nearby. The Establishment Manager argues that, in the establishment into foreign markets, there is good collaboration and discussion with other retailers and competitors. It is not until the actual store opening that the companies start to compete with each other.

The Logistics Manager describes the logistics organisation as being very good at problemsolving. When a problem occurs, the organisation investigates the problem thoroughly. The Logistics Manager mentions a previous problem concerning the distribution with PostNord in Denmark, as there were inexplicably long waiting times for the goods passing through Denmark. The logistics organisation carried out an investigation of the problem and went to PostNord in Denmark. It was found that the Danish organisation was not to blame and that the problem was actually located in Malmö instead. It was discovered that the goods were scanned by hand and placed on pallets in Malmö, which was the reason for the delays. Having identified the problem, the logistics organisation asked PostNord to change the route and carry out this activity in Denmark where the process was more time-efficient. Since the change, the flow has been flawless.

The logistics organisation also gets feedback from the stores and if something is not working in terms of logistics. According to the Logistics Manager, it is logistics' role to ensure that store replenishment is effective.

"We always ask for and get a lot feedback from our stores if something is not working, and then it is our role. If PostNord does not work we replace them. Nothing is sacred that way."

(Logistics Manager)

Logistics also carried out time adaptations for the local market if requested. For instance, if a specific market requests earlier delivery of a clothing collection, the logistics organisation can arrange earlier deliveries. Moreover, the company uses standardised labels (i.e. laundry instructions and content descriptions) for all goods. The labels include all 
languages where Company B has physical stores, as well as English for e-commerce in the EU. This standardisation of goods for all markets simplifies the logistics, as all goods can be distributed and sold to all markets.

\subsubsection{Establishment process into foreign markets}

The main motivation for internationalisation has been growth. Previous market entries have been initiated by the CEO, who has determined which foreign market to investigate. The CEO has extensive market knowledge and previous working experience from several of the foreign markets (i.e. Finland, Denmark and Germany) that the company is present in.

During all establishments, the company has hired a minimum of external actors, with the exception of lawyers and advisors from informal networks. The lawyers' involvement concerned the legal aspects in connection with contract writing. (The rental terms in the different countries vary considerably, and the legal documents need to be translated professionally.) For more support, external advisors from informal networks have been used. For example, before the establishment in Norway, the CEO contacted some old retail acquaintances with business experience from the Norwegian market.

The company strives to create networks with other companies, and the CEO has not hesitated to speak to his contacts and wants open communication. The company shares its own experiences with other retailers, and according to the Establishment Manager, the network has developed and become stronger and the companies in the network have followed each other's development.

"He [the CEO] has always had contact with different brands, and has not hesitated to ask or to be open. So, you could say that the company is one of the first, with me as heir, to have been more active in creating contacts and gaining information that way. Today it is very well-established to work in that way as commerce is very dependent on commerce. We need to know where we stand with each other."

(Establishment Manager)

The Establishment Manager has recognised the market selection as one of the two most important decisions in the foreign establishment process, aside from the final market decision (i.e. go/no-go decision). The market selection depends mainly on two aspects: the potential profitability of the market and image.

"Germany is such an 'image' market, where it is important to be seen, as is continental Europe with large volumes, a lot of people. It is not the cheapest in any way, despite the low salaries. It is associated with a lot of marketing, and high rents, but with enormous market potential eventually."

(Establishment Manager)

"In Germany it is about large volumes in order to penetrate on a large scale."

(Establishment Manager)

The market selection is influenced by consultants and networks that the company has with other retailers. The company has many informal connections that have influenced the market selection. For instance, in the market selection between Germany and Netherlands, the company chose Germany as the market manager knew an individual from H\&M, who had experience of the German market. Company B hired the individual as a consultant for 
the German project. Moreover, the company has dialogue with other Swedish retailers such as Kappahl, Lindex and Stadium.

According to the Establishment Manager, e-commerce and the transparency between the different markets simplify entering new markets. The development of e-commerce via existing e-commerce portals (e.g. Zalando and Asos) is seen as a new business area. In the development of this kind of e-commerce, there is a balance between which products should be sold via the e-commerce portals and what should be sold via the company's own ecommerce website.

Since the last foreign market entry into Germany, the company has changed from being a family-own company to being part of the large group Nordic Capital. The change of management is expected to affect the company's approach towards future market entries. The Establishment Manager believes that decision-making in connection with entering a new market will take much longer, as decisions are taken in several stages and at several different hierarchy levels and will also involve more people, which will increase the complexity of the market entry process. Nordic Capital will set a new framework for how establishments should proceed and Company B will therefore not use the same establishment process as for previous establishments. The Establishment Manager believes that future market entry decisions will include more preparatory work in terms of more detailed calculations. Previous market establishments were based on only a few calculations and the gut-feeling of the CEO. The previous ownership and organisational structure allowed a more hands-on approach with less time-consuming calculations, which led to more rapid retail internationalisation.

In this study, the previous establishment into foreign markets are further investigated as the change of ownership occurred after the last establishment to Germany.

Establishments into new foreign markets is initiated by the board. An establishment team responsible for the establishment project abroad usually included the CEO and the Establishment Manager, who have been the key staff for all establishment into foreign markets. For the market entry into Germany, the CFO and the Marketing Manager were also included in the establishment team.

Moreover, several departments are involved in the establishment into foreign markets. For instance, the Establishment department builds up new stores; the Logistics department manages the flow of goods from manufacturers to company stores; and the HR department recruits new staff for each market. The key staff in the establishment process are described in further detail later on in this chapter.

In this study, the establishment process is defined as the process starting from the first market entry initiative to an operating store(s) that has been opened for at least a year. Figure 9 visualises Company B's general establishment processes for a new foreign market, including projects, important decision points and key staff. The establishment process includes the establishment of both physical stores and e-commerce. The establishment process lasts between 8 and 24 months, due to varying conditions for each market entry. For instance, store establishment takes longer for new store locations than existing store locations. The establishment process is divided into three phases: market analysis, implementation and follow-up, which in turn encompasses several projects. 


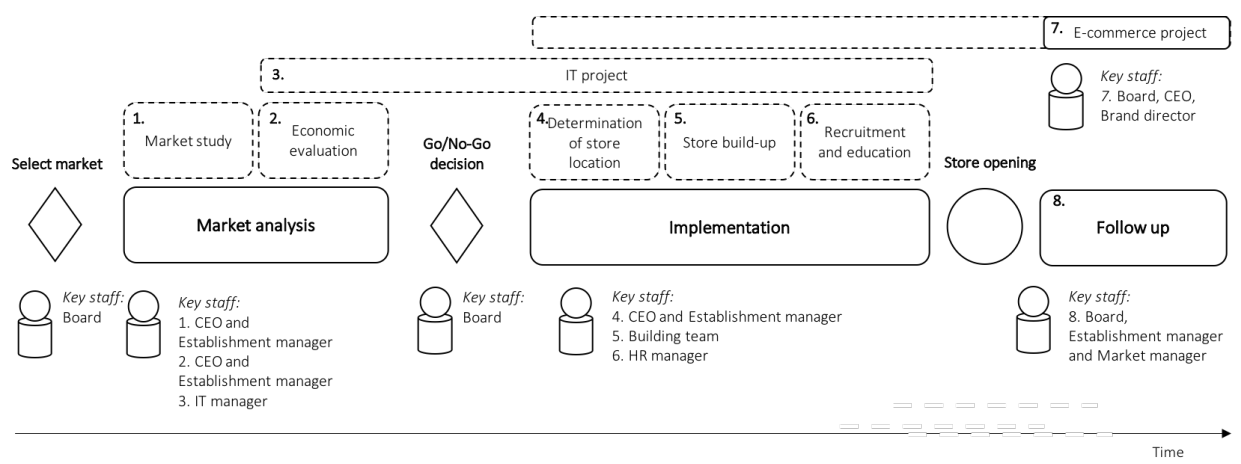

Figure 9 - Establishment process for Company B

In the following sections, the establishment process is described including projects, important decision points and key staff.

\section{Decision point 1. Select potential market}

Establishment in a new market begins with a market selection. The selected market is thereafter investigated in an analysis of the individual market.

This preliminary market decision is made by the board.

\section{Market analysis}

The first phase of the market entry is a market analysis including a market study and an economic evaluation, which are described in the following sections.

Market study: In the market study, the market is investigated to assess the market potential. The potential market is analysed directly in situ. Factors such as demographics, potential locations and customer behaviour are investigated to gain an overall sense of the market. Thereafter, the company makes contact with individuals and retailers to obtain additional market information.

The market study is carried out by the CEO and the Establishment Manager.

Economic evaluation: In the economic evaluation, an economic assessment of the potential market is made. The complete economic assessment is presented and discussed at board meetings and in other forums within the company, before the board makes a final decision to enter the foreign market.

The economic evaluation is carried out by the $\mathrm{CEO}$ and the Establishment Manager.

IT project: IT adaptations for the new market start during this step, as IT systems are closely interlinked to the pricing of products that need to be considered in the economic assessment. IT adaptation continues in parallel with the other steps until store opening.

The IT Manager is responsible for this project.

\section{Decision point 2. Go/no-go decision}

A final decision is made by the board, based on information from the market analysis and the calculation sheet. If the decision is 'Go', the establishment process continues to the next phase. 


\section{Implementation}

The second phase in the market entry was an implementation phase including identification of store location and store build-up, which are described in the following sections.

Identification of store location: In this project, store locations are identified and agreements are signed. As the board has decided to enter the market, Company B contacts property owners in order to find and sign agreements for store locations. In the market analysis phase, Company B has contacted property owners to find potential store locations. After the 'Go' decision, Company B contacts the property owners again and signs leases for these locations. Thereafter, the store build-up starts.

The $\mathrm{CEO}$ and the Establishment Manager have been in contact with local property owners.

Store build-up: The store build-up, involves stores being built based on Company B's store concept. The duration of the project depends on the construction phase during which Company $\mathrm{B}$ enters, as the time for rebuilding a store varies depending on the specific location. A store build-up for a new store is often more time consuming than rebuilding an existing store location.

The store build-up is carried out by an in-house construction team, which includes an architect and a Project Manager. The construction team collaborate with contractors.

Recruitment and training: After the store build-up, staff are recruited locally. The recruitment is carried out by the HR department at HQ. A training team helps staff in the new stores to create a good working culture and routines based on Swedish operations. Usually, the training team includes an experienced region manager from another market. For example, a Swedish region manager was in place for the establishment in Norway, while a Norwegian region manager was in place for the establishment in Denmark.

The HR Manager is responsible for this project.

\section{Store opening}

In this phase, the first store opens. The establishment team hands over responsibility for the foreign market to an operational manager from the Marketing department, who is in charge of sales and store operations.

\section{E-commerce project}

Establishing e-commerce in a new foreign market is a prioritised project that includes various company resources, IT and external resources, and is separate from the store establishment. IT and external parties play a major part in the implementation of the ecommerce platform, while internal resources focus on gathering the necessary contracts ranging from transporters to payment suppliers, as well as internal operations such as customer service and translations. The establishment of e-commerce can be seen as a parallel implementation phase in line with the store implementation. Market analyses are carried out before the establishment of e-commerce. For previous establishments, this been implemented after the establishment of physical stores.

The e-commerce platform was first established in 2008 in Sweden, Norway, Finland and Denmark, and was mainly used as an additional marketing channel that was established 
after the store opening. For the market entry into Germany in 2010, e-commerce was established a few months before the actual store opening and at that point Germany had already been selected. In 2012, Company B opened additional e-commerce operations for the EU.

The board has driven the strategic question of e-commerce establishments together with the CEO. The Brand Director is responsible for the establishment of e-commerce.

\section{Follow-up}

After the store opening, the top management monitors the sales of all markets on a daily basis and the operational manager reports to HQ. However, no formal evaluation of the new market is included in the establishment process. An establishment meeting is held monthly, where store sales are discussed by the Establishment Manager and the board. The Marketing department has a responsibility to analyse the market situation in order to provide an explanation for problems that are raised during the meeting.

"Sales are reported daily. However, there is no formal reconciliation, but we have an establishment meeting once a month, where I speak with the country managers on the phone. Also, I have an establishment meeting with the board once a month and then we go through the revenues of different stores and if something has happened."

\section{(Establishment Manager)}

During the establishment meetings, the individual stores and possible future expansion are investigated. There are frequent follow-ups, but there is no formal follow-up of the establishment process in a new country. It is the Marketing department that is responsible for investigating store sales figures and what these sales figures depend on. 


\section{Company $\mathrm{C}$}

Company $\mathrm{C}$ is a hobby retailer that offers hobby materials to private customers in Europe. The company targets consumers of different ages, both women and men as well as amateurs and professionals, and offers a wide range of materials, tools and DIY kits.

In the mid 1950s, Company $C$ was founded in Denmark. For the first 30 years, the company was mainly a mail-order company. However, in the 1980s, Company C started to expand by opening physical stores. Company $\mathrm{C}$ has further expanded through the acquisition of a Dutch hobby company in 2011 and a Swedish hobby company in 2016. Company C has three sales channels including physical stores, online stores and wholesale for other retailers. Physical stores are the main sales channel, while online stores account for $10 \%$ and wholesale for $15 \%$ of total sales. Today, Company $\mathrm{C}$ has over 100 stores in six countries, online stores in the EU and 250 wholesale stores in Scandinavia.

Since the opening of the first store in 1954, the company has opened stores in Sweden in 1962, Norway in 1986, Germany in 2015, and the Netherlands and Belgium in 2011. Company C has over 100 stores and about 38 stores in Sweden, 19 in Norway, 18 in Denmark, three in Germany, and 25 in the Netherlands and Belgium. Company C first launched its e-commerce operations in Scandinavia in the late 1990s, and has since expanded its e-commerce to the entire EU. The company has an ambition to increase its online sales further in the future, as extensive resources have been used to develop a more attractive e-commerce experience. In 2017, an improved website was launched.

Furthermore, Company $\mathrm{C}$ is planning to expand more in Germany as well as entering new markets, such as Switzerland and Austria. In 2017, Company C had net sales of MSEK 2. In Table 3, turnover, net sales and the number of stores for the last six years are presented.

Table 3 - Turnover, net sales and number of stores for the period 2012-2017 for Company C

\begin{tabular}{|l|l|l|l|l|l|l|} 
& 2017 & 2016 & 2015 & 2014 & 2013 & 2012 \\
\hline Turnover (MSEK) & 830 & 824 & 847 & 604 & 775 & 794 \\
\hline Net sales (MSEK) & 2 & 13 & 12 & 63 & 2 & 26 \\
Number of stores & 103 & 131 & 134 & 136 & - & - \\
\hline
\end{tabular}

Company C has about 600 employees and its headquarters are located in Malmö (2018). The company is managed by the CEO together with the board. The two founders are still active in the company as shareholders, and two sons of one of the founders work as Marketing Manager and Establishment Manager. In Figure 10, the organisation chart for the company is presented. The management team consists of the CEO, the Retail Scandinavia Design Manager, the Marketing Manager, the Digital Channel Manager, the Product Range Manager, the Human Resources Manager, the Retail Manager, the CFO, the Supply Chain Manager and the Concept/Establishment Manager. Each manager, apart from the CEO, is responsible for one department. 


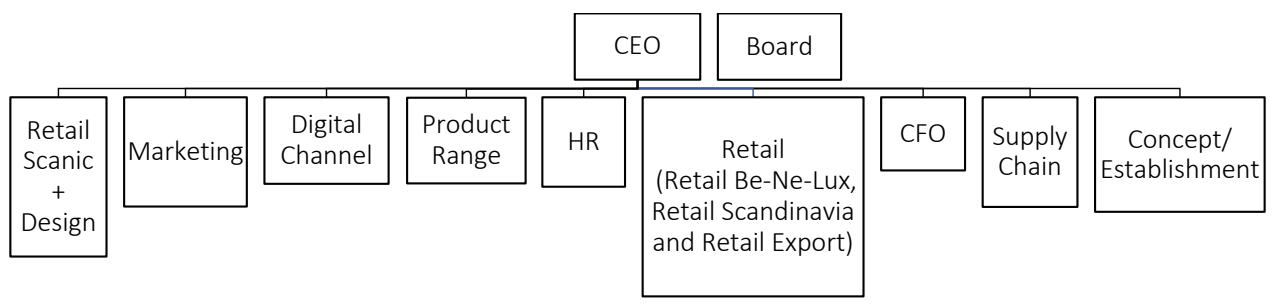

Figure 10 - Organisation chart for Company C

The main departments of Company $\mathrm{C}$ are presented in the organisational chart above, and these departments are divided into smaller divisions and functions. In the next section, the overall Supply Chain division is described. Thereafter, the Deliver function is investigated, which is part of the Supply Chain division.

\subsection{Supply Chain}

The Supply Chain division is located at the headquarters and encompasses four functions. First, the Plan function is responsible for product planning including store restocking and campaign planning. Second, the Buy function is responsible for purchasing goods from manufacturers in Asia and Europe. Third, the Make function is responsible for the assembly of DIY kits. Fourth and last, the Deliver function is responsible for warehousing and logistics in the central warehouse, including warehouse activities and the transportation of products to and from the central warehouse. The division is illustrated in Figure 11 below.

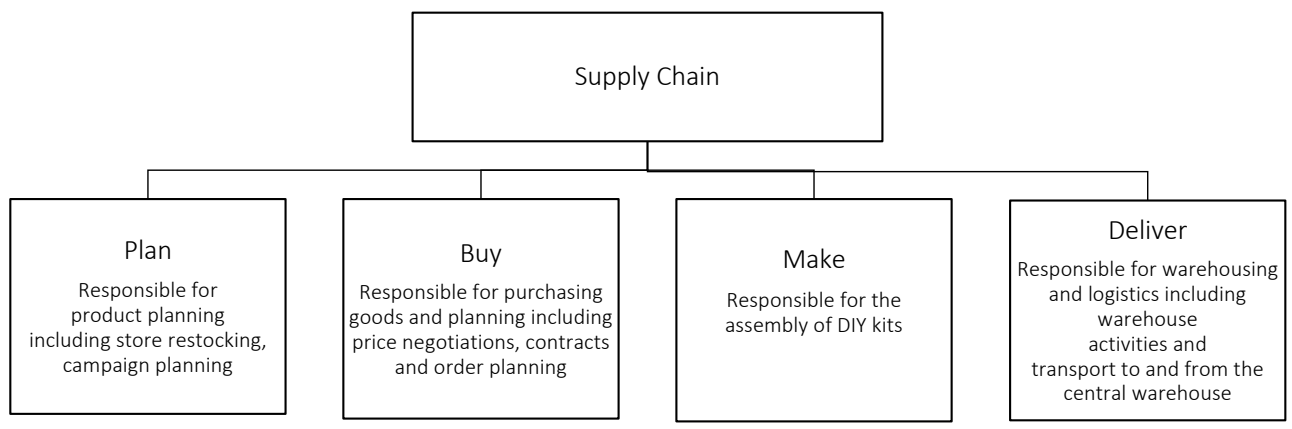

Figure 11 - Organisational chart for the Supply Chain Division

The Supply Chain division is headed up by a Supply Chain Manager, who is responsible for the overall supply chain including the Deliver function. The Supply Chain department communicates frequently with other company departments in order to stay updated about upcoming orders and changes in the product range. As the Product Range department determines the product range as well as locating potential suppliers, the Buy function eventually takes over and negotiates with the suggested suppliers and establishes contracts with these suppliers. The supply chain functions also communicate and collaborate with each other to ensure on-time delivery and a high inventory turnover rate, and to improve logistics operations in terms of planning, assembling operations, picking operations and 
transportation. There is also continuous dialogue between the supply chain functions and the Supply Chain Manager to detect problems in the logistics operations.

This study investigates retail internationalisation. Therefore, the flow of products closest to the foreign sales operations will be studied, ranging from warehouse to distribution to stores, as this part of the supply chain changes considerably as retailers expand abroad, as the warehouse operations and distribution are directly affected. Therefore, the Deliver function is further described below.

\subsubsection{The Deliver function}

The Deliver function is managed by the Logistics Manager, who also is the Supply Chain Manager. The Logistics Manager is responsible for the overall warehouse operations and transportation operations. The Logistics Manager also designs new activities together with managers from the other supply chain functions. The Deliver function includes warehouse facilities and warehouse activities as well as coordinating the transportation of goods to and from the central warehouse, which is illustrated in Figure 11.

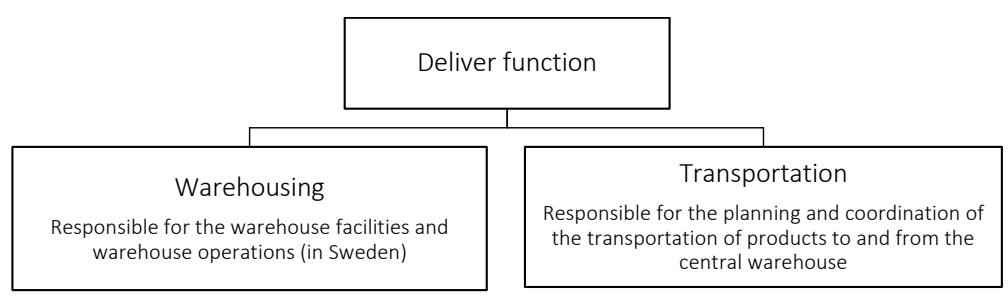

Figure 12 - Organisational chart for the Deliver function

The main goal of the Deliver function is to handle incoming orders and to ensure in-time delivery. The Deliver function interacts with the other supply chain functions. For instance, the Make function is able to develop new kits based on products held in the central warehouse to increase inventory turnover rate.

\section{Warehouse facilities}

The warehouse facilities include a central warehouse located in Malmö, Sweden, and a satellite warehouse in Amsterdam, the Netherlands. All products are distributed from the central warehouse according to a set delivery schedule, apart from local products for the Belgian and Dutch market that are managed locally.

The central warehouse has been operating since 1972 and is owned by the company. Since being established, the central warehouse has been rebuilt several times. The central warehouse now has an area of $15,000 \mathrm{sq} \mathrm{m}$. The central warehouse is located at the headquarters to enable close collaboration with other company functions.

\section{Warehouse operations}

The warehouse operations include standardised operations. About 35-60 employees work at the central warehouse, depending on the season. The warehouse organisation uses both in-house staff and additional external staff. External staff are usually needed for 10 months 
of the year, and two staffing agencies are used. The warehouse staff normally work single shifts on weekdays. For peak seasons, either shifts are extended or an additional shift on Saturdays is added. The peak season is before Christmas in October and November. The warehouse staff are allocated where needed depending on the workload in the central warehouse.

There are three product flows within the Deliver function: a store flow, an e-flow and a wholesale flow. All flows have their own operations, including their own picking and packaging operations. The different flows are also managed by a specific team and all products are picked individually. Overall, the product flow in the central warehouse usually starts when products are delivered to the warehouse by truck or container. When the products arrive, the receiving process starts including unloading, reporting, quality check and labelling. After the products have been received, the products are put away in the storage area. The inventory-planning function of the logistics organisation decides were the specific product should be placed and the location is reported in the WMS. The location depends on the product type. For example, fast-moving products are logically placed in more convenient areas to reduce the transportation time inside the warehouse. Also, market-specific products are placed in individual storage locations. The picking process starts as an order in the business system is transferred into the warehouse system. Orders are picked by voice pick, which is used for all product flows. Furthermore, pickers pick products for one store and e-customer at the time. Thereafter, the packaging process starts including sorting and packing of store pallets and boxes. When the products are packed, the logistics provider receives information about the shipment including number of packages, in order to check that the right number of packages are distributed. Thereafter, the orders are distributed.

In addition, there are other differences between the product flows such as the picking operations. For instance, specific operations are used for the e-commerce flow within the e-commerce warehouse. There are some differences in the picking operations in terms of validation and the use of pallets and boxes. For the store flow, one validation step is removed as store products are within company ownership, while validation is more important for the e-flow as the company is distributing products directly to end consumers. For the e-flow, the majority of products are scanned at the packaging stations to ensure that the right products are delivered. Moreover, the layout of the storage area depends on the specific sales channel, as storage shelves for e-commerce products are typically placed closer together as pickers pick products in smaller boxes, which requires smaller aisles. For stores, pickers pack on pallets, which requires larger aisles. Furthermore, the warehouse operations allow some flexibility as small wholesale orders can be picked at the e-commerce warehouse as these can be seen as larger e-orders.

"For a smaller wholesale order, the order can be picked at the e-warehouse as it (the order) can be seen as a large e-order."

(Supply Chain Manager)

The store orders are managed by a replenishment system that keeps track of inventory levels for the company's stores. As a minimum inventory level is reached at a store, a store order is created and sent to the central warehouse automatically. Wholesale orders are created manually by retail customers. The e-commerce orders are created online by the customer and are managed by an ordering system. 
Within the warehouse operations, there is some IT flexibility that allows IT systems to manage orders between the e-flow and the store flow. There are established delivery schedules in the warehouse planning system that keep track of the store deliveries and the number of orders delivered in each delivery.

\section{Transport operations}

The transport operations are managed by the Supply Chain Manager, who is responsible for all sorts of transport to and from the central warehouse. Three large shippers are used to deliver to end consumers, and depends on which country that it should be delivered to. The logistics organisation use logistics providers that are familiar with the foreign markets that the company is operating in. All orders are delivered from the central warehouse, except for some market-specific products for the Belgian and Dutch market. For the Norwegian market, custom management is added, which is partly performed internally by the logistics organisation as well as partly by the Customer service.

The company offers three main delivery options to its private customers. The first delivery option is Click and Collect, where the order is collected from the local store for free. The second option is MyPackCollect, where the order is collected from the local post office. This alternative is free if the customer spends a specific minimum amount, otherwise a fee is added. Company $\mathrm{C}$ also offers an express delivery solution for a higher fee as a third delivery option. The lead time for the first two alternatives is normally $2-3$ days, while for express delivery it is normally one day.

The Supply Chain Manager mentions that the company always offers free delivery for the Click and Collect solution in order to encourage customers to visit the stores to obtain more inspiration and products.

"We always offer free delivery to stores regardless of how much the customer buys. This because we want to attract the customer into the store as often as possible in order to increase sales and to bave a proper customer interaction as our staff are very customer-oriented."

(Supply Chain Manager)

The solution does not cost any extra for the company as the orders are delivered together with store orders, which makes it a very beneficial solution. However, there is no Click and Collect solution in Germany and Norway. Instead, packages are delivered directly to the customer for a shipping fee.

The number of store deliveries varies among the stores. All stores have at least two deliveries a week, while some have up to five deliveries per week. There are more store deliveries during the peak season before Christmas.

When it comes to the return flows, the company does not usually receive returns from any market. For example, in Norway products are not returned due to customs. However, seasonal products from the other markets can be returned to the central warehouse. For the return operations, operations for receiving, sorting and put away are performed.

\section{Key performance indicators}

The logistics organisation uses a number of key performance indicators (KPIs) to measure the performance of the warehouse operations. The goal of these KPIs is to improve the logistics operations and reduce the cost of operations. KPIs are used in all of the supply chain functions. The main KPIs for the Deliver function are: cost per order item, pick order 
rate per minute, output of a packaging station per hour, and lead time from order to delivery from each product flow. Availability in the central warehouse and tied-up capital are also measured. The KPIs are measured for all flows and their importance differs depending on the flow. For example, lead time is of greater importance for the store flow as the store delivery flows follow a fixed time schedule. For the e-commerce flow, the cost per item is important as e-orders are costlier.

The differences in cost between the different flows have previously been unknown and have been difficult to clarify. The Deliver function has started to learn about how the flows differ, which has enabled it to create better logistics operations.

"There are actually different costs for managing an order line if you do it there, there or there. E-commerce orders are much more expensive than a store order."

(Supply Chain Manager)

"I believe that the hardest thing right now is learning what differ between the flows. When I first started no one knew this. We have since been able to improve operations further."

(Supply Chain Manager)

\section{IT systems}

The Deliver function includes a number of IT systems that are crucial for standardised logistics operations and to measure KPIs. Since 2003, the company has used the business system Bison, which is used as a reporting system. Bison has been developed for retailers and is a standardised system that covers monitoring of sales as well as measuring logistical KPIs in the Deliver function. Bison also monitors sales via both stores and e-commerce. The basic version of the IT system only monitors sales. However, an additional logistics function has been added that measures the logistical performance within the Deliver function. An external consulting firm called ConSafe develops the business system according to the needs of the Supply Chain department.

\subsection{Retail internationalisation}

Company A started its retail internationalisation to achieve further growth. The company has expanded by using a standardised concept for all markets, with scope for some local adaptations. The company strives to enter culturally and geographically close markets and for the last 60 years has established itself in nearby markets.

The company established its first store in Denmark in 1954, where the company now has 18 stores. A couple of years later, the company entered Sweden in 1962, which later became the base for the company. The company now has 38 stores in Sweden. In 1986, the company established in Norway where it now has 19 stores. The next establishment occurred about two decades later in 2015 in Germany, where the company has three stores. In 2011, the company acquired a Dutch and Belgian hobby brand that has about 25 stores in the Netherlands and Belgium.

The company aims to become the leading company in the hobby materials sector in Europe. Recently, the company has also expanded its offering by acquiring a Swedish art materials company. The company has plans to expand further in the next few years, and a five-year plan has been established including plans for new establishments into foreign markets including physical stores and online stores. 
"We have had many discussions during the last year. We have drawn up a five-year plan of what we are planning to do with some directions, which certainly includes new establishments in other countries, ecommerce and more."

(Supply Chain manager)

For the next 3-4 years, Company C plans to speed up its expansion in Germany by opening five new stores. After the German expansion, the company also plans to establish stores in Switzerland and in Austria. The company has hired an external retail consulting firm for advice and guidance when planning its further retail internationalisation.

The company has an ambition to increase its online sales further in the future as extensive resources have been used to create a more attractive online experience. In 2017, an improved website was launched. The Supply Chain Manager believes that sales in physical stores will decrease and sales from the online stores will increase, as the company can see direct effects of marketing via social media ads. By using Google AdWords and Instagram, the company can create better ads and better attract customers online.

"Honestly, I think they [stores] will decrease and we will attract more and more on the digital side as we work with Google AdWords, Insta and so forth where you can see the effects directly. It is very difficult to see the effects of physical expression."

(Supply Chain Manager)

\subsubsection{International strategy}

The international strategy is developed by the board of Company $\mathrm{C}$, and the board makes all strategic decisions concerning retail internationalisation. The company aims to achieve a flexible expansion strategy as it enters foreign markets via both greenfield setups and acquisitions.

The international strategy centres around three key ambitions: central control of the foreign sales operations, a standardised business concept and creating a local feel through local adaptations in the product range. Figure 13 below visualises the key ambitions in the international strategy, which are described further in the following sections.

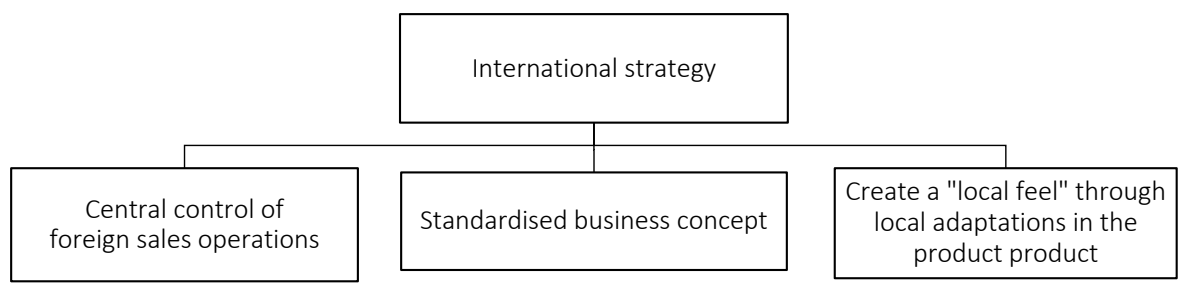

Figure 13 - Key ambitions in the international strategy of Company C

One of the cornerstones of the international strategy is to have centralised control of the foreign operations. All strategic decisions regarding retail internationalisation are made by the top management at headquarters. The company has a sales office in Norway for the wholesale operations and a group of staff in Amsterdam responsible for HR and customer service. The centralised management is to ensure control of the retail internationalisation 
and the foreign sales operations. Central control allows the company to act fast in different situations as the majority of the organisation is based in Malmö. For instance, the Make function is located at headquarters, which allows the company to design new product offers quickly using existing inventory.

The second cornerstone is to use a standardised business concept (i.e. store layout, product offering, product range, marketing and company image) for all markets. However, the product range may vary slightly depending on the store.

"It [product range] may vary slightly as we have big stores on the streets of Stockholm and others that are big ones, which are in three-storey buildings and big stores and where we have maximised [the product range]. There is no store that has all items for different reasons."

(Supply Chain Manager)

The business concept is mainly based on the Swedish market as this is the largest market in terms of sales. Central operations such as marketing, sourcing and concept development are usually standardised and are managed at a central level. For market establishments, especially the establishment in Germany, the company has used the same concept as for other markets in order to save time and resources, which otherwise would have been used to develop a market-specific concept. The company believes that the current business concept works and local adaptations are made with time. Despite the use of standardised operations, there are some local operations and products for the local markets. However, these are only a few.

"That has been the thing that we have said, we try and we copy the concept to the fullest. Therefore, no resources have been used for something specifically German. We believe that in some parts, such as northern Germany at least, the current concept works quite well."

(Supply Chain Manager)

The third and last cornerstone is to create a local feel for the company brand. This is achieved by making some local adaptations to the product range. Despite the fairly standardised business concept including product range, the company has a few countryspecific products to achieve a local feel. The company works in a sector that is more sensitive to local traditions and culture, which makes it necessary to have some local products for each market. However, less than $10 \%$ is country-specific products.

"We are very much affected by where we work and there are very local traditions and cultures."

(Supply Chain Manager)

All markets have their own traditions that the company wants to capture in its product range. For example, confirmation is a very important tradition in Denmark, which has resulted in more products related to confirmation in Denmark than in other markets.

"Confirmations is still very big in Denmark compared to Sweden. It occurs in first quarter in Denmarke. and then it is really big with confirmation stuff and in Sweden we have it in the second quarter and it is smaller."

(Supply Chain Manager) 
With the acquisition of a Dutch and Belgian hobby brand, the company kept the old company name to maintain the trademark that was already well established in Belgium and the Netherlands.

Some local adaptations of the websites have taken place in terms of local language for the Swedish, Danish, Norwegian and German markets. These language adaptations have been carried out during the establishment in a new market. The Dutch and Belgian website is also translated and follows the same concept as Company C's other websites. The overall European website is in English.

The majority of the company's products have labels written in multiple languages to allow them to be sold throughout Europe and to simplify distribution to end consumers.

"We have our kits in English and they are multilingual so the products should work in Europe."

(Supply Chain Manager)

"It is about the language. It is important that in an early stage decide which languages to use and what service to offer to the consumers."

(Supply Chain Manager)

For the Belgian and Dutch market, 50\% of the products are sourced and sold locally and the other half come from the standard product range distributed from the central warehouse. This mix model is used to better meet the local demand as well as to appear more local. The company kept part of the local product range after the acquisition in order to keep the local feel of the company in those markets.

"Half of what we sell there comes from the company and the other part is sourced locally as they know their own traditions. So, it is a mixed model."

(Supply Chain Manager)

Also, some identical traditions occur at different times in different markets, which have led to local time adaptations and product adaptations. For instance, the time at which confirmations take place differs between Sweden and Denmark. However, most products for the Scandinavian markets are the same.

\subsubsection{The role of logistics in the retail internationalisation}

Logistics plays a vital role in the overall business of Company C's retail internationalisation as it enables sales in multiple markets. In previous establishments into foreign markets, the Supply Chain division has not been of great importance. It has only been seen as a supporting function with little strategic importance. However, the company recently acquired a new CEO, who saw the great importance of logistics at a strategic level. The CEO realised that the basic planning of products was an important function that needed to be prioritised more. The Supply Chain division has therefore been represented in the management team since 2016.

"Partly, I think it is due to having a CEO with 30 years of CEO experience who has realised that the supply chain is an important function, that planning is an important function. And he realised that there was a gap in the basic planning for products and how to get [products] out onto the shelves." 
Due to the recent recognition of the importance of the logistics organisation and operations, the Supply Chain Manager believes that logistics will have a greater influence in upcoming establishments into foreign markets.

"Logistics will have sometbing to say about future establishments."

(Supply Chain Manager)

However, the most important aspects of the establishment in a new foreign market are still the marketing aspects, such as the business concept and potential markets.

"The most important thing is the strategic aspects. Does our concept work in that country? Which cities would then be of interest? Where are our potential customers?"

(Supply Chain Manager)

According to the Supply Chain Manager, logistics operations can be established fairly quickly in a new market. The Deliver function can quickly estimate the price of moving products from the central warehouse to the new foreign market. The operations within the central warehouse are standardised and can easily be used for multiple markets.

"I can quite quickly get the price picture of distributing stuff from here and the packaging is already in place."

(Supply Chain Manager)

Furthermore, the Supply Chain Manager mentions that the distribution to end consumers is fairly easy as long as it is within the EU. Companies outside the EU are more complicated due to customs.

"As long as it [the deliveries] is within the EU it is fairly easy."

(Supply Chain Manager)

The establishment into foreign markets has resulted in increased complexity for the logistics organisation, as different delivery solutions are used for different markets and sales channels, and product returns are managed differently for the different markets. The Deliver function investigates different delivery alternatives and measures the cost of the different alternatives to find the most profitable solution. In recent years, the Supply Chain function has carried out several projects to improve processes and operations as well as implementing new IT tools. For instance, the Deliver function uses voice picking and picking lists in the picking operations. However, some of the staff that usually worked in one product flow were not familiar with voice picking, which made it hard to move staff between the different products flows. This barrier was solved by training the operational staff to use both tools.

"... but now we have removed those barriers so now everyone can move around."

(Supply Chain Manager) 

APPENDIX 3

Interview guide 



\section{Interview guide}

In this appendix, the standardised interview guide is presented.

\section{Intervjuguide}

Nedan följer intervjufrågorna för intervjun. På intervjuguidens sista sida återfinns en beskrivning om forskningsprojektet.

\section{Om respondenten}

- Bakgrund.

- Roll och ansvar.

\section{Om internationaliseringen}

1. Vad var startskottet för er internationalisering?

○ Vad är den främsta drivkraften?

○ Vem eller vilka var är drivande av företagets internationalisering?

2. Vilka marknader är ni verksamma i?

○ Vilket år skedde inträdet på dessa marknader?

○ Varför dessa marknader?

3. Har företaget erfarenheter av internationalisering sen tidigare?

○ Vem har den kunskapen inom företaget?

- Har inspiration tagits från andra företag?

4. Hur ser expansionsplanen ut idag?

\section{Om etableringen till en ny utländsk marknad}

5. Finns det dokumentation kring etableringsprocessen till utländska marknader?

6. Etableras först fysiska affärer eller online-handel?

7. Vilka faser består etableringsprocessen av?

○ Namnge dessa?

- Vilka individer ingick inom varje fas? 
○ Under hur lång tid pågick de olika faserna?

○ Finns det faser som överlappar och sker parallellt?

○ Hur länge pågick etableringsprocessen totalt? Går det att uppskatta hur länge de olika faserna på gick?

○ Har etableringsprocessen ändrat sedan den första utländska etableringen?

o Hur skiljer sig etableringen av nya butiker på hemma- och utländska marknaden?

8. Vilka individer/funktioner var involverade i etableringsprocessen?

○ Beskriv deras roll/uppgift.

○ Extern support i form av individer/organisationer/nätverk med erfarenhet av den utländska marknaden?

- Vilka faser hade man externt stöd?

- Vad fick man hjälp med?

9. Vilka är de viktigaste beslutspunkterna i etableringsprocessen?

○ När sker dessa beslutspunkter i etableringsprocessen?

○ Vilka i företaget tar dessa beslut?

- Var i hierarkin fattas dessa beslut?

10. Vad har varit viktiga grundförutsättningar för att möjliggöra etableringsprocessen?

11. Vilka är de viktigaste lärdomarna från tidigare etableringsprocessen?

○ Hur tar man hänsyn till dessa lärdomar i kommande etableringar?

\section{Om logistikverksamheten}

12. Beskriv flödet av färdiga produkter (från centrallager) till den utländska marknaden?

○ Sköter företaget hela sin logistikverksamhet eller sköts delar av extern part?

○ Används ett centralt lager för alla marknader?

- Alla produkter går via centrallagret? 
○ Hur sker distributionen av varor till de utländska marknaderna?

- Hur ofta?

13. Hur sker arbetet i logistikverksamheten?

○ Vilka processer/arbetssätt används?

○ Vad använder ni för typ av information- och rapporteringssystem?

14. Hur sker styrningen av logistikverksamheten?

○ Finns det en central styrningsenhet som designar logistikverksamhetens struktur och arbetar med logistikkoncept (hur distributionen ska utföras) utifrån ett totallogistikkostnads- och prestationsperspektiv? (Alltså inte utifrån lokala omständigheter eller optimeringar)

○ Finns det en ledare som ansvarar för logistikverksamheten i sin helhet?

○ Har ledaren styrande kontroll över logistikverksamheten?

○ Finns planeringsverktyg?

○ Finns mätning för logistikprestationer?

\section{Om logistikens roll $\mathrm{i}$ internationaliseringen}

15. Beskriv logistikens roll i internationaliseringsprocessen?

16. Hur stödjer logistiken de strategiska besluten, som en nyetablering och expansion på utländska marknader?

17. Vilka logistikaspekter tas i beaktning vid internationaliseringsbeslut?

- Anses logistik vara en viktig parameter vid val av marknad?

○ Skapas kalkyl på logistikkostnader?

18. Vilken prioritet har logistikaspekter i internationaliseringsprocessen?

○ Har logistikens betydelse förändrats $\mathrm{i}$ och med etableringen till flera utländska marknader? 


\section{Bakgtund till forskningsprojektet}

Nedan föjjer övergripande information om forskningsprojektet 'Logistikens betydelse för detaljhandelns geografiska expansion", samt syftet med intervjuguiden och därefter interyjufrågorna.

\section{Om oss}

Erik Sandberg är docent och Biträdande Professor i logistik. Han har de senaste 10 åren forskat om organisations- och strategifrågor som berör logistikens strategiska betydelse i handels-företag. I detta projekt är han projektledare och huvudhandledare för Linnea.

Linnea Haag är civilingenjör i Energi, Miljö och Management (EMM) från LiTH. Sitt examensarbete genomförde hon inom logistik på SSAB, där hon arbetade fram ledtidsreduceringsförslag för stålföretagets verksamhet i Borlänge. Hösten 2016 började hon som doktorand inom logistik och har därefter påbörjat forskning inom det aktuella projektet.

\section{Om det aktuella forskningsprojektet}

Forskningsprojektet "Geografisk expansion av detaljhandeln" avser att kartlägga och erhålla lärdomar från etableringsprocessen vid geografisk expansion av svensk detaljhandel. Det innefattar processen från det att potentiella marknader utvärderas till att den första butiken är etablerad och i fulldrift, samt den fortsatta etableringen på den nya marknaden. Projektet avser att ge ökad förståelse för logistikens roll i etableringsprocessen och dess betydelse för en lyckosam etablering på sikt. Vidare kommer projektet ge ett teoretiskt och praktiskt bidrag som handlar om hur företags logistikverksamhet bör förberedas och organiseras inför en geografisk expansion. Projektets finansiärer är Hakon Swenson stiftelsen samt Jan Wallander och Tom Hedelius stiftelsen.

\section{Syftet med intervjuguide}

Syftet med kommande intervjuer är att samla in data om företagets expansion till utländska marknader. Den insamlade informationen kommer att användas i två akademiska artiklar och en licentiatavhandling (en avhandling halvväggs till doktor). Den första artikeln beskriver etableringsprocessen till utländska marknader som definieras som processen från första incitamentet från företaget att etablera sig på en ny utländsk marknad, till att etablera fysiska butiker (och online butiker) som varit öppna i minst ett år. Den andra artikeln handlar om hur logistiken möjliggör detaljhandelns expansion till nya utländska marknader. Avhandlingen handlar om att beskriva logistikens roll i den geografiska expansionen av detaljhandelsföretag.

\section{Respondenter}

Tanken är inte att en ensam person som ska besvara alla intervjufrågor, utan frågorna ska delas upp mellan flera respondenter. För att kunna kartlägga etableringsprocessen behöver vi intervjua personal som varit involverad i etableringsprocessen från första initiativet till färdigutvecklade butiker på den utländska marknaden. Vi behöver också intervjua logistiknära personal som exempelvis förtagets logistikchef för att förstå logistikorganisationens uppbyggnad och operationer, samt dess roll under etableringen till utländska marknader. 


\section{FACULTY OF SCIENCE AND ENGINEERING}

Linköping Studies in Science and Technology, Licentiate Thesis No. 1834, 2019 Department of Management and Engineering

Linköping University

SE-581 83 Linköping, Sweden

WWW.liu.se 